\section{Pacific Northwest}

National Laboratory

Operated by Battelle for the

U.S. Department of Energy

\title{
A Tutorial on Detection and Characterization of Special Behavior in Large Electric Power Systems
}

\author{
J. F. Hauer \\ J. G. DeSteese
}

July 2004

Prepared for the U.S. Department of Energy under Contract DE-AC06-76RL01830 


\title{
DISCLAIMER
}

This report was prepared as an account of work sponsored by an agency of the United States Government. Neither the United States Government nor any agency thereof, nor Battelle Memorial Institute, nor any of their employees, makes any warranty, express or implied, or assumes any legal liability or responsibility for the accuracy, completeness, or usefulness of any information, apparatus, product, or process disclosed, or represents that its use would not infringe privately owned rights. Reference herein to any specific commercial product, process, or service by trade name, trademark, manufacturer, or otherwise does not necessarily constitute or imply its endorsement, recommendation, or favoring by the United States Government or any agency thereof, or Battelle Memorial Institute. The views and opinions of authors expressed herein do not necessarily state or reflect those of the United States Government or any agency thereof.

\author{
PACIFIC NORTHWEST NATIONAL LABORATORY \\ operated by \\ BATTELLE \\ for the \\ UNITED STATES DEPARTMENT OF ENERGY \\ under Contract DE-AC06-76RL01830
}

Printed in the United States of America

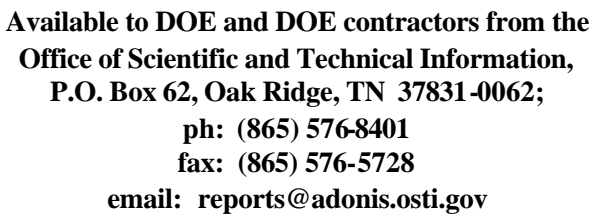

Available to the public from the National Technical Information Service, U.S. Department of Commerce, 5285 Port Royal Rd., Springfield, VA 22161 ph: (800) 553-6847 fax: (703) 605-6900

email: orders@ntis.fedworld.gov online ordering: http://www.ntis.gov/ordering.htm (3) This document was printed on recycled paper. 


\title{
A Tutorial on Detection and Characterization of Special Behavior in Large Electric Power Systems
}

\author{
J. F. Hauer \\ J. G. DeSteese
}

July 2004

Prepared for

U.S. Department of Energy

under Contract DE-AC06-76RL01830

Pacific Northwest National Laboratory

Richland, Washington 99352 


\section{Summary}

The document brings together work performed by Pacific Northwest National Laboratory over a period of years prior to and including 1999. This information is presented in the form of a tutorial to inform the reader about the nature and propagation of grid disturbance events and to introduce advanced but practical methods used in their analysis. An earlier version of this document was developed and informally distributed within the Pacific Northwest National Laboratory during the course of other work.

This document assembles reviews and analyses of significant electrical disturbances that occurred on the western grid interconnection of North America, operated under the auspices of the Western Electricity Coordinating Council. The issues discussed focus on four main topics: 1) event observability; 2)

instrumentation factors; 3) mathematical tools and 4) special considerations in the analysis of dynamic behavior. 


\section{Contents}

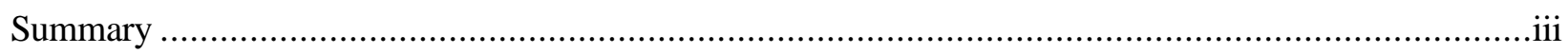

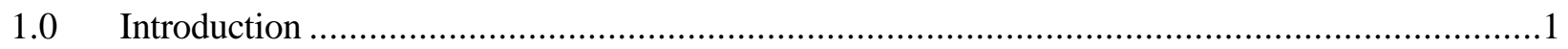

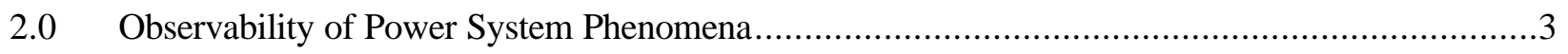

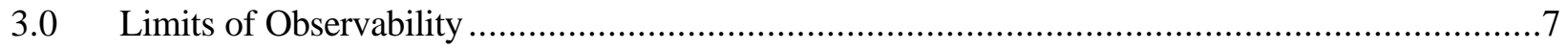

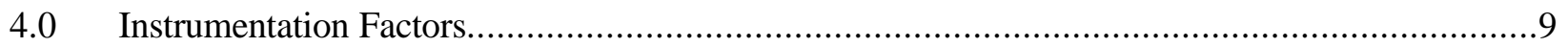

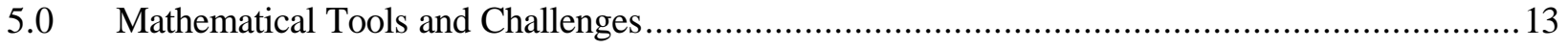

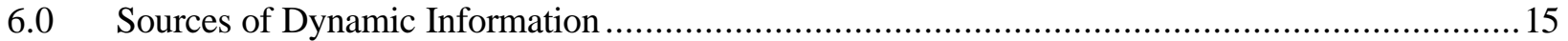

$6.1 \quad$ Sources of Dynamic Information - System Disturbances............................................. 16

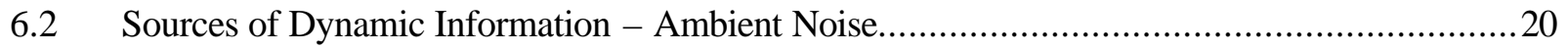

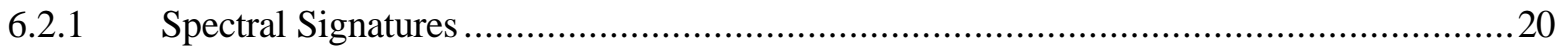

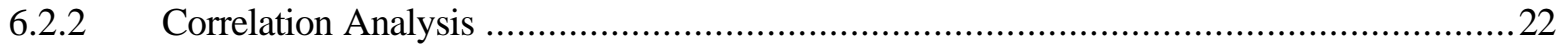

6.2.3 Open-Loop/Closed-Loop Spectral Comparisons ....................................................24

6.3 Sources of Dynamic Information - Direct Tests........................................................25

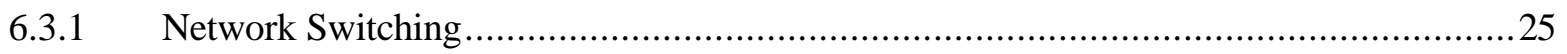

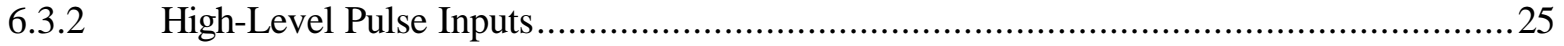

6.3.3 Mid-Level Inputs With Special Waveforms ....................................................29

6.3.4 Low-Level Noise Inputs ........................................................................... 31

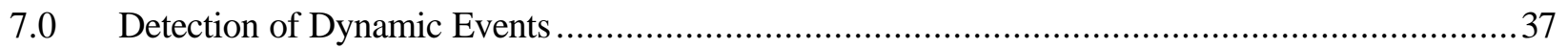

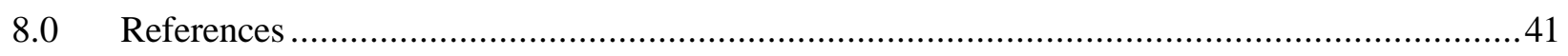

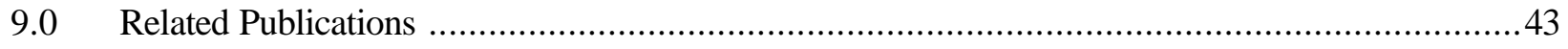

APPENDIX A. Characteristics of the Western North America Power System.................................1

APPENDIX B. Mathematical Modeling of Electric Power Systems ......................................... B.1

APPENDIX C. The Signal Environment for Power System Measurements.................................... C.1

APPENDIX D. Component Analysis of Highly Structured Point-on-Wave Signals .......................... D.1

APPENDIX E. Probing Signals for Direct Tests of power System Dynamics................................ E.1 


\section{Figures}

Figure 1. Phasor measurements for San Francisco trip of December 8, 1998 .............................4

Figure 2. Oscillation buildup for the western system breakup of August 10, 1996. ....................

Figure 3. Oscillation detail for loss of the Keeler-Allston 500-kV transmission line .........................8

Figure 4. Time response of four Malin area transducers for Chief Joseph dynamic brake insertion \#1 on

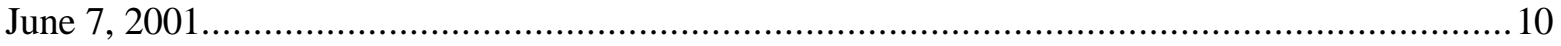

Figure 5. Time response of four Malin area transducers for Chief Joseph dynamic brake insertion \#1 on

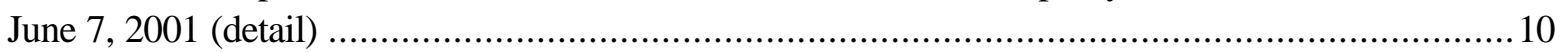

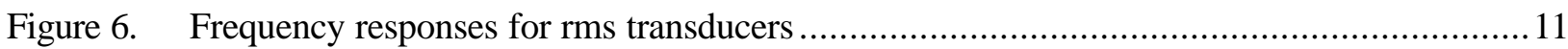

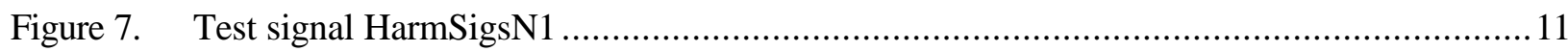

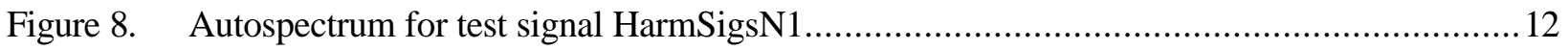

Figure 9. A structure for information sources in process identification .................................. 16

Figure 10. Frequency transients for the San Francisco trip of December 8, 1998 (signals from 14

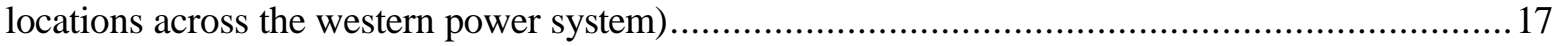

Figure 11. Frequency transient details for the San Francisco trip of December 8, 1998 ................ 17

Figure 12. Detail of Malin bus frequency for the San Francisco trip of December 8, 1998 ..............19

Figure 13. Malin MW for Palo Verde generator trip of June 18, 1999................................... 19

Figure 14. Malin voltage for Palo Verde generator trip of June 18, 1999 .................................20

Figure 15. Ambient autospectra for BPA power interchanges with Canada and California, with Alberta weakly connected. Brake insertion tests of 09/04/97 ...........................................21

Figure 16. Ambient autospectra for BPA power interchanges with Canada and California, with Alberta strongly connected. Brake insertion tests of 09/04/97 .............................................21

Figure 17. Ambient coherency for BPA power interchanges with Canada and California, Alberta strongly connected. Brake insertion tests of 09/04/97 
Figure 18. High resolution coherency estimate for BPA power interchanges with Canada and California, Alberta weakly connected. Brake insertion tests of 09/04/97.

Figure 19. Spectral comparison for HVDC modulation loop open and closed. Ambient noise in PACI

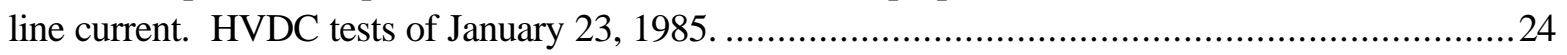

Figure 20. Ringdowns of Malin-Round Mountain MW, for brake insertions \#1 and \#2 on 09/04/97. 26

Figure 21. Autospectra for ringdowns of Malin-Round Mountain MW, brake insertions \#1 and \#2 on

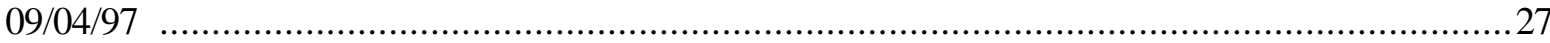

Figure 22. Effect of Alberta connection on ambient autospectra, tests of 09/04/97 ......................2

Figure 23. Signals and fitting windows for multioutput Prony fit to brake insertion \#1, 09/04/97.

Data collected on Dittmer portable power system monitor (PPSM) ......................................29

Figure 24. Dominant modes for initial Prony fit to brake insertion \#1, 09/04/97 ......................... 30

Figure 25. Power system response to two applications of two-cycle probing signal. .....................30

Figure 26. Power system response to two-cycle probing signal, test event B6...........................31

Figure 27. Response of PACI line current to low-level modulation of PDCI. .............................. 32

Figure 28. Response gain of PACI line current to low-level PDCI modulation. ............................ 32

Figure 29. Response phase of PACI line current to low-level PDCI modulation. ..........................33

Figure 30. Response of Big Eddy -Celilo 230 line MW to PDCI probing signals ..........................34

Figure 31. Response of Malin-Round Mountain Circuit \#1 to PDCI probing signals ...........................34

Figure 32. Correlation of Malin-Round Mountain Circuit \#1 against Big Eddy-Celilo 230 line MW.

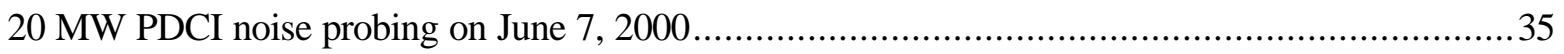

Figure 33. $[0.20 .5] \mathrm{Hz}$ square-law activity signal for oscillations of August 10, 1996 ................38

Figure 34. [0.52 0.31] Hz square-law activity signal for oscillations of August 10, 1996...............39

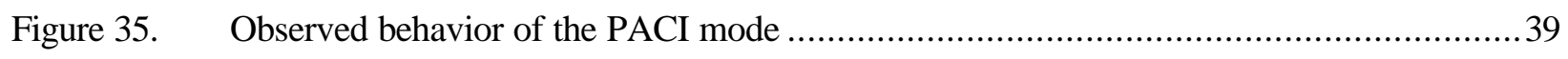

Figure 36. Spectral signatures for Keeler-Alston trip event in breakup of August 10, 1996 .................40 
Figure A.1. General structure of the western North America power system.

A. 1

Figure A.2. Gain response of PACI line power to complex power injections at terminals of the PDCI

Figure C.1. Autospectrum for A-phase current (100 Hz processing) .......................................1

Figure C.2. Autospectrum for A-phase current $(500 \mathrm{~Hz}$ processing) ........................................2

Figure C.3. Autospectrum for watt transducer $(500 \mathrm{~Hz}$ processing) ….................................. 2

Figure D.1. Test data HarmSigsN1 for point-on-wave analysis ....................................... D.2

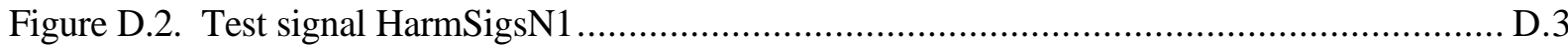

Figure D.3. Autospectrum for test signal HarmSigsN1 …................................................ D. 3

Figure D.4. Autospectrum for test signal HarmSigsN1 (detail 1) ........................................ D.4

Figure D.5. Autospectrum for test signal HarmSigsN1 (detail 2) ......................................... D.4

Figure E.1. Nomenclature for an ideal pulse ................................................................... E.2

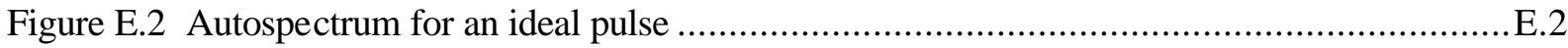

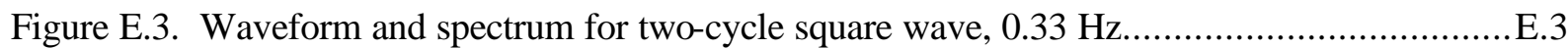

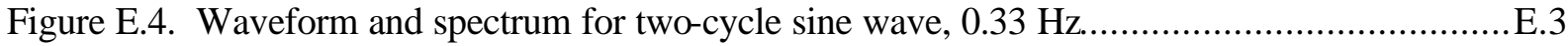

\section{Tables}

Table D.1. Components Identified in Test Signal HarmSigsN1 by Prony Analysis ..................... D.5 


\subsection{Introduction}

The objective of this document is to report results in the detection and characterization of special behavior in large electric power systems. Such behavior is usually dynamic in nature, but not always. This is also true for the underlying sources of special behavior. At the device level, a source of special behavior might be an automatic control system, a dynamic load, or even a manual control system that is operated according to some sharply defined policy. Other possible sources include passive system conditions, such as the state of a switched device or the amount of power carried on some critical line.

Detection and characterization are based upon "signature information" that is extracted from the behavior observed. Characterization elements include the signature information itself, the nature of the behavior and its likely causes, and the associated implications for the system or for the public at large. With sufficient data and processing, this characterization may directly identify a particular condition or device at a specific location. Such conclusive results cannot always be done from just one observation, however. Information environments that are very sparse may require multiple observations, comparative model studies, and even direct testing of the system. 


\subsection{Observability of Power System Phenomena}

Some phenomena may be visible throughout an entire power system, even though the stimulus has a power level that is far smaller than the total power capacity of that system. This is especially true for phenomena that affect the frequency of a system that is "loosely connected," such as the power system in western North America or the systems that serve the smaller industrialized countries.

Some other phenomena are very difficult to observe from a distance, even though the stimulus may be comparatively strong. This is most likely for local phenomena that are characterized by voltage signatures only, especially if the power system is "strongly connected" or "tightly meshed." The power systems that serve the more densely populated areas of eastern North America and Europe are in this category. These systems contain many automatic controllers that are designed to suppress even small voltage deviations, and the strong network connections let all of those controllers sense and counteract any significant deviation. So, as a general rule for normal operating conditions, the observability of voltage signatures tends to quickly diminish with distance from the source. Global phenomena, such as power or frequency oscillations, may produce voltage signatures throughout the system, however.

To actually observe and detect the signatures for some phenomenon of interest, one must know when, where, and how to look. Records for intermittent activity can be difficult to capture or recognize, especially if the observable signatures are local to the source and the signatures themselves are masked by other activity. Good data, obtained under known conditions and close to the source, greatly contribute to the prospect of success in such efforts. So do good tools, and good insights into power system behavior.

The work described here involves a considerable amount of exploratory work. Much of this is based upon measurements from the western North America power system, for reasons that are explained below.

The general literature contains few results about the observability of power system phenomena, and what does appear there is largely based upon the DOE Wide Area Measurements System (WAMS) effort in the western power system (Hauer et al. 1997, Hauer et al. 1999). Though their coverage and technologies are still evolving, the WAMS facilities in the western system are unique in the world. Figure 1 shows the centralized phasor measurements system there as it existed when San Francisco was separated from the main grid on December 8, 1998. This particular measurement system has continued to expand since that time. In addition, there are many other regional or local monitors at key locations. The primary WAMS facilities provide high resolution recordings that are virtually continuous.

In addition, Federal utilities in the western system operate powerful devices that can be used to directly test power system dynamics. These include the

- Chief Joseph dynamic braking resistor, at the Bonneville Power Administration (BPA) Chief Joseph substation in north central Washington state.

- Series and shunt capacitors on the BPA transmission system. 


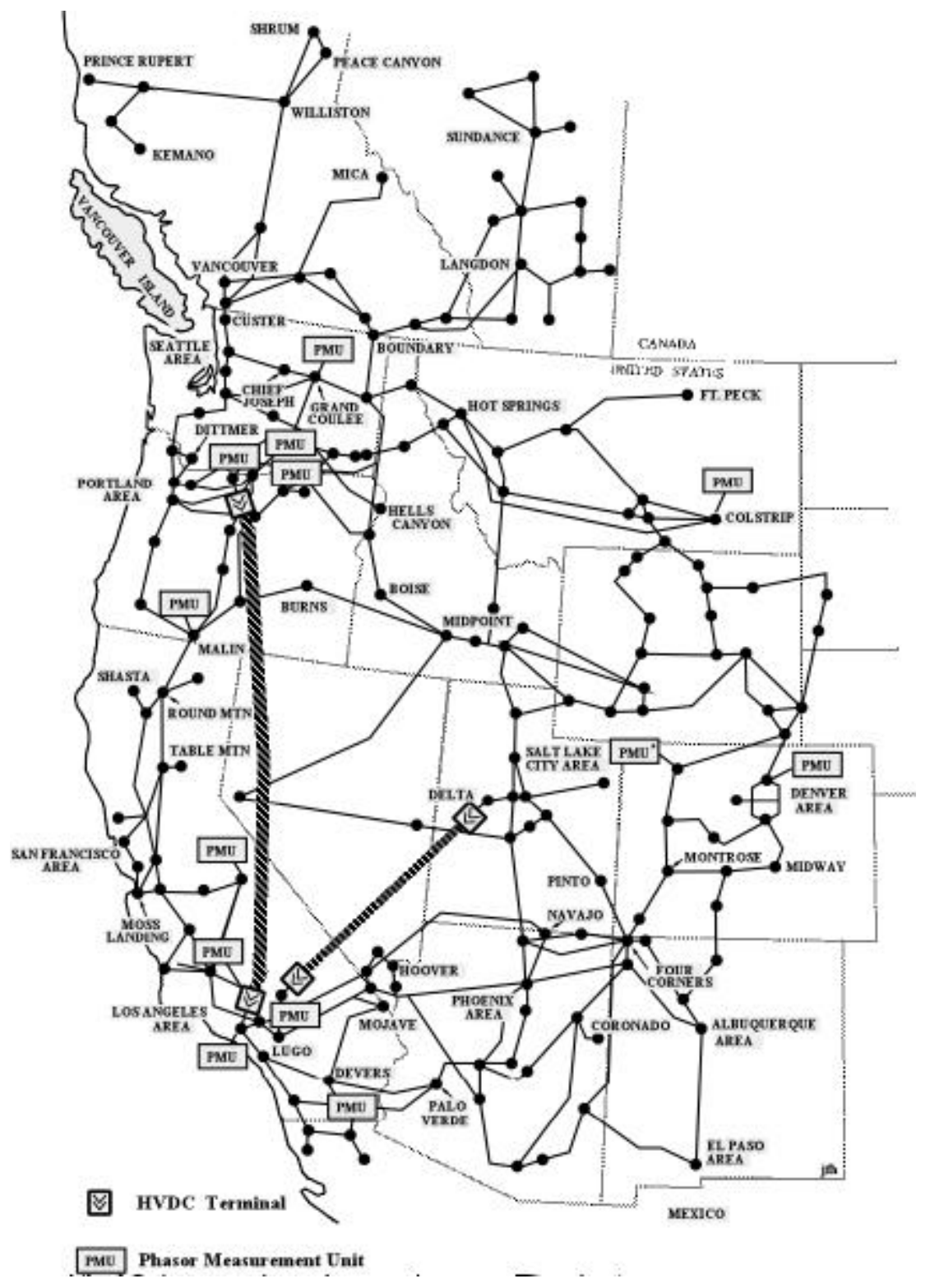

Figure 1. Phasor measurements for San Francisco trip of December 8, 1998

- Pacific HVDC Intertie, from the lower Columbia River to the Los Angeles basin.

- Static Var compensator (SVC) units at BPA's Keeler and Maple Valley substations, near Portland, Oregon and Seattle, Washington, respectively. 
- Thyristor controlled series capacitor (TCSC) unit at BPA's Slatt substation, on the Slatt-Buckley leg of the 500-kV Pacifica AC Intertie

- $\quad$ TCSC at Kayenta substation, on the Western Area Power Administration (WAPA) 230-kV Glen Canyon-Shiprock line in northern Arizona.

- Phase shifting transformers and other switchable devices on the WAPA transmission system.

- Generators operated by the U.S, Bureau of Reclamation (USBR) and the U.S. Corps of Engineers (USCoE).

The Pacific Northwest National Laboratory (PNNL) is regularly involved in such tests and in all aspects of WAMS. Overall, the western power system is an excellent testbed for the work at hand. While many of the experimental results are explicit to western system, they can be scaled to other (usually smaller) systems that have similar characteristics. 


\subsection{Limits of Observability}

This section provides some examples of what can be observed in a large power system. It also indicates some of the challenges that may arise in interpreting incomplete observations.

The first example draws upon WAMS data for the massive breakup that occurred in the western system on August 10, 1996 (Hauer et al. 1997, Taylor 1999, Hauer and Dagle 1999). A particularly critical event took place at 15:42:03 hrs, with loss of the Keeler-Allston 500-kV transmission line near Portland, Oregon. Figure 2 shows this as taking place at 400 seconds into the monitor record. The signal there is power flowing on circuit \#1 of the Malin - Round Mountain transmission line on the California-Oregon border.

Figure 2 and many other records indicate that loss of this particular line seriously degraded the oscillatory stability of the system. Immediate suggestions of this are found in the transient ringdown produced by the line trip itself, and in the oscillatory noise that followed after.

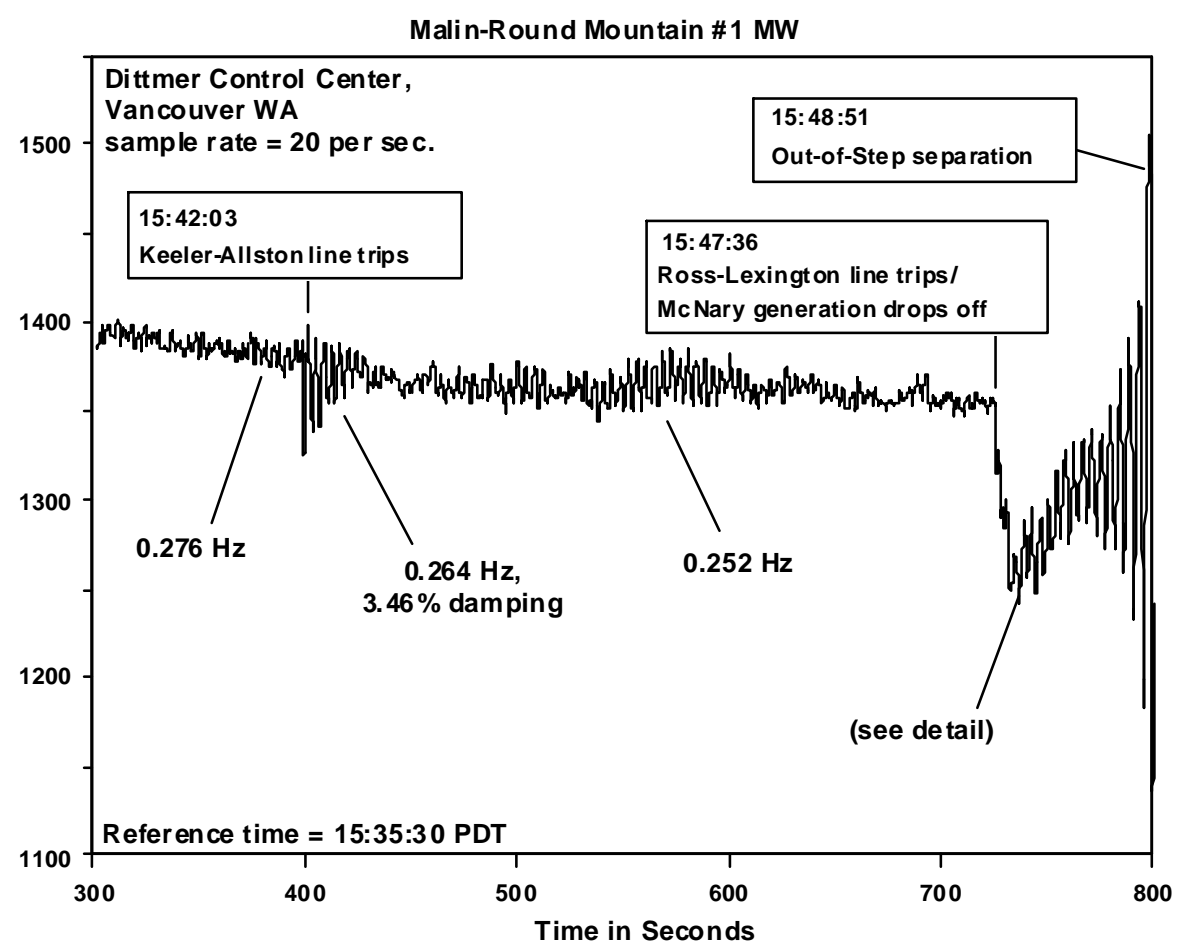

Figure 2. Oscillation buildup for the western system breakup of August 10, 1996. 
Enigmatically, there are also unusual oscillations just before the line tripped. Figure 3 shows these as starting 28 seconds before and lasting right up to the trip itself. Their frequency, $0.276 \mathrm{~Hz}$, characterizes normal behavior for this system. Furthermore, they are visible (though less strongly) at the usual places in Canada and California. All in all, it seems highly likely that these precursor oscillations were produced by the same mechanism that tripped the line.

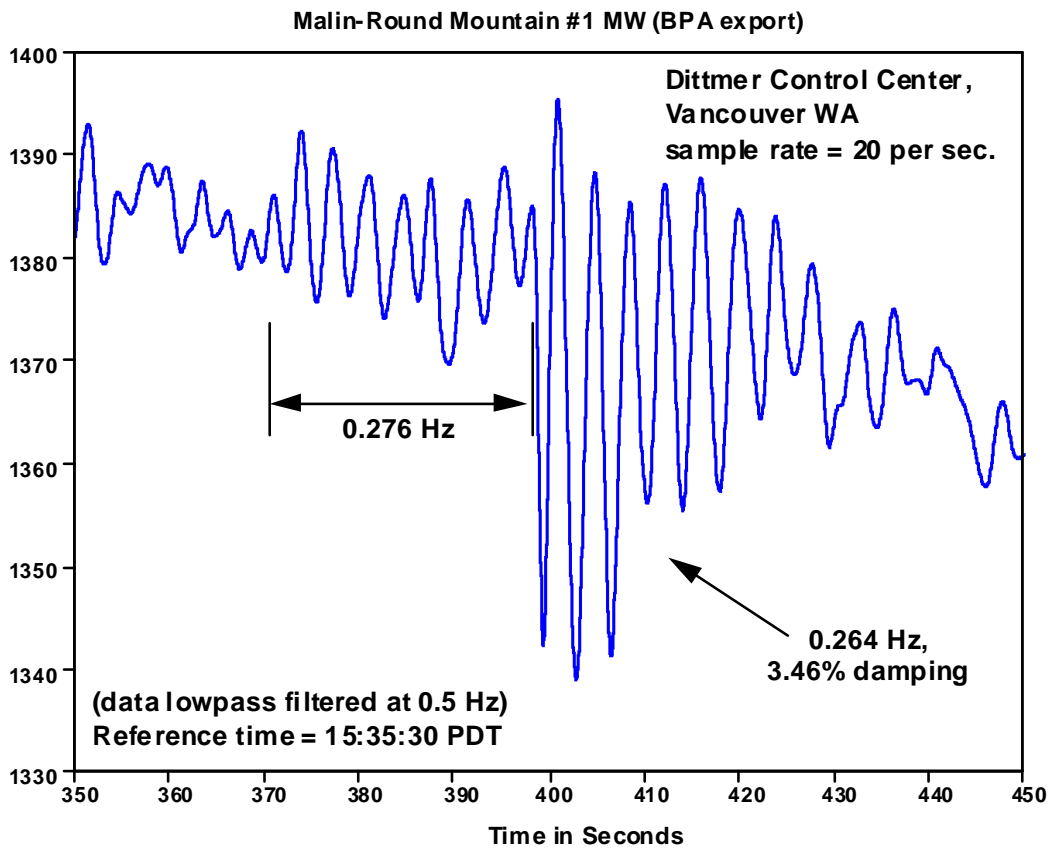

Figure 3. Oscillation detail for loss of the Keeler-Allston 500-kV transmission line

The core of the enigma is that this mechanism seems to have been an arc between the line and a nearby tree. Is it possible for such an arc to develop slowly, and to persist for 28 seconds? If this is indeed what happened, then this was the most "observable" tree on record. Unfortunately, the offending tree was just one among many that were promptly cleared from the right-of-way, and it was not specifically identified. 


\subsection{Instrumentation Factors}

The signal shown in Figure 2 and Figure 3 represents rms (root-mean-square) power as calculated by a conventional analog transducer. Instruments of this type may lack the bandwidth to track some of the faster processes in a power system, and their processing may sometimes produce artifacts that mimic actual system behavior (Hauer et al. 1999a, Hauer 1996). Correct interpretation of power system measurements requires that such factors be considered very carefully.

Figure 4 and Figure 5 show that different transducers can give very different views of the same power system event. The two slowest transducers have frequency response characteristics similar to the lowest bandwidth case shown in Figure 6. This characteristic is typical of most transducers in service. The fastest transducer has a frequency response characteristic similar to the highest bandwidth case shown in Figure 6. This bandwidth enhancement, which adds roughly $20 \%$ to the transducer cost, minimizes filter "coloration" of rms signals. This provides a much sharper view of actual system behavior, and it avoids the filter compensation effort that is sometimes necessary for important data that have been collected with low bandwidth instrumentation.

Intermediate between the analog transducer characteristics in Figure 6 is the expected characteristic for a representative digital transducer (phasor measurement unit). The "sidelobes" represent substantial gain at frequencies above $15 \mathrm{~Hz}$. This is the Nyquist frequency of the instrument, so aliasing effects may well cause inputs at frequencies above $15 \mathrm{~Hz}$ to exit the instrument at frequencies below $15 \mathrm{~Hz}$. Data defects of this sort cannot be removed reliably, and they should be avoided within the hardware itself.

No matter how they are instrumented, conventional rms calculations produce average measures that cannot fully reflect all of the "finestructure" that may be present in the point-on-wave (POW) signals being processed. Examples of this include unbalanced multiphase loads, turbine blade vibrations, and resonances within the power delivery system.

In the limiting case, it is necessary to directly analyze the POW signals themselves. Figure 7 and Figure 8 describe a test signal for evaluating the options for this. (See Appendix D and references Hauer et al. 1999a and Hauer 1996 for more details.) The signal contains 7 harmonics and a total of 18 signal components. The first three harmonics are amplitude modulated, at frequencies that are typical for large power systems and the generators in them. There is also an additive signal, at $52 \mathrm{~Hz}$, that typifies a network resonance near Los Angeles that has sometimes interacted with control equipment in the Pacific Northwest. 


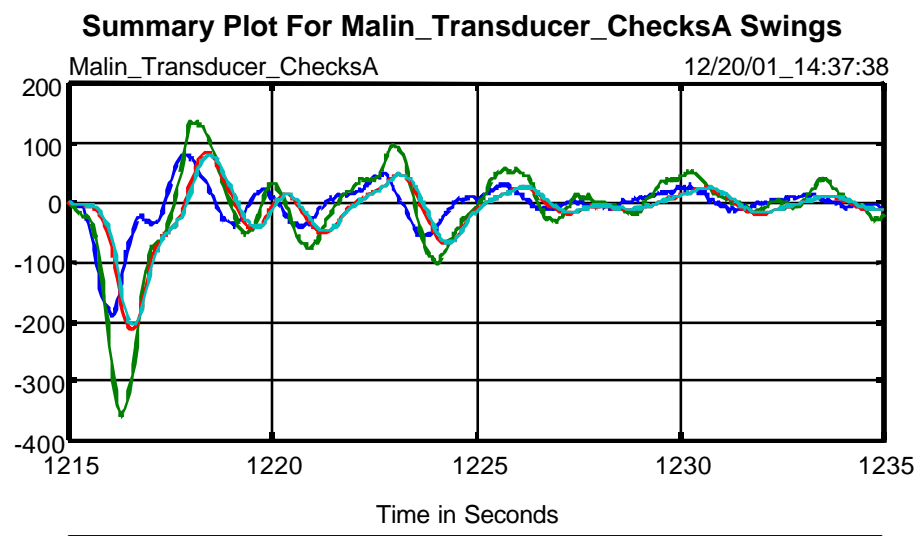

Malin-Round Mountain \#1 MW (MW)

PG\&E Malin Sum MW (MW)

$P G \& E$ Captain Jack MW (MW)

Figure 4. Time response of four Malin area transducers for Chief Joseph dynamic brake insertion \#1 on June 7, 2001

Summary Plot For Malin Transducer Checks Swings
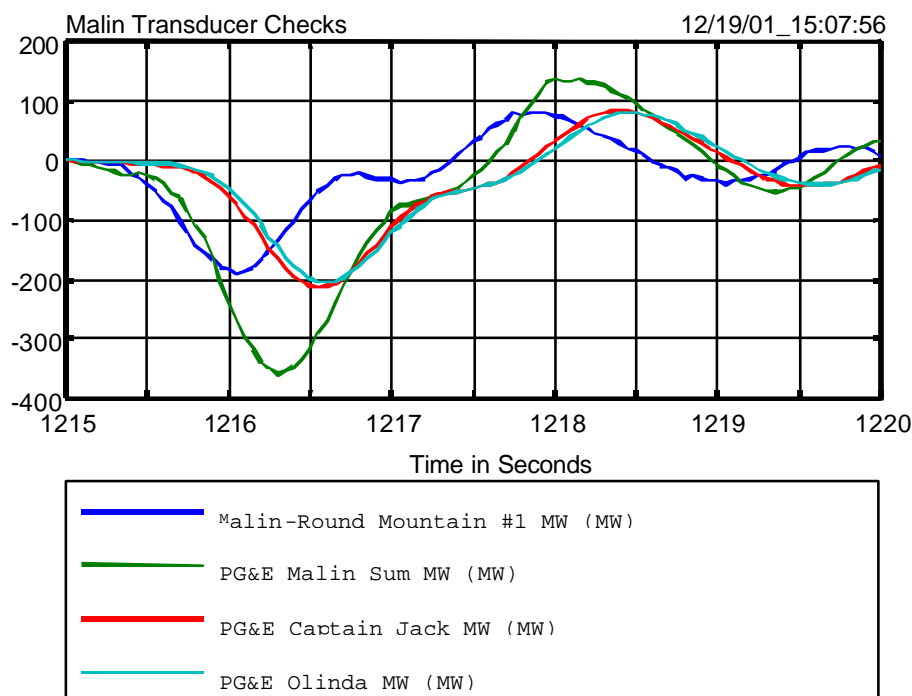

Figure 5. Time response of four Malin area transducers for Chief Joseph dynamic brake insertion \#1 on June 7, 2001 (detail) 


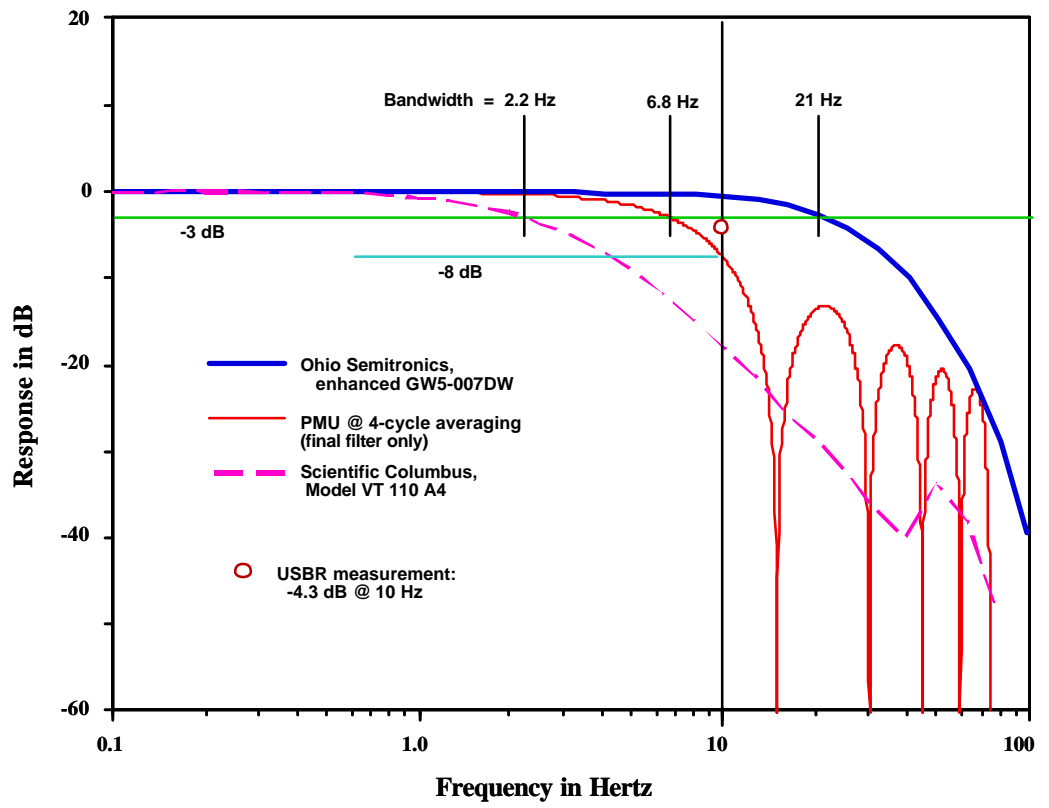

Figure 6. Frequency responses for rms transducers

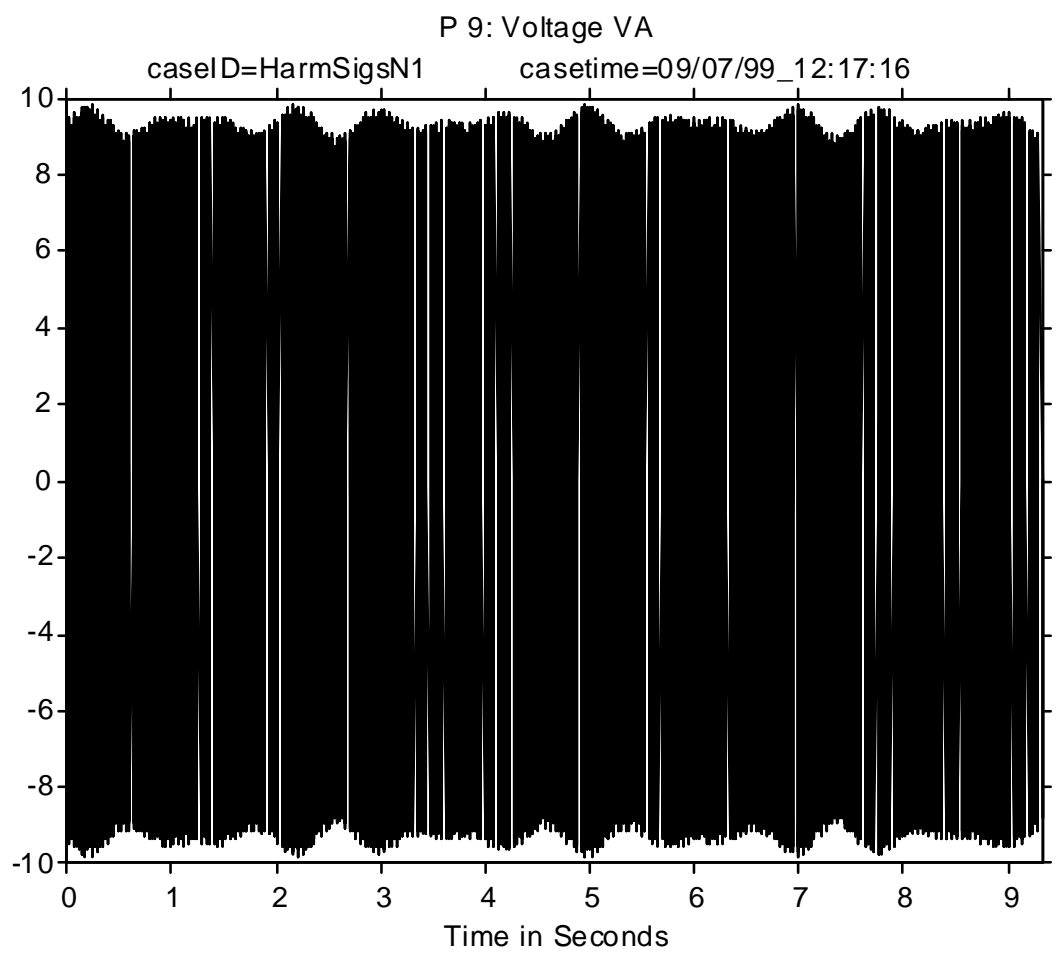

Figure 7. Test signal HarmSigsN1 


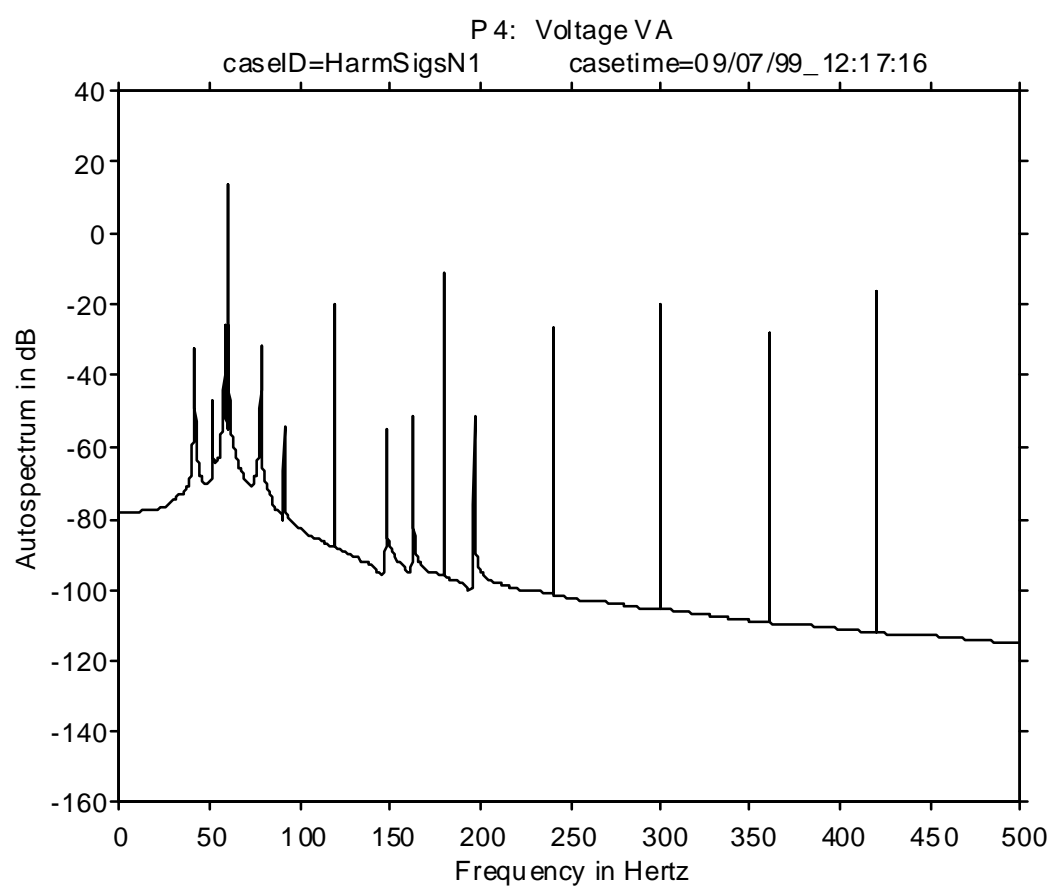

Figure 8. Autospectrum for test signal HarmSigsN1

Results shown in Appendix D demonstrate that Prony analysis can accurately extract all 18 of the signal components from a 0.3 -second record. The identification process will become more difficult if noise is added, or if secondary components are made weaker. Numerical experiments can be performed to assess these problems and to develop countermeasures. Severe data environments will likely require that several identification methods be used in combination, and that candidate process models be fitted to redundant sets of (noisy) data. 


\subsection{Mathematical Tools and Challenges}

Many of the results in this work press the state of the art in power systems analysis. Some of the phenomena have not been measured before in such detail, or on such a scale. This has uncovered hints of embedded dynamic interactions that have not been recognized before. Causal models for some of the extracted signatures are conjectural, and these are being refined in parallel with better characterizations for the sources of "random" power system activity. The most effective of the signal processing tools used for signature extraction tend to be complex research prototypes that that are still in the technology transfer process from the aerospace industry. Aside from the WAMS effort, there is little or no published application experience for the use of such tools in the analysis of power system measurements.

As a result of these challenges, the results shown in this document have required a considerable amount of methods development. The details of this can be found in the Appendices, and in the cited references. 


\subsection{Sources of Dynamic Information}

There are many sources for dynamic information in a large power system. Typical examples are the following:

\section{- Disturbance analysis}

- Ambient noise measure ments

- $\quad$ spectral signatures

- correlation analysis

- open-loop/closed-loop spectral comparisons

- Direct tests with

- network switching

- $\quad$ high-level pulse inputs

- mid-level inputs with special waveforms

- low-level noise inputs.

Each of these has particular merits, disadvantages, and technical implications. For comprehensive results, under a wide range of conditions, it is necessary to draw upon all of these sources in combinations that are tailored to the circumstances at hand.

A structure for these information sources is shown in Figure 9. Note that measurements of interest may be accompanied by a (possibly deliberate) change in network topology, and that noise enters the structure at two places. Input noise is colored by plant dynamics and produces a process noise component in the output $\mathrm{y}(\mathrm{t})$. The final output also contains measurement noise produced by instruments, communication channels, recording systems, and similar devices.

Process noise is particularly attractive as a basis for non-intrusive identification of system dynamics - that is, identification without a special test signal or changes to the system. However, when a test signal is applied, there is no direct way to separate process noise from response to that signal. The natural input noise $\mathrm{u}(\mathrm{t})$ is not observable, and there is not a great deal of knowledge concerning its true nature (Hauer and Cresap 1981, Trudnowski et al 1999). The present effort is adding to this knowledge as a matter of course. 


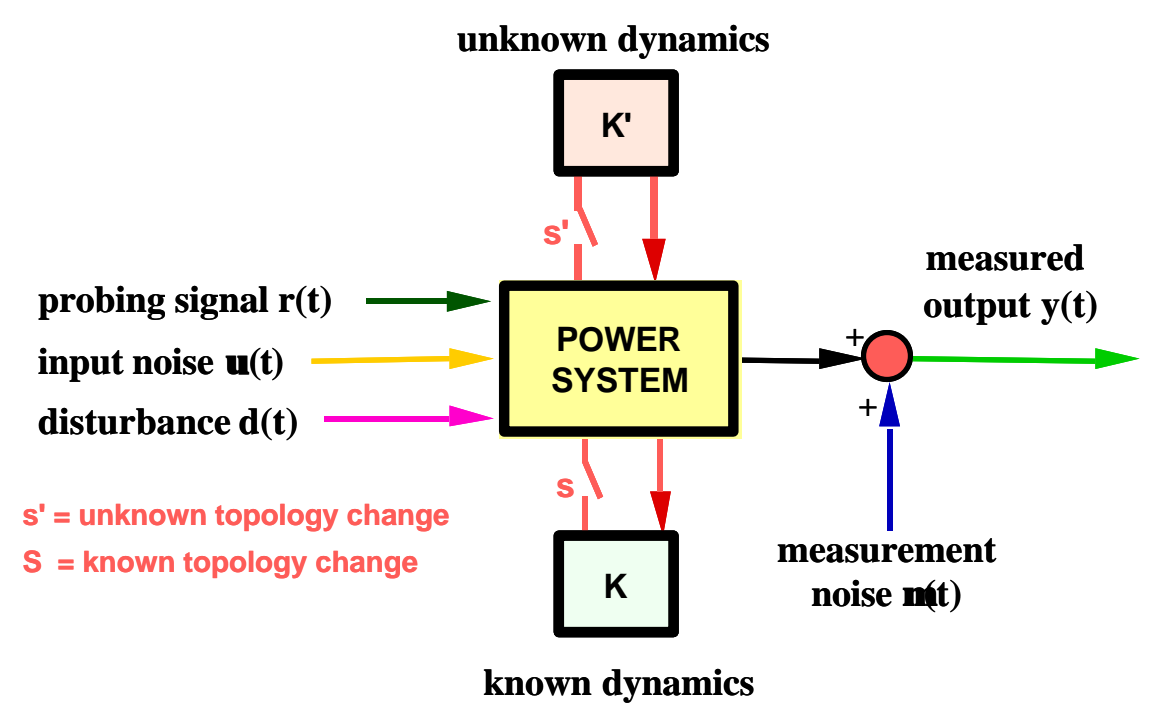

Figure 9. A structure for information sources in process identification

\subsection{Sources of Dynamic Information - System Disturbances}

The signatures for dynamic events on a large power system are embedded in ambient noise and in the response to discrete system changes or inputs. Figure 10 shows a large-signal disturbance in which noise is at most a secondary factor. The event was the total loss of electrical services to the city of San Francisco on December 8, 1998. The traces represent 14 frequency signals from widely separated areas of the western North America power system. Their specific locations are shown in Figure 1, which also indicates various place names used in this document. 


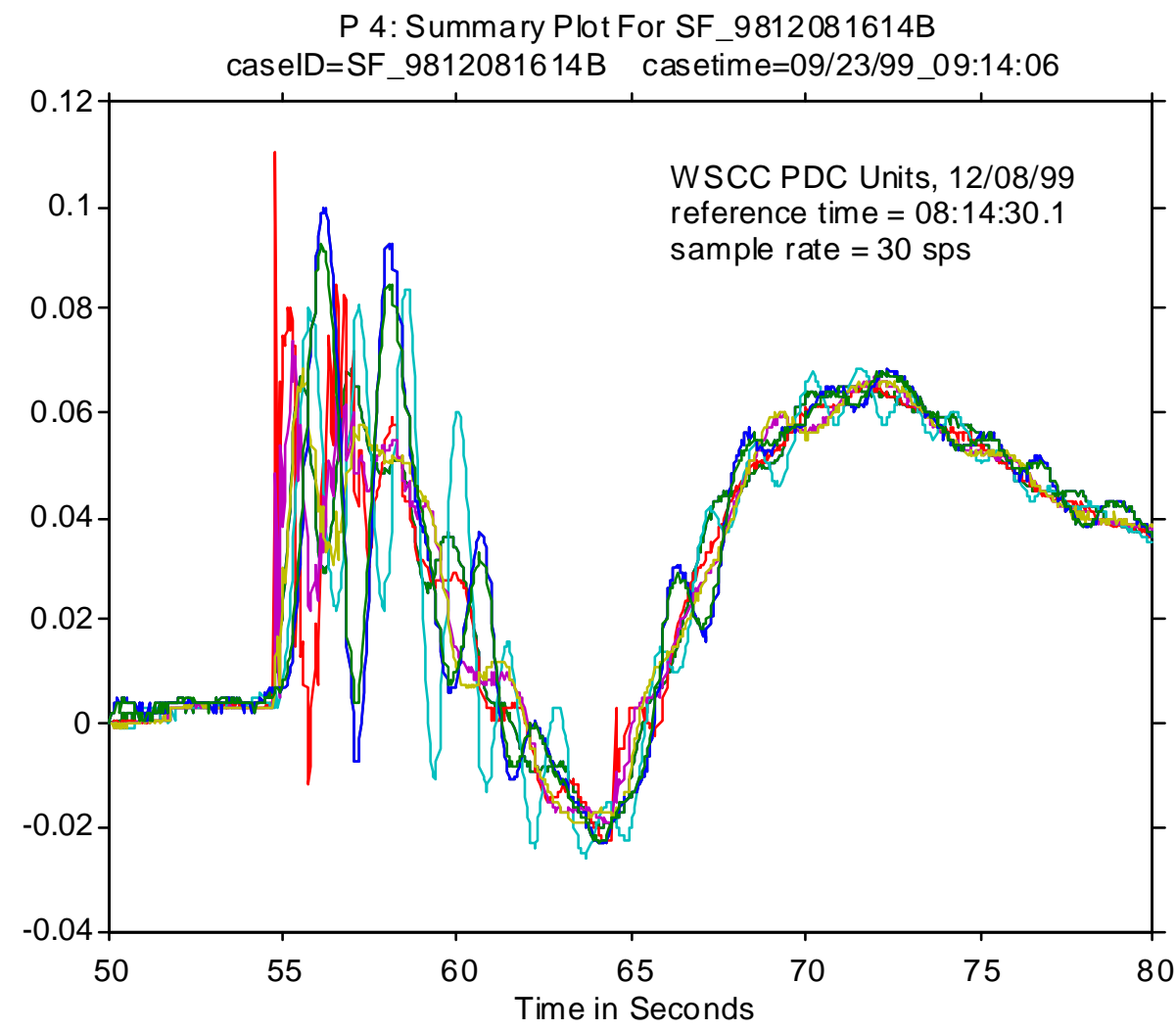

Figure 10. Frequency transients for the San Francisco trip of December 8, 1998 (signals from 14 locations across the western power system)

Summary Plot For SF_9812081614B

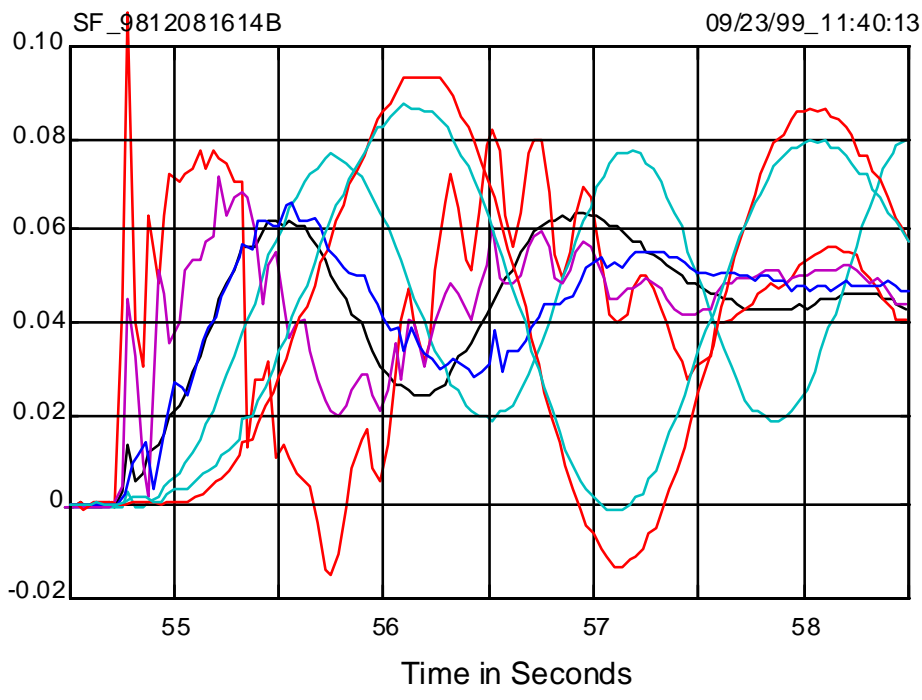

Figure 11. Frequency transient details for the San Francisco trip of December 8, 1998 
Detailed examination (Figure 11) shows that the fast transients are strongest near San Francisco. The fact that all of the signals converge to the same value in Figure 10 indicates that the measurement areas are still interconnected, and the fact that this value is greater than the original 60-Hz system frequency indicates that the interconnected system has suffered a net loss of load. Done very carefully, model studies would likely estimate the load deficit at a value close to the $600 \mathrm{MW}$ that was actually lost, or approximately $0.5 \%$ of the 120,000 to 150,000 MW total for the western power system.

Additional signals and/or some deeper signal analysis would show that the overall power system was still intact, and would locate the loss of load at San Francisco. Success in reaching such specific results depends very much upon what signals are accessible. Full instrumentation of the electrical feeders into San Francisco would have made this very straightforward. Such fortuitous information is exceptional outside of staged tests, however.

Even moderate disturbances tend to be more complicated than the analyst might prefer. The event that initiates the disturbance is very likely to trigger various protective controls, and it may also lead to cascading failure of power system elements that are remote from the initial point of failure. The next several figures illustrate this.

The early portions of Figure 12 indicate the onset of the San Francisco disturbance and what appear to be switching events. The behavior from $55.8 \mathrm{sec}$. to $55.8 \mathrm{sec}$. is quite different. There are about 3.5 smooth "swings" at a frequency near $5 \mathrm{~Hz}$, followed by about 2.5 more swings near $3 \mathrm{~Hz}$. These swings may be associated with progressive tripping of generator units near San Francisco. The frequencies are unusually high, though, and this raises the possibility that some other process was involved. Such issues cannot be resolved without more data and better knowledge of event timing, though, and these seem unavailable for this disturbance. Such uncertainties are very common in disturbance analysis.

Figure 13 and Figure 14 provide an example of secondary inputs to the system that may follow loss of a major facility. The facility in this case is the Palo Verde \#2 generator, operated by Arizona Public Service (APS) near Phoenix, Arizona. The trip occurred at $2229 \mathrm{hr}$ PDT on 06/18/99, at a loading of $1258 \mathrm{MW}$.

The 0.3-Hz Canada-California mode is highly responsive to Palo Verde unit trips, and system response to them is regularly examined for signature information. Outwardly at least, the data in Figure 13 appears typical. Figure 14 indicates that system response in this case is not entirely the result of the negative step in generator power, however. The voltage steps near 90 seconds and 180 seconds suggest switching of reactive devices near Malin. A disturbance of this scale is very likely to trigger secondary inputs of this kind, and some of them may be better hidden from casual inspection. The analysis procedure should reflect this possibility. 


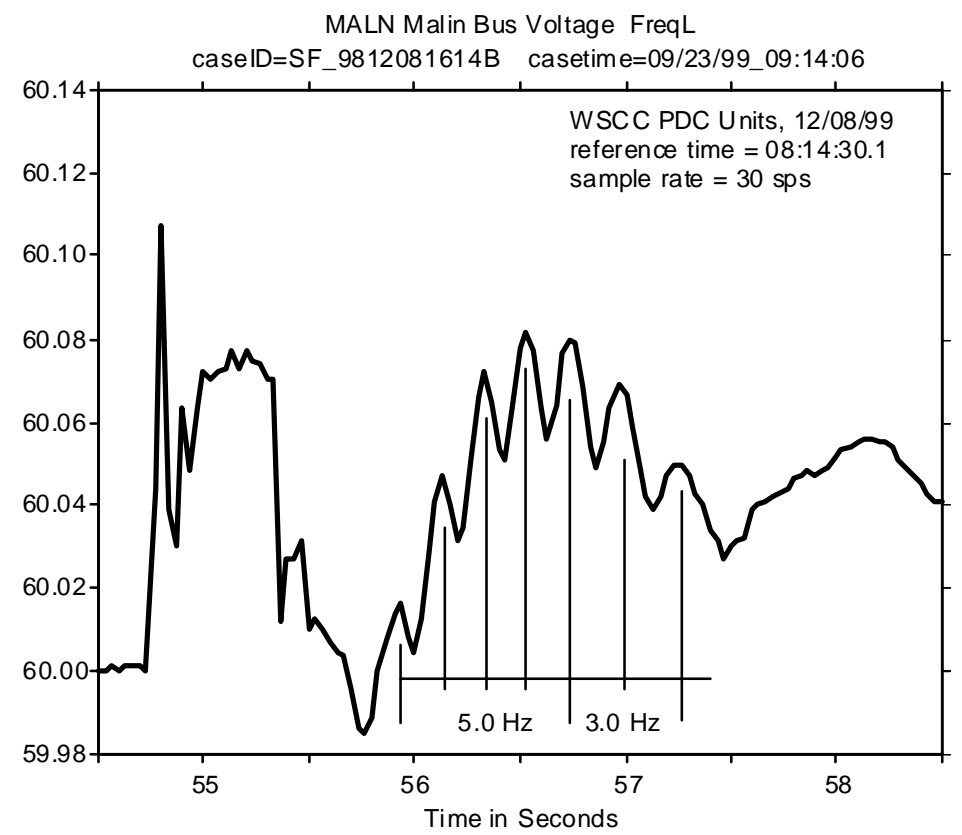

Figure 12. Detail of Malin bus frequency for the San Francisco trip of December 8, 1998

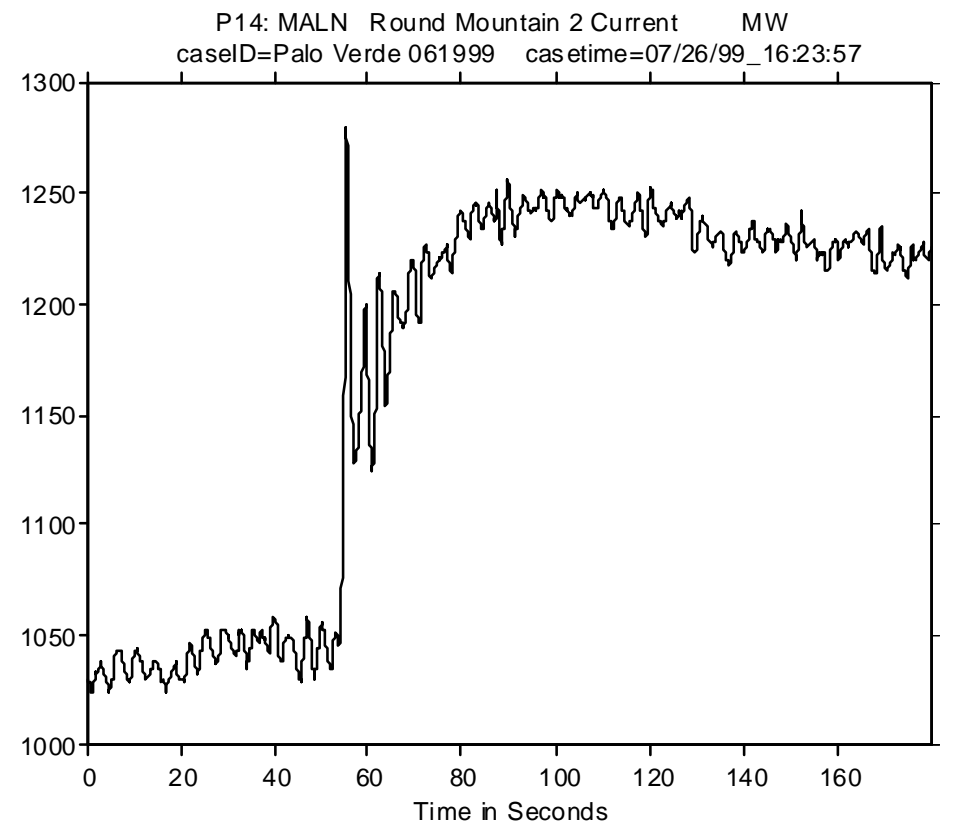

Figure 13. Malin MW for Palo Verde generator trip of June 18, 1999 


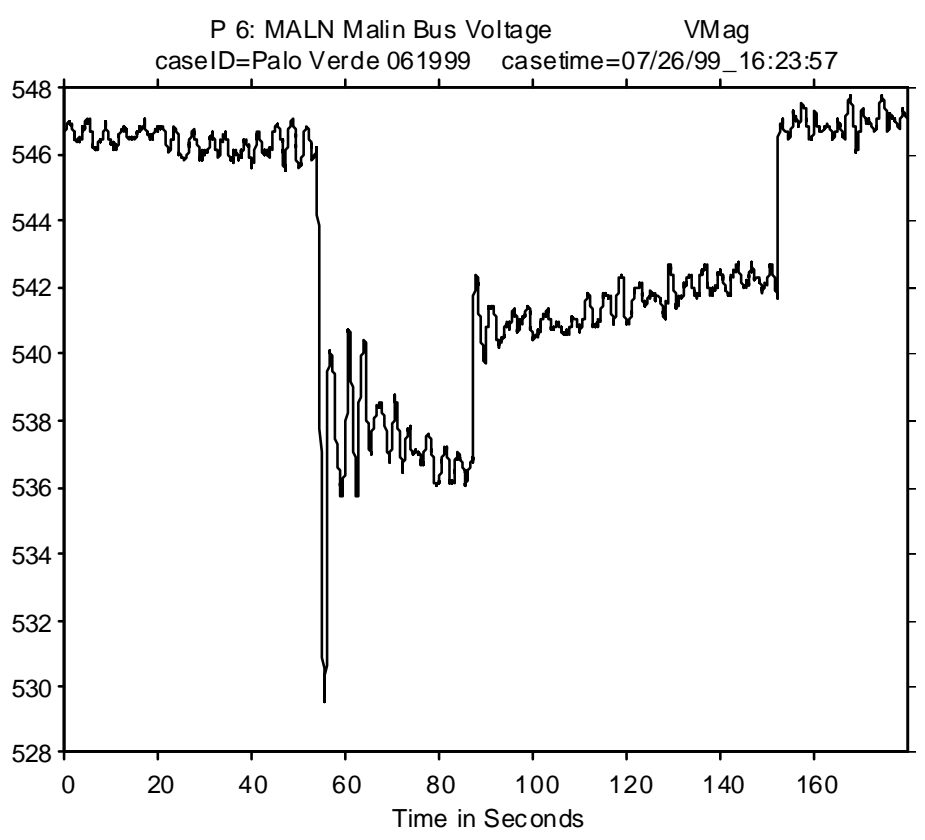

Figure 14. Malin voltage for Palo Verde generator trip of June 18, 1999

\subsection{Sources of Dynamic Information - Ambient Noise}

System noise itself can contain a great deal of information. The "information density" in system noise tends to be fairly low, however, and this usually requires some kind of averaging process for signature extraction. Non-parametric spectral methods based upon the Fast Fourier Transform (FFT) are particularly simple and efficient for this when direct quantitative results are not needed (Brigham 1988, Bendat and Piersol 1980)

\subsubsection{Spectral Signatures}

Examples of this are provided by the autospectra in Figure 15 and Figure 16. These were developed from ambient data collected before and after two staged insertions of BPA's 1400-MW dynamic braking resistor on September 4, 1997. This device is located at the Chief Joseph powerhouse in north-central Washington State. The Malin signal was acquired on the Pacific AC Intertie (PACI), where it crosses the California - Oregon border. This is a focal point for energy transfers from Canada into California, and thus a good location for observing gross dynamics of the overall power system. The other two signals in the figures correspond to BPA energy imports from British Columbia Hydro $(\mathbf{B C H})$, on the CusterIngledow and the Boundary-Nelway lines. These two lines cross into Canada north of Seattle and Spokane, respectively. 


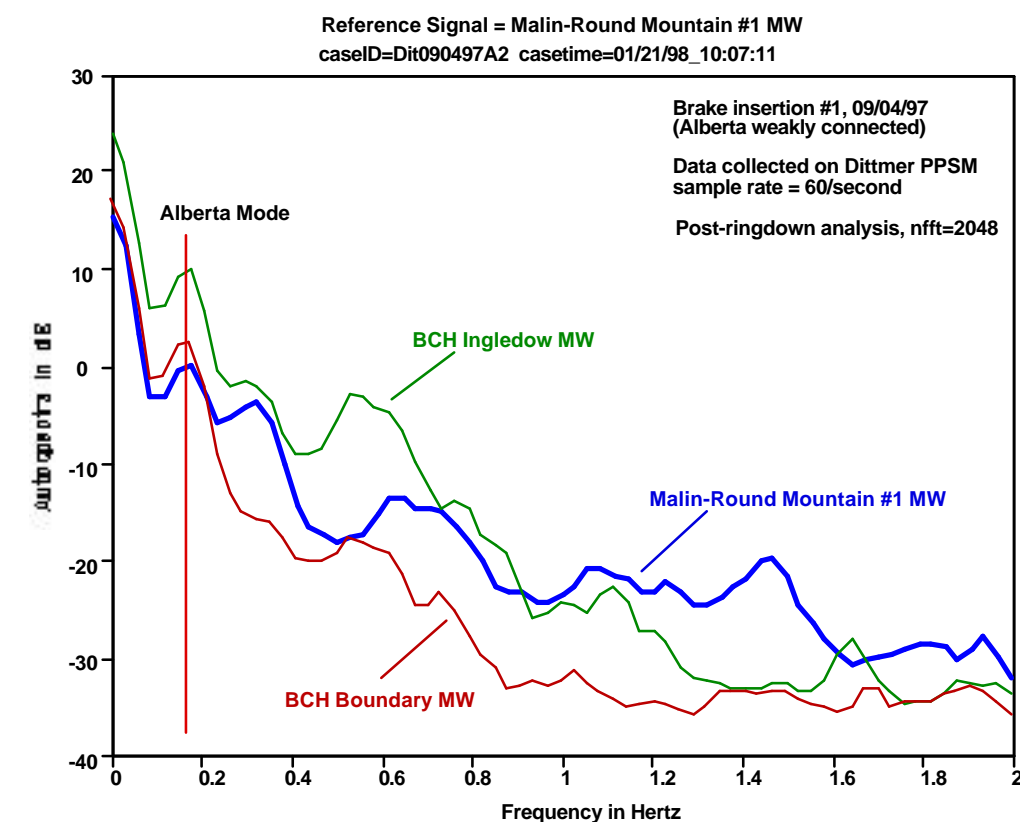

Figure 15. Ambient autospectra for BPA power interchanges with Canada and California, with Alberta weakly connected. Brake insertion tests of 09/04/97

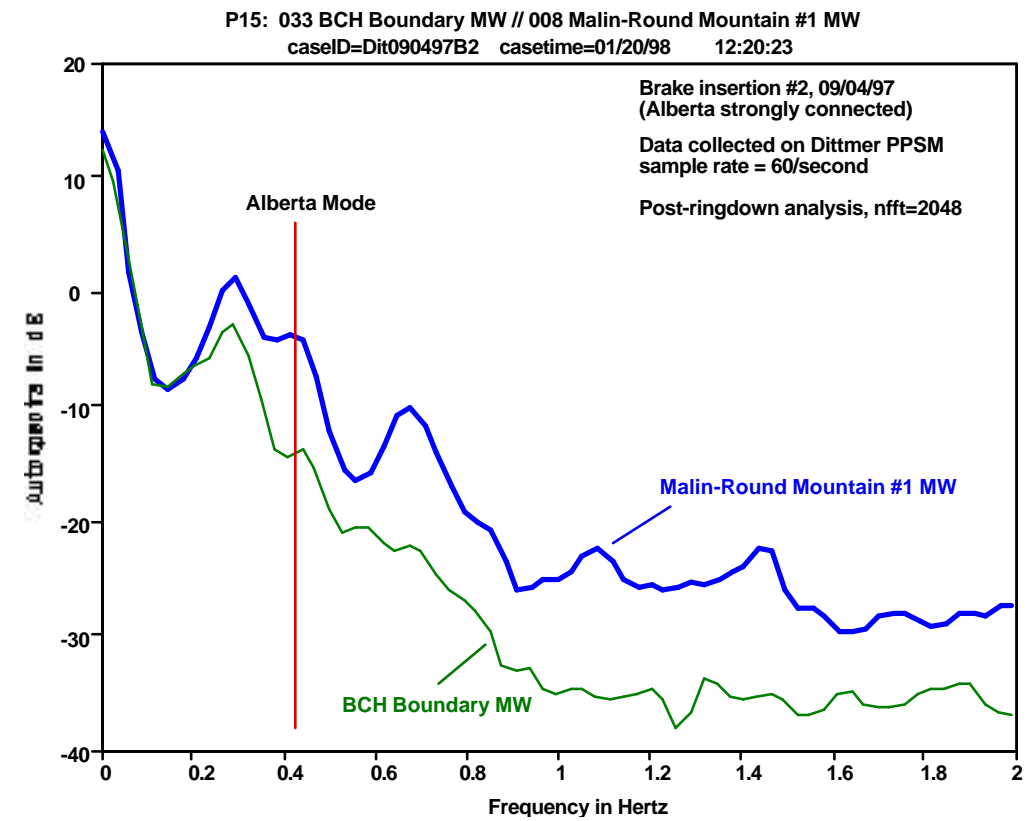

Figure 16. Ambient autospectra for BPA power interchanges with Canada and California, with Alberta strongly connected. Brake insertion tests of 09/04/97

In the first case (Figure 15), the Canadian Province of Alberta is weakly connected to the remainder of the grid through a 138-kV transmission line. In the second case, Alberta is strongly connected through both the $138-\mathrm{kV}$ line and a much stronger $500-\mathrm{kV}$ line. A primary signature element of the weak connection is 
a peak in noise energy that is located somewhere near $0.18 \mathrm{~Hz}$. This peak generally shifts to a frequency in the range of $0.42 \mathrm{~Hz}$ to $0.45 \mathrm{~Hz}$, when Alberta is strongly connected, and the peak essentially disappears when the lines to Alberta are out of service. Though the Alberta signature is especially visible on these two lines into Canada, it is distinctly observable through most of the western power system.

This change in signature is clearly evident in the figures provided. The spectra also show normal activity on the PACI, near $0.3 \mathrm{~Hz}$, and for a cluster of modes in the general vicinity of $0.7 \mathrm{~Hz}$. Most of these involve generators in British Columbia. One of these, the Kemano plant, has a very conspicuous signature near $0.63 \mathrm{~Hz}$. This signature can sometimes be recognized as far away as Arizona.

With a few exceptions, oscillatory activity in the general range of $0.1 \mathrm{~Hz}$ to $1.0 \mathrm{~Hz}$ is associated with "interarea" modes that encompass most or all of the power system. Modes in the range of $1.0 \mathrm{~Hz}$ to perhaps $1.8 \mathrm{~Hz}$ are usually "local" to some particular generator or plant, and not globally observable Figure 15 and Figure 16 indicate a number of local modes.

Interpreting spectral estimates of this sort requires some knowledge of how they were developed. The numerical processing must achieve a good balance among the following:

- accuracy of the estimates

- frequency resolution of the estimates

- length of the record from which the estimates are derived.

Record length is a dominant factor in this. During the middle of the night, power system dynamics tend to change very little and, from a statistical point of view, random signals extracted from it are "stationary." Then very good spectral estimates can be developed by processing very long records. During the remainder of the day, the signals may be far from stationary. Abrupt changes in system configuration and loading are likely near the start of each hour, when transmission schedules change. Load changes and small disturbances may affect system dynamics at any time. In the absence of other information, estimates for ambient noise spectra must be formed from records having lengths in the general range of 5 to 20 minutes.

\subsubsection{Correlation Analysis}

Sharper signatures for system activity can sometimes be formed with cross-analysis tools that correlate signals against one another. Coherency estimates such as those in Figure 17 are particularly useful for this. This is a normalized spectral measure of the degree to which the two signals "move together" at specific frequencies. Its use in the present context is still a subject of exploratory research, so some caveats should be observed (Hauer et al. 1999b, Trudnowski et al. 1999). Given data of sufficient quality, however, it seems possible to recognize the presence of particular generation plants. The high resolution coherency spectrum of Figure 18 illustrates this conjecture. 


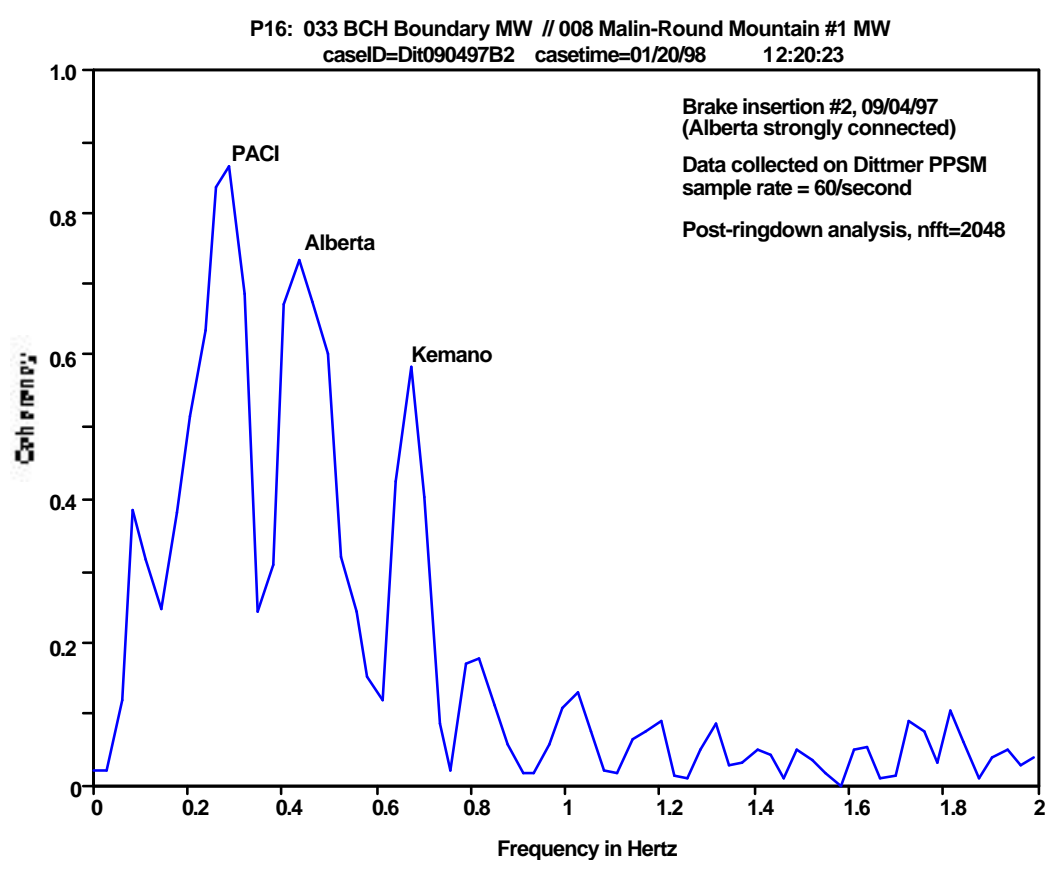

Figure 17. Ambient coherency for BPA power interchanges with Canada and California, Alberta strongly connected. Brake insertion tests of 09/04/97

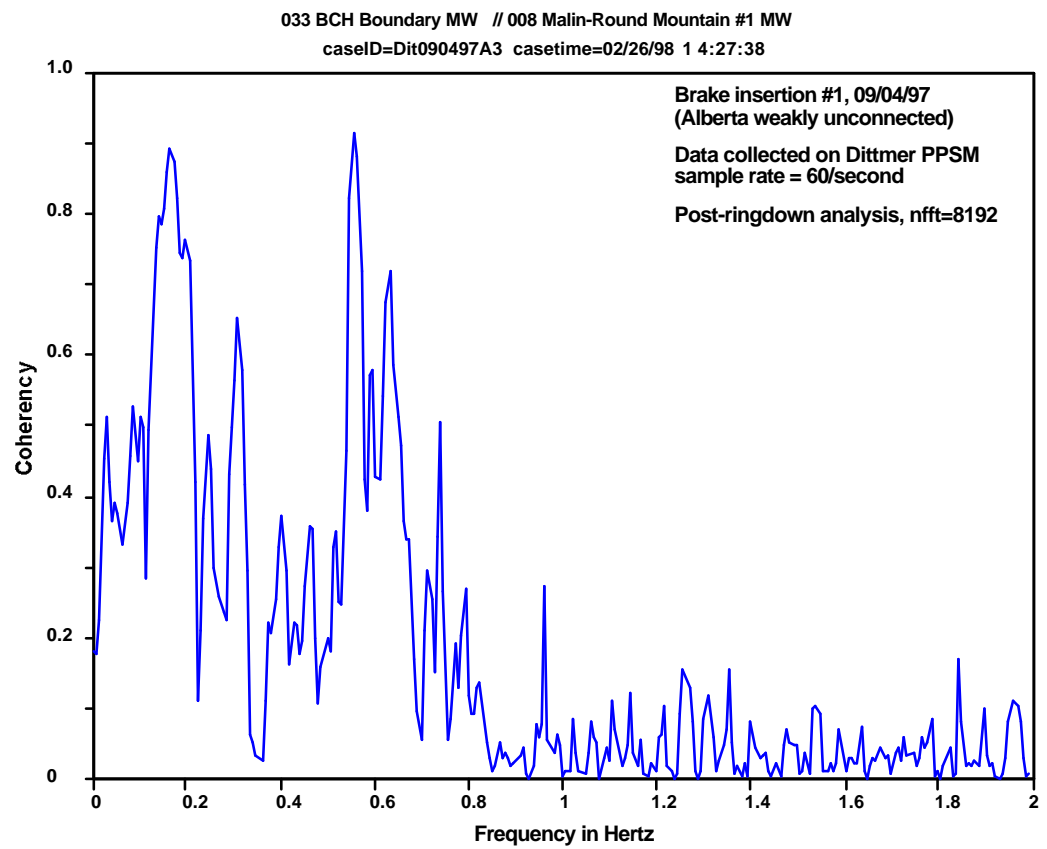

Figure 18. High resolution coherency estimate for BPA power interchanges with Canada and California, Alberta weakly connected. Brake insertion tests of 09/04/97 


\subsubsection{Open-Loop/Closed-Loop Spectral Comparisons}

The basic notions in this sort of information gathering are illustrated in Figure 19. The measurements were among the last performed on BPA's HVDC modulation system for damping the $0.33 \mathrm{~Hz}$ oscillation mode between Canada and southern California. At that time the $500-\mathrm{kV}$ link to Alberta was not yet operational, and the Alberta mode was usually located between $0.28 \mathrm{~Hz}$ and $0.22 \mathrm{~Hz}$.
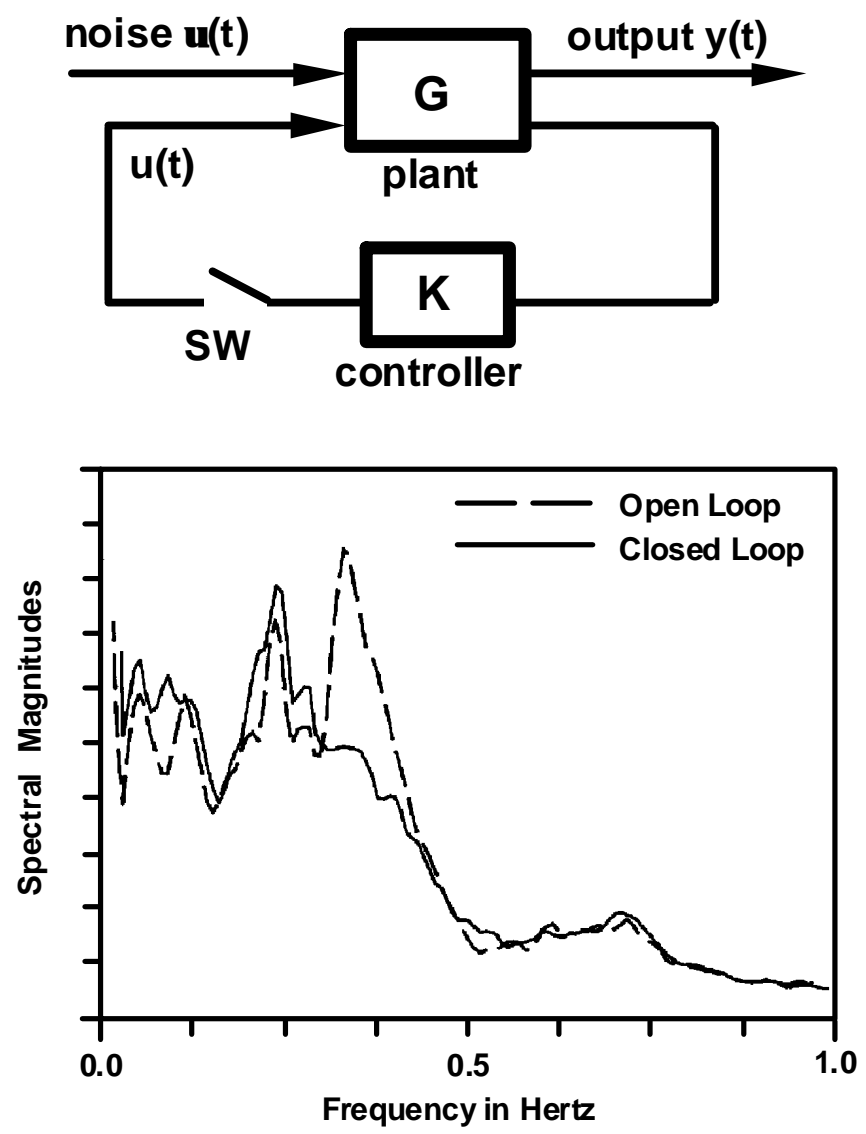

Figure 19. Spectral comparison for HVDC modulation loop open and closed. Ambient noise in PACI line current. HVDC tests of January 23, 1985.

The data were collected in the very early morning (02:00 AM to 03:07 AM), when system activity was minimal. Each spectral measurement is about 20 minutes long. Above $0.5 \mathrm{~Hz}$ the spectra coincide very closely. The differences below $0.1 \mathrm{~Hz}$ may represent changes in very slow mechanical processes, or just a shortage of statistical information in the record. More research in this area would be useful.

It is apparent that opening the loop has roughly doubled the strength of ambient activity for the mode near $0.33 \mathrm{~Hz}$, and slightly decreased activity for the mode near $0.22 \mathrm{~Hz}$. This is a partial but clear indicator of controller effectiveness. If a good model exists for the dynamics of either the controller or the plant, then 
it should be possible to refine modeling data for the other. There seems to have been little research in this area, however. New projects in wide area feedback control may cause it to be revisited.

\subsection{Sources of Dynamic Information - Direct Tests}

The least ambiguous way to examine power system behavior is through direct tests. Some reasons for this are the following:

- The test procedure can be focused on specific information targets

- Supplemental recording equipment can be installed at key locations before the test

- Advanced coordination minimizes failures to record and/or retain data.

Direct tests require some way to stimulate the system.

\subsubsection{Network Switching}

The most straightforward means to stimulate the system is to open and/or close a breaker. Even when this is safe, it may still produce poor results. One reason is that abnormal breaker status produces an abnormal network topology, and observed behavior under this condition may also be abnormal. Another reason is that "safe" breaker operations may not provide a sufficiently strong stimulus to the power system. These handicaps are minimized when the breakers are used to switch a radially connected generator or load.

A controllable actuator provides many more options for "probing" power system response. Typical probing signals include the following:

- high-level pulse inputs

- mid-level inputs with special waveforms

- low-level noise inputs.

The first of these is typified by BPA's Chief Joseph dynamic brake.

\subsubsection{High-Level Pulse Inputs}

Nominally, the Chief Joseph dynamic brake applies a 1400-MW load pulse that is 0.5 -second long. Response to this pulse diminishes with distance, but useful results can still be obtained at the far edges of the power system.

Mid-level and low-level probing involves more complex waveforms, and generally requires an actuator that can be modulated. Results shown here are based upon modulation the Pacific HVDC Intertie (PDCI), at the Celilo converter station. The same methodology can be applied to devices such as a thyristor controlled series capacitor (TCSC), a static Var compensator (SVC), or the excitation controls of a suitably equipped electrical generator. The response of a large power system to modulation of an SVC or generator is likely to be just locally observable, however. 
Section 6.2 presented some results for ambient noise analysis associated with the Chief Joseph brake insertions of September 4, 1997. The next several figures show results for the insertions themselves. As before, most of these results are based upon response signals collected at Malin.

Figure 20 and Figure 21 show the ringdown signals and derived autospectra for the two brake insertions. The signature of the Alberta connection is fairly evident in the signals of the first figure, and strongly so in the autospectra of the second figure. The spectral differences in the range from $0.5 \mathrm{~Hz}$ to $1.0 \mathrm{~Hz}$ are almost certainly a result of system changes between the first insertion (at $1345 \mathrm{hr}$ ) the second insertion (at $2345 \mathrm{hr}$ ).

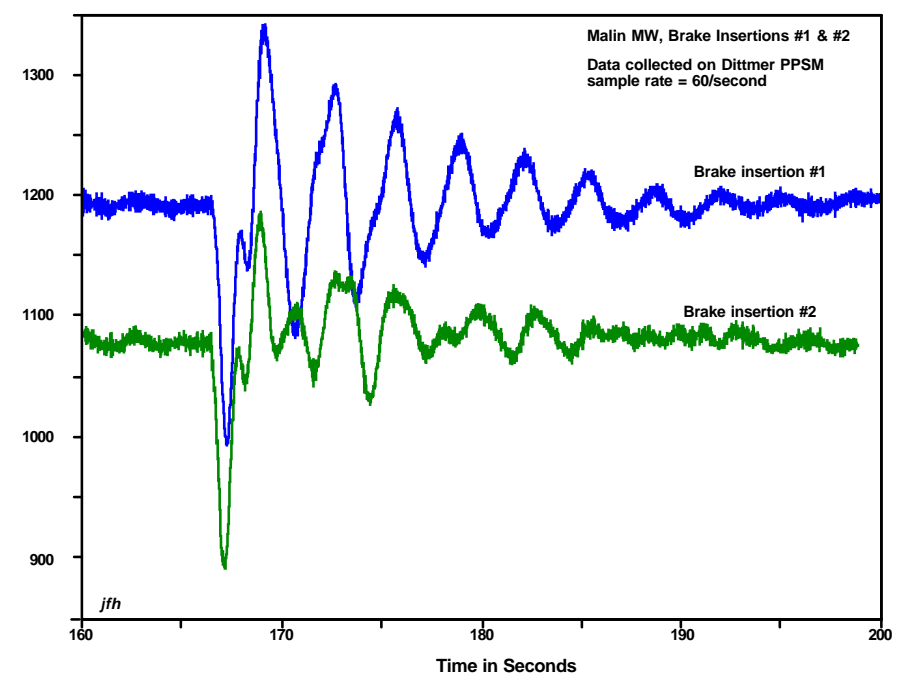

Figure 20. Ringdowns of Malin-Round Mountain MW, for brake insertions \#1 and \#2 on 09/04/97. 


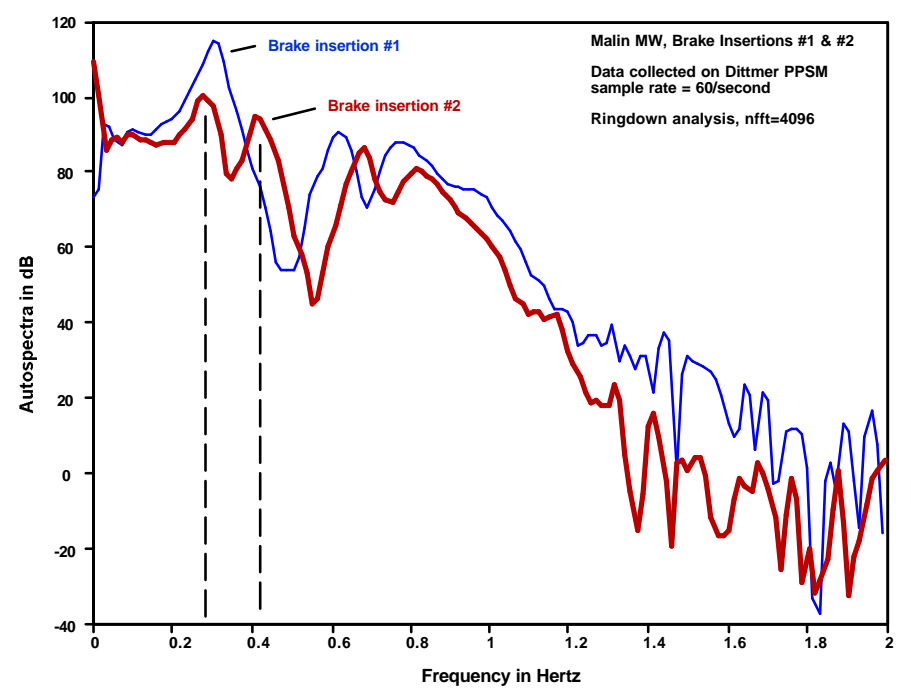

Figure 21. Autospectra for ringdowns of Malin-Round Mountain MW, brake insertions \#1 and \#2 on $09 / 04 / 97$

The noise analysis of Section 6.2 provides a somewhat different view of these signature changes. The earlier noise autospectra are overlain in Figure 22, for comparison against Figure 21. It is apparent that spectra for the brake insertion are sharper than those for the noise analysis, but that the brake insertions did not produce much information above $1 \mathrm{~Hz}$ (in this particular signal). The very important interarea modes for wide area dynamics are in this range. The noise spectra provide reliable signature information out to at least $2 \mathrm{~Hz}$, which includes the vast majority of local generator modes.

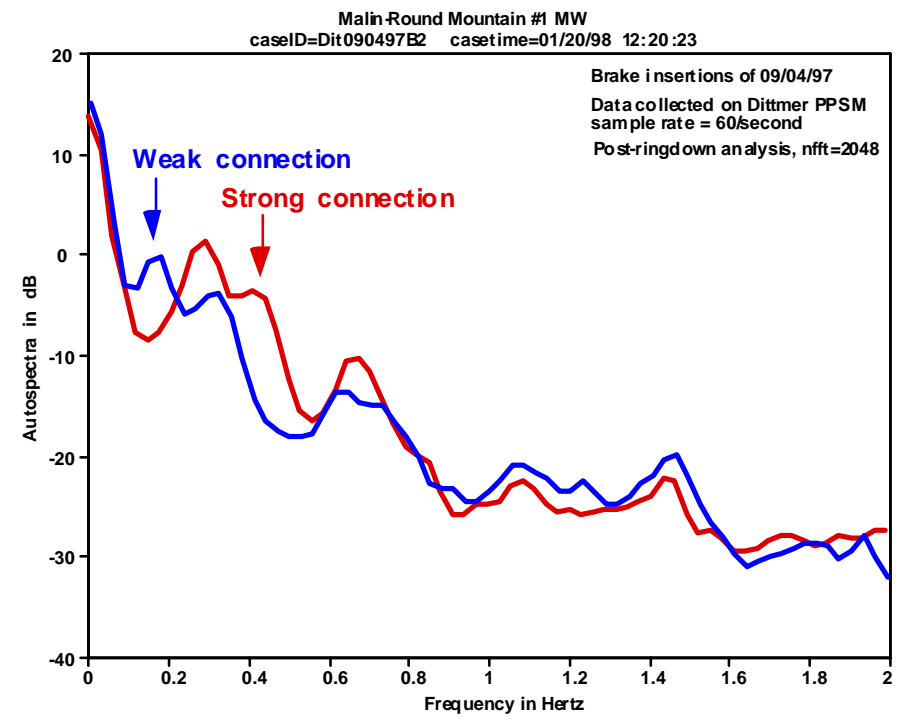

Figure 22. Effect of Alberta connection on ambient autospectra, tests of 09/04/97 
There are also differences in the general shape of the spectra produced by these two methods. Underlying reasons for these differences include the following:

- The ambient noise stimulus is primarily a result of randomly switched loads, and this stimulus is applied at thousands of locations across the system. The brake pulse is applied at just one point, and produces a different response pattern.

- System response to random noise switching rarely produces sharp notches in measured autospectra. Such notches are, in effect, filled in by non-dynamic response components plus a certain amount of measurement noise. The signal analysis tools used to estimate such spectra differ considerably in their ability to remove these components. Results from Fourier analysis are usually not very sharp unless cross-analysis is used (e.g., as in Figure 17 and Figure 18).

- Ringdown analysis produces a time-localized snapshot of system dynamics across a processing window that is rarely more than 30 -seconds long. Noise analysis produces an averaged measure across a window that is rarely less than 3-minutes long. Long processing windows may incur shifts in system characteristics, or data contamination through unobserved disturbances to the system.

A comprehensive test will use both ringdown signals and ambient noise.

It is instructive that the 1400-MW capacity of the Chief Joseph brake is just one percent of the full capacity of the western system. The fact that brake insertions produce good response data is the result of brake location, and the oscillatory nature of the power system itself. These same factors lead to very useful data when certain generators trip off under heavy load. The 1100-MW Palo Verde units in Arizona are notable for this (Hauer et al. 1977, Hauer and Hunt 1996)

Ringdown signals can be very useful sources of information. Not everything there is useful, however. The overall ringdown signal is likely to contain

a) Response for an equivalent linear model that approximates the dynamic phenomenon

b) Process noise produced by the autonomous noise input to the system

c) Nonlinear effects, usually the result of device saturation and controller deadbands

d) Slow trends, associated with motion of the system toward a new operating point

e) Response to hidden inputs such as tripping of a small generator or load

f) Measurement noise.

Measurement noise is not usually a serious problem, or of particular interest as an information source. With this exception, each of the above signal components may contain useful signature information under at least some circumstances. Thus the overall analysis procedure must be able to decompose the ringdown signal into these components.

The procedure followed here starts with formation of the linear model. Ordinarily this is done with a tandem Prony fit to multiple signals, as indicated in Figure 23. The signals are selected to provide fairly independent views of system response. The processing window for each signal starts after nonlinear effects have become weak or unlikely, and ends before the ringdown has faded too far into the process noise. A fair degree of experimentation and judgement is involved in this, and the governing principle is 
that the result should be insensitive to small changes in processing. Figure 24 is indicative of the first step in this.

\subsubsection{Mid-Level Inputs With Special Waveforms}

For present purposes, a probing signal will be considered "mid level" if it is much weaker than a highlevel pulse input but still manages to produce useful information without temporal averaging (e.g., the response resembles a ringdown signal). There are two means for achieving this:

- focus the probing signal on a narrow band within the frequency range of interest

- use analysis tools that, while the input is being applied, correlate the response against the input.

The preference here is for analysis tools that extract information during the "ringup" as well as the ringdown. In most cases these will require that the input probing signal be directly measured.

Figure 25 and Figure 26 show partial results for a test of this sort that was conducted by the BPA on April 27,1999 . The test signal was two cycles of a \pm 125 MW square wave, inserted into the power system by modulation of the PDCI. Figure 25 shows that the resulting response was repeatable, but that the ringdown was brief and quickly settled into the ambient noise. This was a result of unusually high damping for the mode under examination. The overall response is clearly visible against the background noise, however, and Figure 26 shows that signature information is available throughout the power system. This provides good opportunities for refined estimates through spatial averaging.

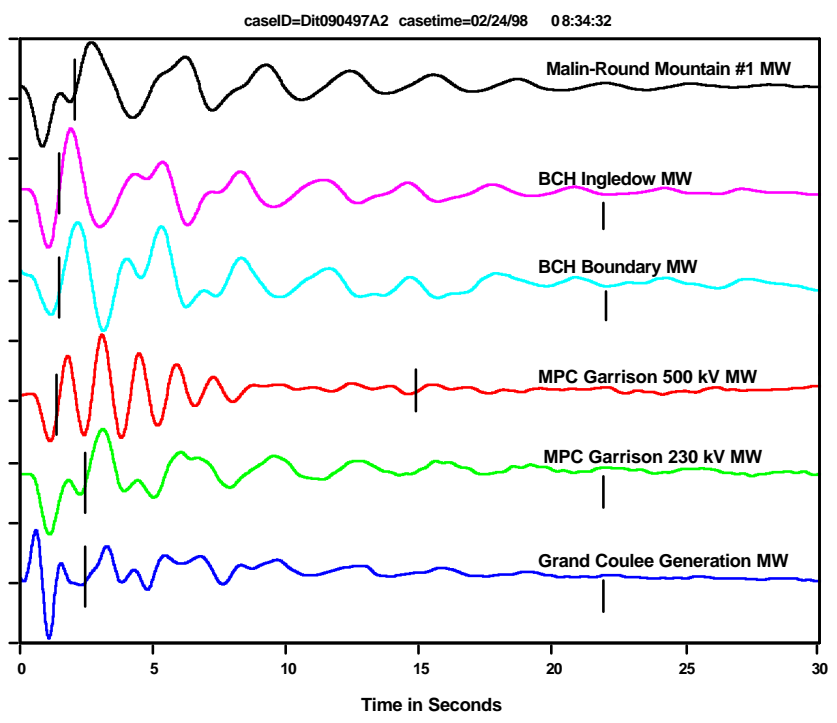

Figure 23. Signals and fitting windows for multi-output Prony fit to brake insertion \#1, 09/04/97. Data collected on Dittmer portable power system monitor (PPSM). 


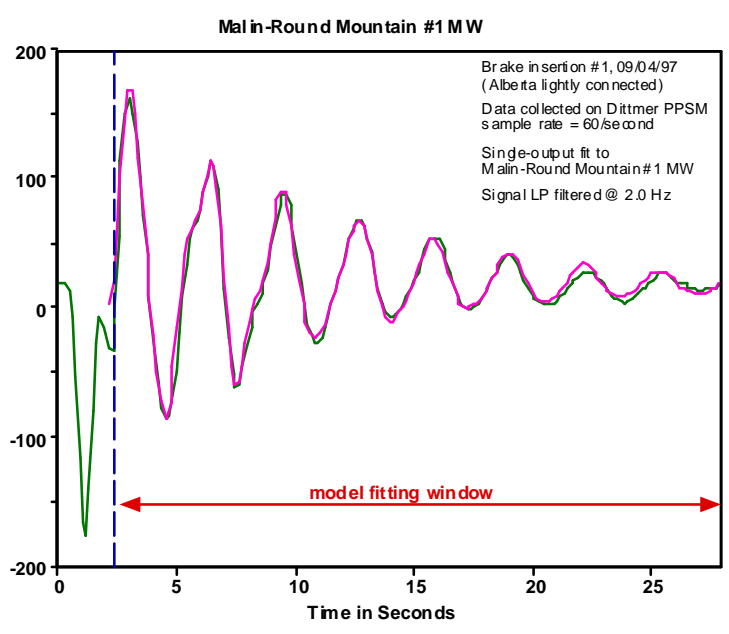

\begin{tabular}{|c|c|c|c|c|}
\hline Mal in-Round Mo untain \#1 MW \\
\hline Mode & $\begin{array}{c}\text { Frequency } \\
(\mathrm{Hz})\end{array}$ & $\begin{array}{c}\text { Damping } \\
2 \backslash \mathrm{pi}\end{array}$ & $\begin{array}{c}\text { D a m ping } \\
\text { R a to }\end{array}$ & $\begin{array}{c}\text { R e lative } \\
\text { A mp lit ude }\end{array}$ \\
\hline 1 & 0.312878 & 0.018338 & 0.058511 & 1.000000 \\
\hline 2 & 0.000000 & 0.002698 & $\cdots--$ & 0.161491 \\
\hline 3 & 0.639105 & 0.028935 & 0.045228 & 0.381566 \\
\hline 4 & 0.755600 & 0.039238 & 0.051860 & 0.223305 \\
\hline 5 & 0.791731 & 0.036887 & 0.046540 & 0.193271 \\
\hline
\end{tabular}

Figure 24. Dominant modes for initial Prony fit to brake insertion \#1, 09/04/97.

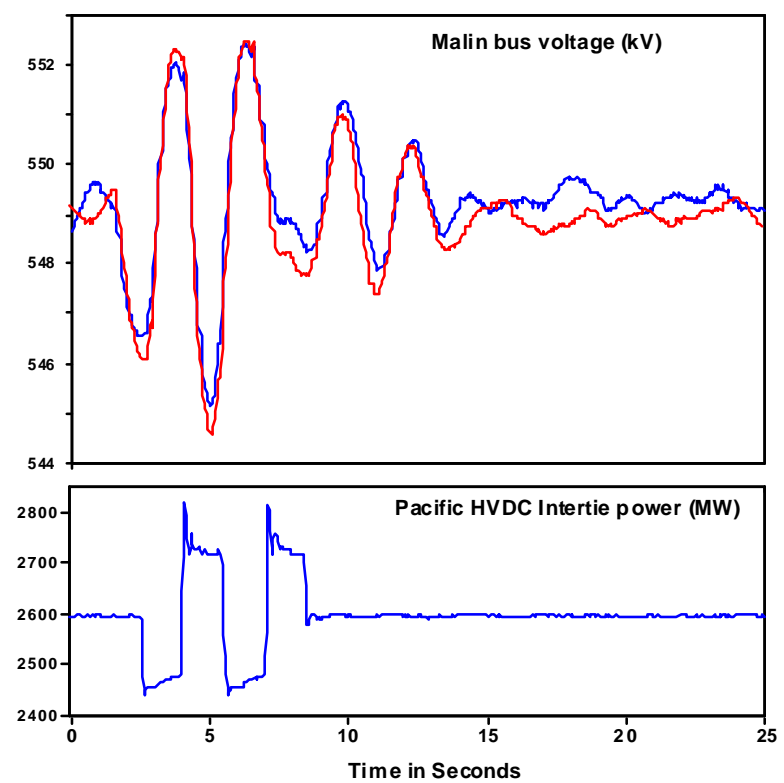

Figure 25. Power system response to two applications of two-cycle probing signal. HVDC tests of April 27, 1999 


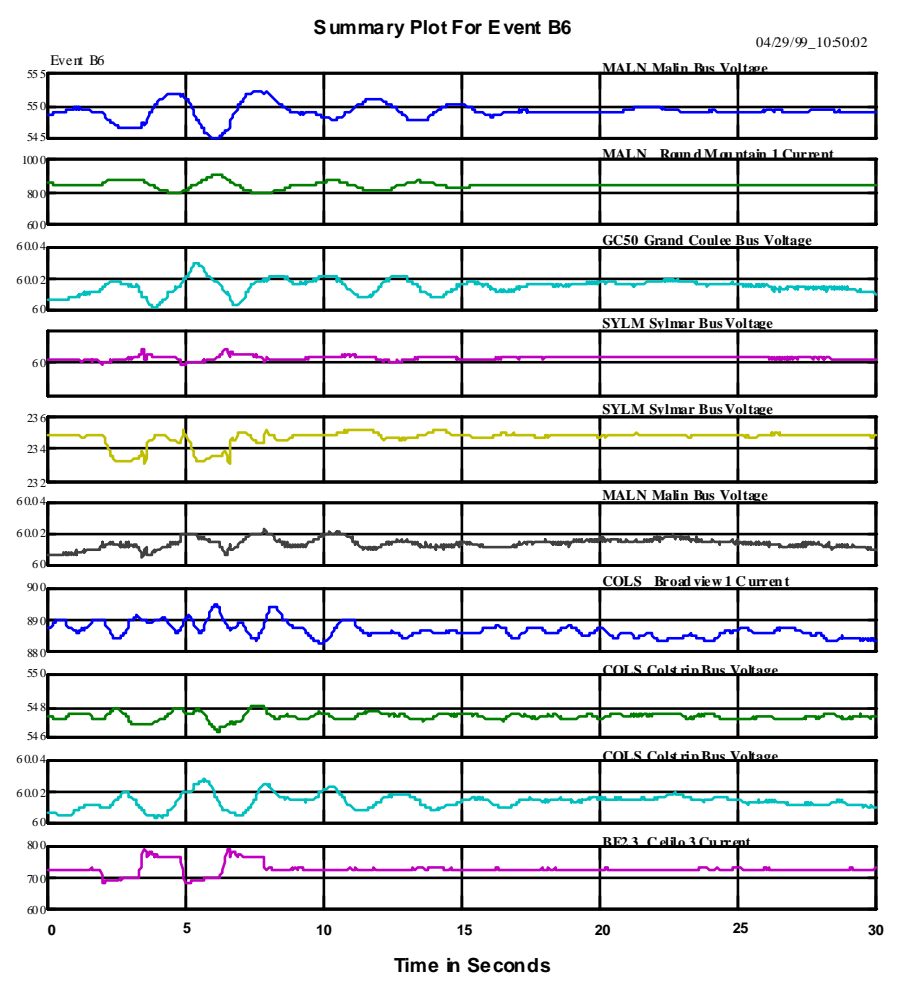

Figure 26. Power system response to two-cycle probing signal, test event B6. HVDC tests of April 27, 1999

Important aspects of such probing signals are that it they are simple to generate and process, and that they are believed to pose no significant risk to the power system. The BPA is developing an automatic system that would repeatedly use such signals to examine critical power system modes during the course of each day. It is likely that this would be used in association with the low-level probing that is discussed below.

\subsubsection{Low-Level Noise Inputs}

Band-limited white noise can be very useful as a probing signal. Possible actuators for injecting such signals include electrical generators (Farmer and Agrawal 1983), superconducting electromagnetic energy storage (SMES) units (Hauer and Boenig 1987), HVDC transmission facilities (Hauer 1987, Grund et al. 1990, Hauer 1995), thyristor controlled series capacitor (TCSC) units (Hauer et al. 1996), and other precisely controllable devices.

Probing with low-level random noise was once commonplace in PDCI operation, and it may become so again. The results in Figure 27 through Figure 29 are typical of the western system before construction of the strong connection to Alberta. The next generation of noise probing, nominally scheduled for late 1999, will draw upon a far better measurement resource, but follow the same general procedure (Hauer 1997). 


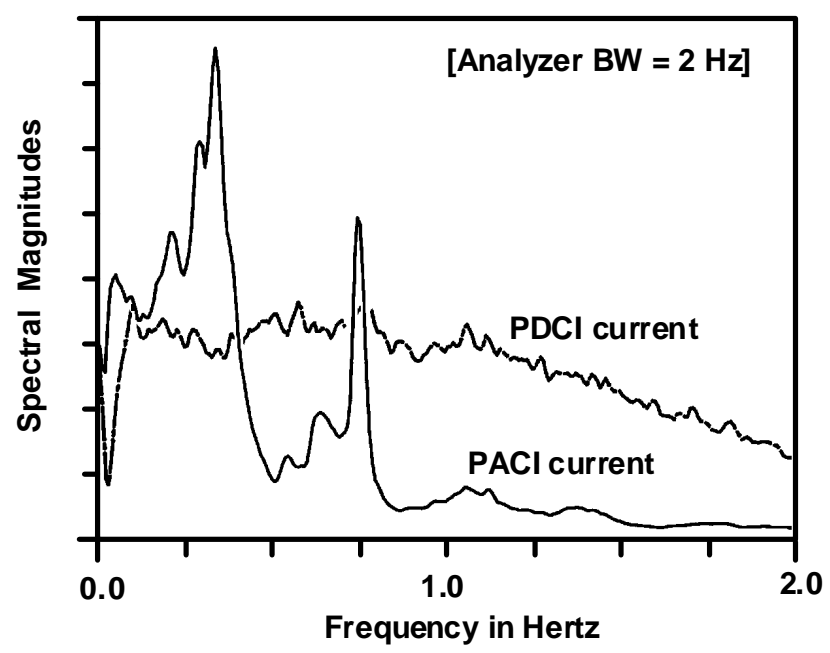

Figure 27. Response of PACI line current to low-level modulation of PDCI. HVDC tests of May 7, 1985.

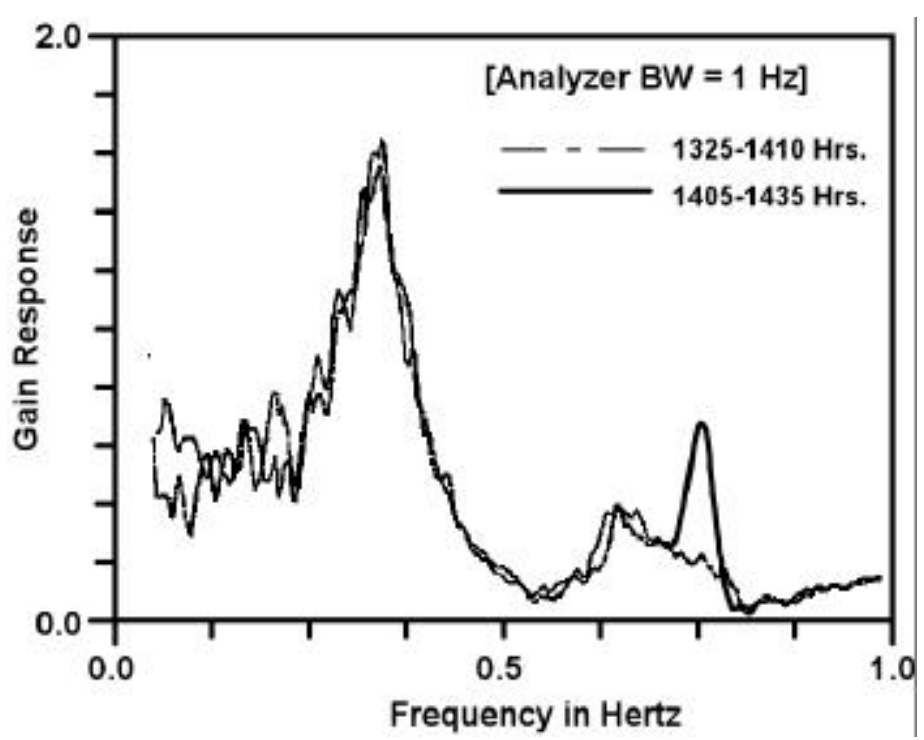

Figure 28. Response gain of PACI line current to low-level PDCI modulation. HVDC tests of May 7, 1985.

The main products obtained consist of autospectra (Figure 27), frequency response estimates (Figure 28 and Figure 29), and associated coherency estimates. All of these are directly useful as signature information. Quantitative dynamic information can be extracted by model fits to the frequency response estimates (Hauer 1987, Hauer 1982), or by model fits to equivalent data in the time domain (Hauer et al. 1999b, Juang 1994, Van Overshee and De Moor 1996). In either case the response data is developed through sustained averaging processes that correlate observed system activity against the applied probing signal. 


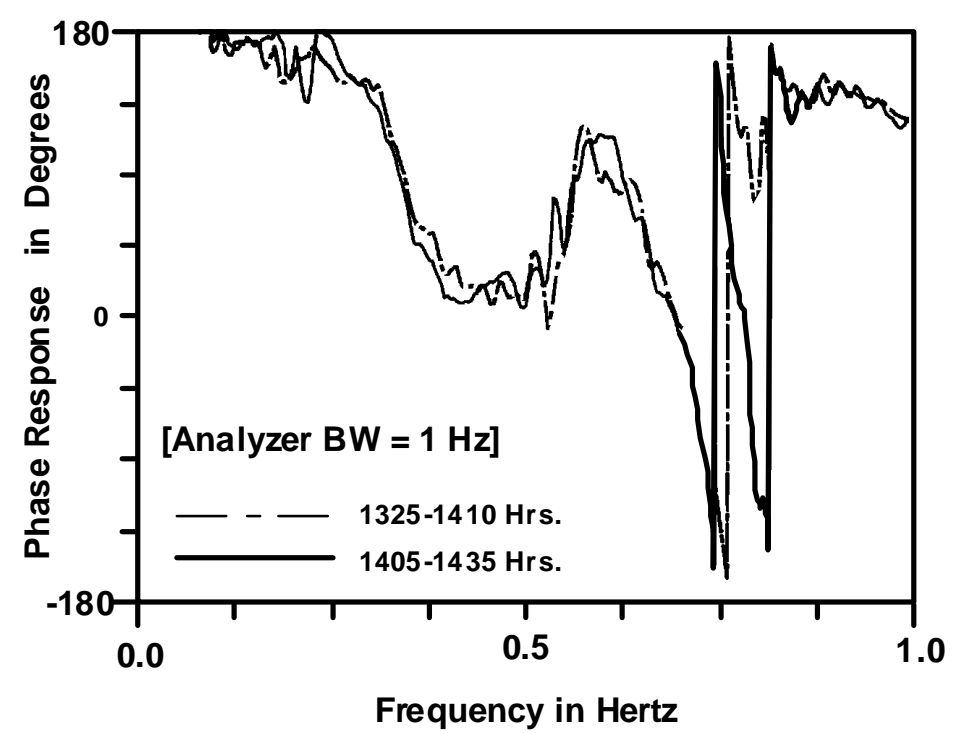

Figure 29. Response phase of PACI line current to low-level PDCI modulation. HVDC tests of May 7, 1985.

Even very small noise inputs can yield useful information, provided that system dynamics are stationary enough for long averages to be meaningful. Hauer and Boenig (1987) shows estimates for the more responsive PACI dynamics that were obtained with a probing signal of less than $\pm 5 \mathrm{MW}$. The sustained rating for the actuator (the Tacoma SMES unit) was just $0.004 \%$ of total power system capacity. Averaging times were on the order of an hour, however, and the measurements were made during the very early morning.

More recent results are shown in Figure 30 through Figure 32. Figure 30 shows a series of probing signals that were applied to the Pacific HVDC Intertie (PDCI) to measure oscillation dynamics. There were two applications of band limited white noise; the first at $10 \mathrm{MW}$ peak-to-peak and the second at 20 MW peak-to-peak ${ }^{1}$. These were followed by several series of square waves designed to probe specific modes of oscillation (as in Figure 25).

The noise probing was designed to be minimally intrusive, and at the lowest level that might reasonably be expected to yield useful results within a 10-minute period. Noise probing is essentially invisible in Figure 31, and on other AC lines that do not feed directly into the PDCI. Despite this, Figure 32 shows that the experiment produced clear indications of dynamic response and that it was close to the threshold of producing useful quantitative data. Fully practical results will require some optimization of the probing signal through filtering and clipping, and perhaps a modest increase in the probing level.

\footnotetext{
${ }^{1}$ The intended probing levels were $\pm 10 \mathrm{MW}$ and $\pm 20 \mathrm{MW}$, and some reports erroneously use these values.
} 


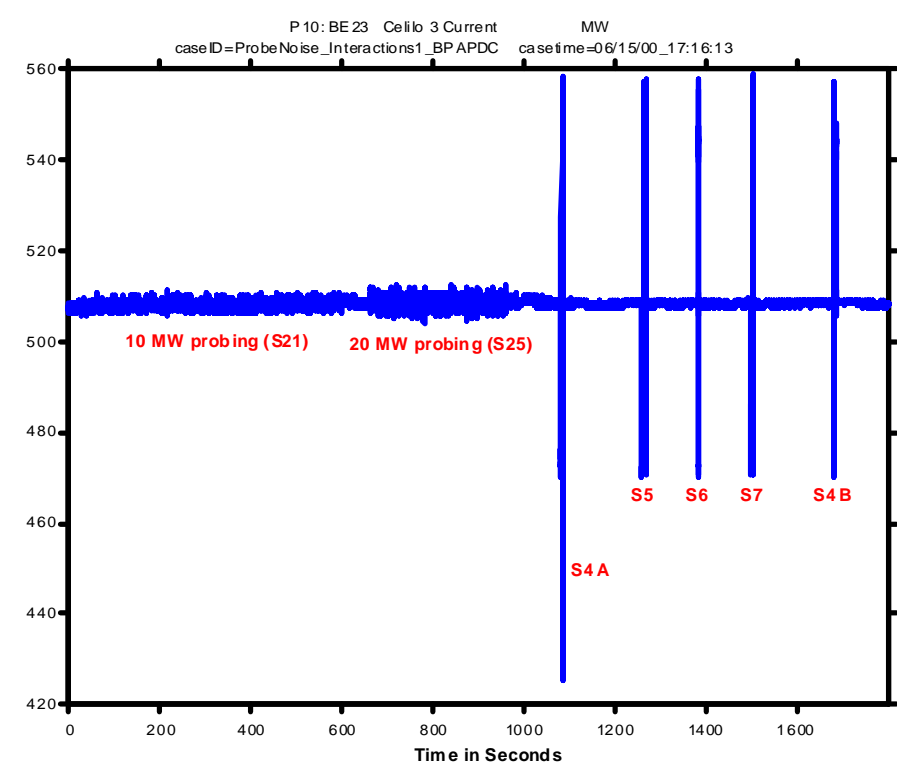

Figure 30. Response of Big Eddy -Celilo 230 line MW to PDCI probing signals

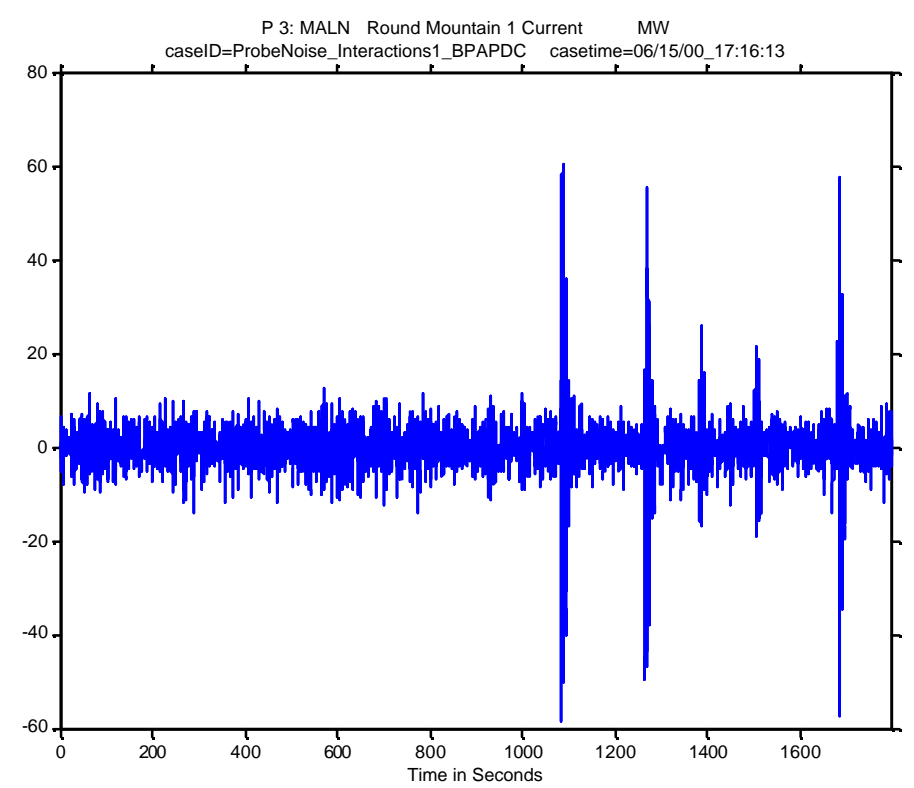

Figure 31. Response of Malin-Round Mountain Circuit \#1 to PDCI probing signals 


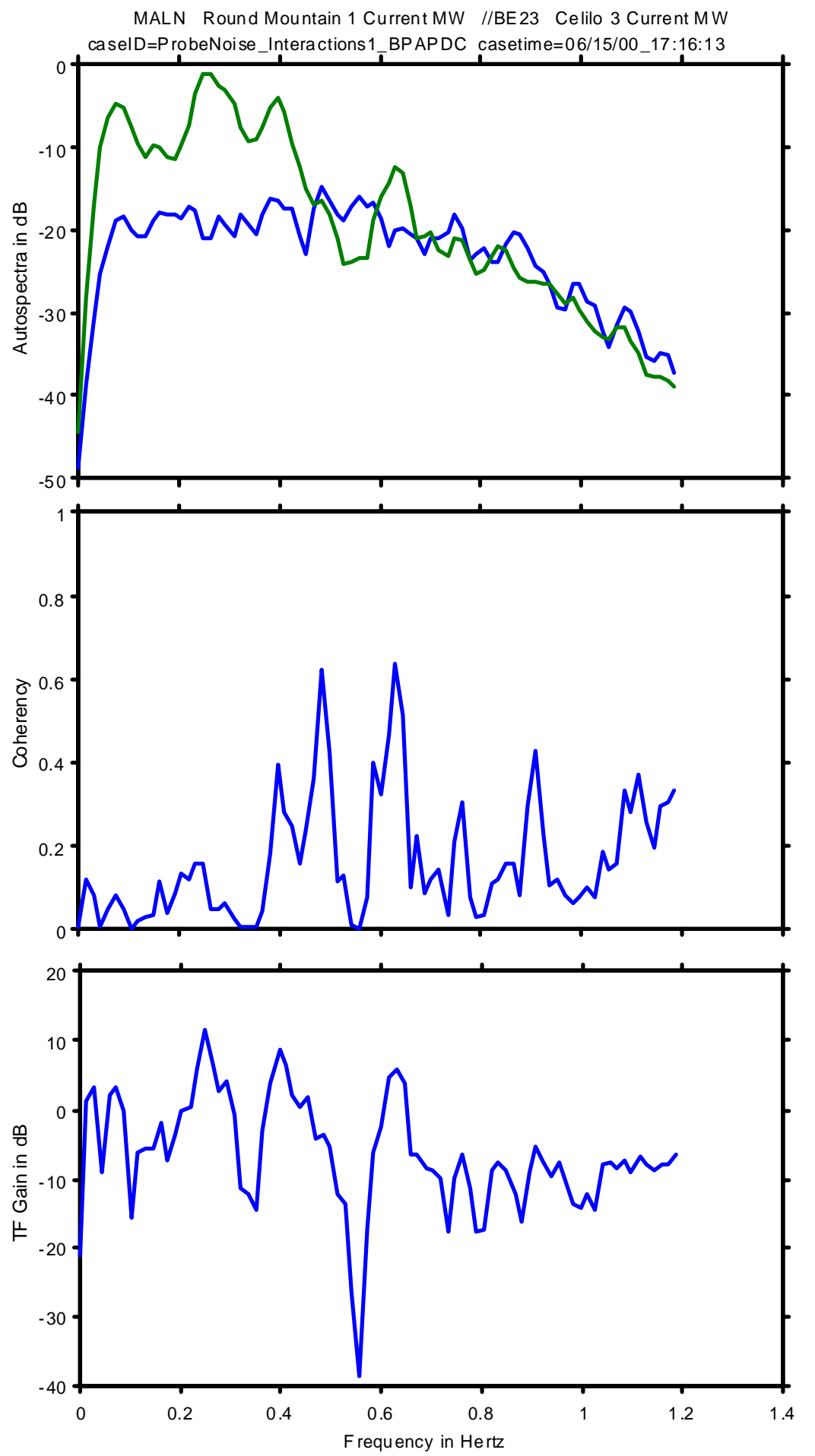

Figure 32. Correlation of Malin-Round Mountain Circuit \#1 against Big Eddy-Celilo 230 line MW. 20 MW PDCI noise probing on June 7, 2000

35 


\subsection{Detection of Dynamic Events}

Special behavior in a power system is usually brief and intermittent. Recognizing it as special requires good characterizations for ordinary behavior, together with a rationale and a mechanism for making the necessary comparisons. Detecting the candidate behavior is a first step in this. Dynamic events illustrate most of the principles involved.

There are four basic factors involved in detecting the onset of a dynamic event. They are

- magnitude

- persistence

- frequency content

- context.

Basic detection logic might examine just magnitude and persistence, in tests of form "Do the latest $\mathrm{M}$ samples each exceed the given threshold T(M)?" It is useful to think of the context factor as adjusting such thresholds to particular system conditions. These might include stress on the electrical network, the operational status of key electrical resources, and any other factor that affects either the likelihood of an event or the importance of recording it.

A partial list of signature activity through which events can be detected, and perhaps recognized, includes the following:

a) A step or swing in the flow of electrical power.

b) A large change, or rate of change, in bus voltage or frequency.

c) Sustained or poorly damped oscillations, perhaps in conjunction with some other event.

d) A large increase in system noise level.

e) An increase of system activity in some critical frequency band.

f) Unusual correlation or phasing between fluctuations in two given signals.

Nearly all of these are apparent in Figure 2, as precursors to the August 10 breakup, and in the records already shown for other disturbances. The one exception, item $\mathrm{f}$, requires a deeper analysis than has been used in the foregoing examples.

Automated logic for detecting dynamic events calls for some way to measure the activity in signals. A useful approach to this is to pass each signal through a bandpass filter, square the output, and pass the result through a smoothing filter (Hauer and Vakili 1990). Figure 33 shows this for the oscillations of Figure 2, for a bandpass filter set to pass signals in the range of $0.1 \mathrm{~Hz}$ to $0.5 \mathrm{~Hz}$. Note that this detector is not selective enough to indicate the precursor oscillations of Figure 3. Narrower settings for the bandpass filter, while they can be useful for some other purposes, do not correct this. As indicated in 


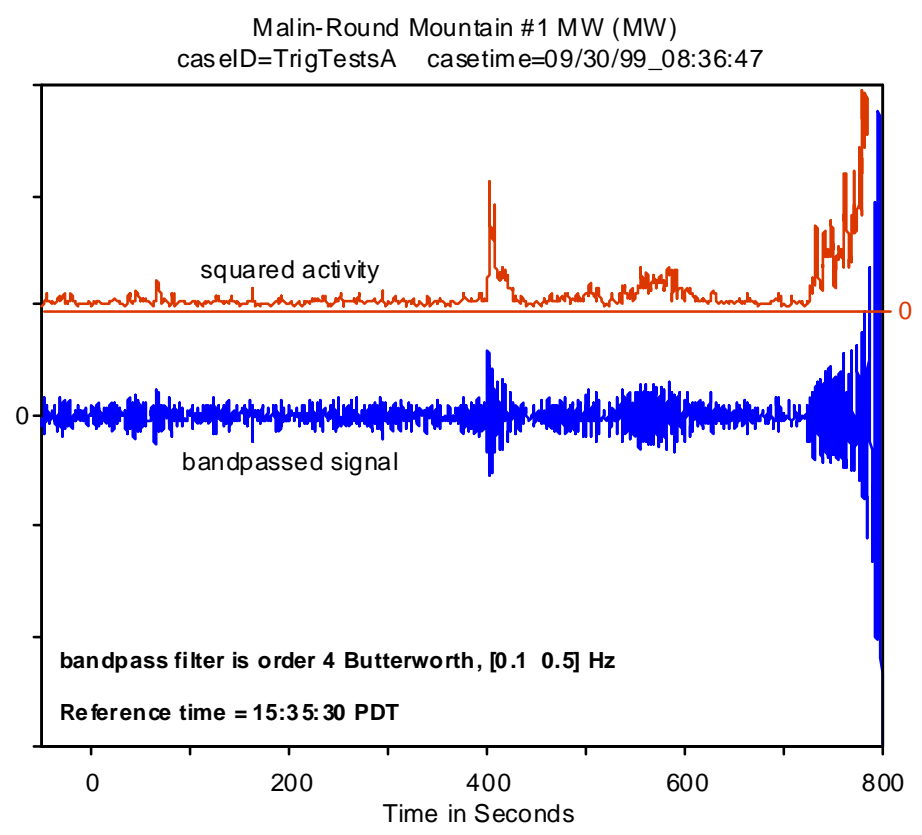

Figure 33. [0.2 0.5] Hz square-law activity signal for oscillations of August 10, 1996

Figure 34, the detector may become overly sensitive to random shifts in noise characteristics. It will also fail to track events in which the dominant frequencies undergo substantial changes with time. This has happened toward the end of Figure 34 where, from Figure 35, the oscillation frequency is declined to $0.22 \mathrm{~Hz}$.

When narrow band event detectors are needed, it is likely best to deploy them in sets, and in combination with wide band detectors. Elegant mechanisms for this are appearing in the literature of wavelet analysis (Strang and Nguyen 1996).

Changes in spectral signature can also be useful as detectors for such events. Figure 36 shows ambient noise spectra before and after the Keeler-Alston line trip, plus the spectrum of the ringdown signal itself (as displayed in Figure 3). The latter is much higher than the running average based upon pre-disturbance noise, and thus a clear indication that a dynamic event has occurred. The post-disturbance noise indicates that the event has made the ambient activity of the Canada-California mode much stronger, and shifted it to a lower frequency. In short, power system dynamics have undergone a substantial change. Once the change is detected, it can be characterized and assessed through deeper analysis. 


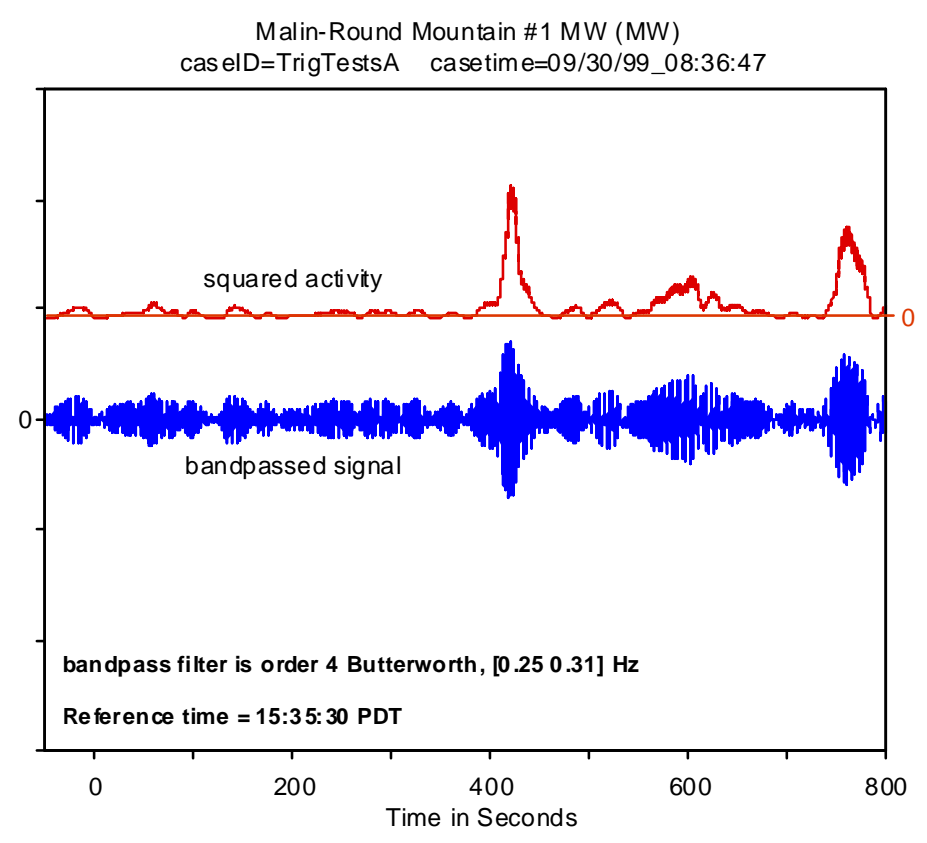

Figure 34. [0.52 0.31] Hz square -law activity signal for oscillations of August 10, 1996

PACI mode bef ore Aug ust 10, 1996

$\begin{array}{ccr}\text { Date/Event } & \text { Frequency } & \text { Damping } \\ \text { 12/08/92 (Palo Verde trip) } & 0.28 \mathrm{~Hz} & 7.5 \% \\ \text { 03/14/93 (Palo Verde trip) } & 0.33 \mathrm{~Hz} & 4.5 \% \\ \text { 07/11/95 (brake insertion) } & 0.28 \mathrm{~Hz} & 10.6 \% \\ \text { 07/02/96 (system breakup) } & 0.22 \mathrm{~Hz} & 1.2 \%\end{array}$

PACI mode on August 10, 1996

\begin{tabular}{lrc}
\multicolumn{1}{c}{ Time/Event } & Frequency & Damping \\
10:52:19 (brake insertion) & $0.285 \mathrm{~Hz}$ & $8.4 \%$ \\
14:52:37 (John Day-Marion) & $0.264 \mathrm{~Hz}$ & $3.7 \%$ \\
15:18 (ringing) & $0.276 \mathrm{~Hz}$ & \\
15:42:03 (Keeler-Allston) & $0.264 \mathrm{~Hz}$ & $3.5 \%$ \\
15:45 (ringing) & $0.252 \mathrm{~Hz}$ & \\
15:47:40 (oscillation start) & $0.238 \mathrm{~Hz}$ & $-3.1 \%$ \\
15:48:50 (oscillation finish) & $0.216 \mathrm{~Hz}$ & $-6.3 \%$
\end{tabular}

Figure 35. Observed behavior of the PACI mode 


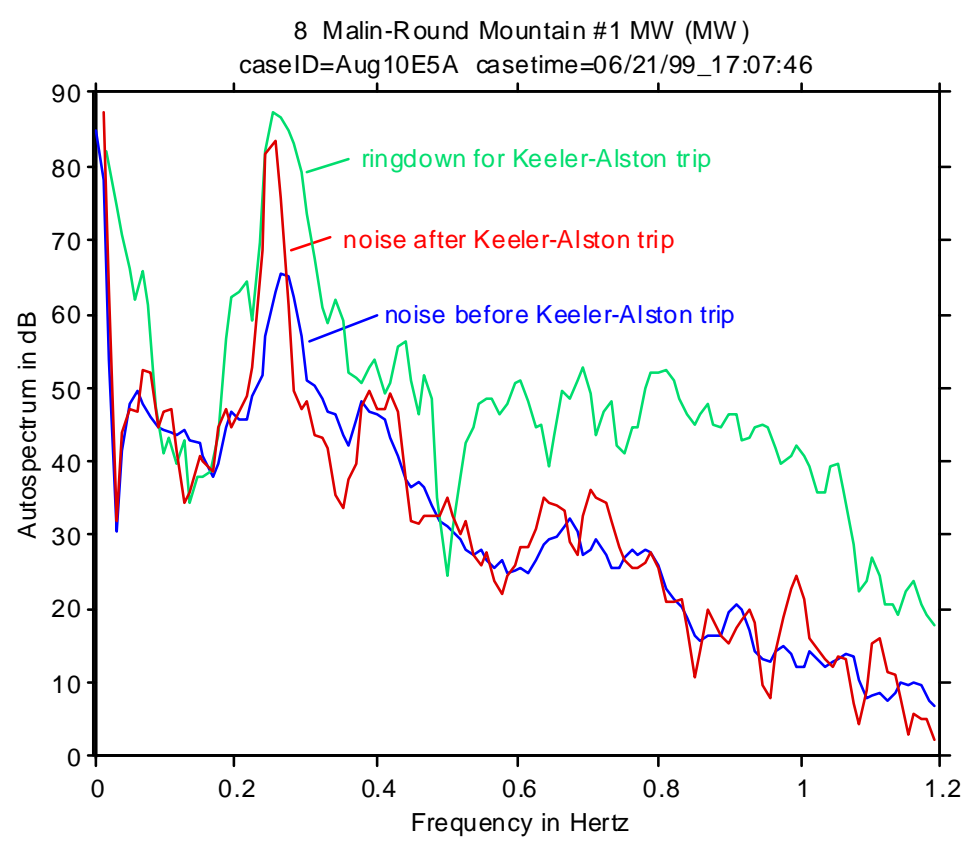

Figure 36. Spectral signatures for Keeler-Alston trip event in breakup of August 10, 1996 


\subsection{References}

Bendat, J. S., and A. G. Piersol. 1980. Engineering Applications of Correlation and Spectral Analysis. John Wiley, New York.

Brigham, E. O. 1988. The Fast Fourier Transform and Its Applications . Prentice-Hall, Englewood Cliffs, NJ:

Farmer, R. G., and B. L. Agrawal. 1983. "State-of-the-Art Techniques for Power System Stabilizer

Tuning," IEEE Trans. PAS, pp. 699-709, March.

Grund, C. E., J. F. Hauer, L. P. Crane, D. L. Carlson, and S. E. Wright. 1990. "Square Butte HVDC

Modulation Field Tests," IEEE Trans. Power Delivery, pp. 351-357, January.

Hauer, J. F. 1997. "A Perspective on Use of the Pacific HVDC Intertie for Wide Area Tests of Western Power System Dynamics." Prepared under BPA/EPRI WAMS Tailored Collaboration.

Hauer, J. F. 1996. Signal Processing Examples for Powe r System Digital Transducers: DXD Model Series \#1. WAMS Working Note, July 3, 1996. Attachment to Hauer et al. 1999a.

Hauer, J. F. 1995. "BPA Experience in the Measurement of Power System Dynamics," Inter-Area Oscillations in Power Systems, IEEE Publication 95 TP 101, pp. 158-163.

Hauer, J. F. 1987. "Reactive Power Control as a Means for Enhanced Interarea Damping in the Western U. S. Power System-A Frequency-Domain Perspective Considering Robustness Needs," Application of Static Var Systems for System Dynamic Performance, IEEE Publication 87TH0187-5-PWR, pp. 79-92.

Hauer, J. F. 1982. "Power System Identification by Fitting Structured Models to Measured Frequency Response," IEEE Trans. PAS, pp. 915-923, April.

Hauer, J.F. and H. J. Boenig. 1987. "Control Aspects of the Tacoma Superconducting Magnetic Energy Storage Project," IEEE Trans. Power Systems , pp. 443-450, May.

Hauer, J. F., and R. L. Cresap. 1981. "Measurement and Modeling of Pacific AC Intertie Response to Random Load Switching," IEEE Trans. PAS, pp. 353-359, January.

Hauer, J. F. and J. E. Dagle. 1999. Review of Recent Reliability Issues and System Events. Prepared for the U.S. Department of Energy by the Consortium for Electric Reliability Solutions (CERTS), August.

Hauer, J. F., F. J. Hughes, D. J. Trudnowski, G. J. Rogers, J. W. Pierre, L. L. Scharf, and W. H.

Litzenberger. 1999b. A Dynamic Information Manager for Networked Monitoring of Large Power Systems. EPRI Report TR-112031, Electric Power Research Institute, Palo Alto, California. 
Hauer, J. F., and J. R. Hunt in association with the WSCC System Oscillations Work Groups. 1996. "Extending the Realism of Planning Models for the Western North America Power System," V

Symposium of Specialists in Electric Operational and Expansion Planning (SEPOPE), Recife (PE) Brazil, May 19-24, 1996.

Hauer, J. F., W. A. Mittelstadt, W. H. Litzenberger, C. Clemans, D. Hamai, and P. Overholt. 1999a. Wide Area Measurements For Real-Time Control And Operation of Large Electric Power Systems - Evaluation And Demonstration Of Technology For The New Power System Prepared for U.S. Department of Energy Under BPA Contracts X5432-1, X9876-2; January 1999. This report and associated attachments are available on compact disk.

Hauer, J. F., W. A. Mittelstadt, R. J. Piwko, B. L. Damsky, and J. D. Eden. 1996. "Modulation and SSR Tests Performed on the BPA $500 \mathrm{kV}$ Thyristor Controlled Series Capacitor Unit at Slatt Substation," IEEE Trans. Power Systems, Vol. 11, pp. 801-806, May.

Hauer, J. F., D. J. Trudnowski, G. J. Rogers, W. A. Mittelstadt, W. H. Litzenberger, and J. M. Johnson. 1997. "Keeping an Eye on Power System Dynamics," IEEE Computer Applications in Power, pp. 5054 , October.

Hauer, J. F., and F. Vakili. 1990. "An Oscillation Trigger for Power System Monitoring," IEEE Trans. Power Systems , pp. 74-79, February.

Juang, J. N. 1994. Applied System Identification. Prentice-Hall PTR, Upper Saddle River, NJ.

Praprost, K. L., and K. A. Laparo. 1996. "A Stability Theory for Constrained Dynamic Systems with Applications to Electric Power Systems," IEEE Trans. Automatic Control, vol. 41, no. 11, pp. 16051617, November.

Samuelsson, O. 1997. Power System Damping - Structural Aspects of Controlling Active Power. $\mathrm{Ph} . D$. Thesis, Department of Industrial Electrical Engineering and Automation, Lund Institute of Technology, Lund University, Lund, Sweden.

Strang, G. and T. Nguyen. 1996. Wavelets and Filter Banls. Wellesley-Cambridge Press, Wellesley, MA.

Taylor, C. W. 1999. “Improving Grid Behavior,” IEEE Spectrum, vol. 36, no. 6, pp. 40-45, June.

Trudnowski, D. J., J. F. Hauer, J. Pierre, W. H. Litzenberger, and D. J. Maratukulam. 1999. "Using the Coherency Function to Detect Large-Scale Dynamic System Modal Observability." In Proceedings of the 1999 American Control Conference, pp. 2886-2890, San Diego, California, June.

Van Overshee, P. and B. De Moor. 1996. Subspace Identification for Linear Systems . Kluwer Academic Publishers, Norwell, MA. 


\subsection{Related Publications}

Fouad, A. A., W. Kliemann, V. Vittall et al. 1997. Nonlinear Power System Behavior Using Normal Forms: Extension of Linear System Analysis via Higher Order Correction. EPRI Report TR-107798 8050-05, Electric Power Research Institute, Palo Alto, California, February.

Hauer, J. F. 1991. "Application of Prony Analysis to the Determination of Modal Content and Equivalent Models for Measured Power System Response." IEEE Trans. Power Systems , pp. 10621068, August.

Hauer, J. F., C. J. Demeure, and L. L. Scharf. 1990. "Initial Results in Prony Analysis of Power System Response Signals." IEEE Trans. Power Systems , pp. 80-89, February.

Hauer, J. F., W. A. Mittelstadt, R. Adapa, W. H. Litzenberger, and M. K. Donnelly 2001. Direct Analysis of Wide Area Dynamics Section 11.8: pp 11-82 through 11-120 of The Electric Power Engineering Handbook, L. L. Grigsby ed., CRC Press, 2001.

Hauer, J. F., T. J. Overbye, J. E. Dagle, and S. E. Widergren 2002. Advanced Transmission Technologies. Issue Paper for the U. S. Department of Energy National Transmission Grid Study 2002. May 2002 Final Report, available at web sites http://www.energy.gov and http://www.ntgs.doe.gov.

Hauer, J. F., W. A. Mittelstadt, K. E. Martin, and J. W. Burns 2003. Integrated Monitor Facilities for the Western Power System: The WECC WAMS in 2003. Interim report of the WECC Disturbance Monitoring Work Group, June 25, 2003. (Available at ftp://ftp.bpa.gov/outgoing/WAMS\%20Information/ and/or http://www.wecc.biz/committees/JGC/DMWG/documents/)

Hauer, J. F., Navin Bhatt, Kirit Shah, and Sharma Kolluri 2004. "Performance of 'WAMS East' in Providing Dynamic Information for the North East Blackout of August 14, 2003." IEEE/PES Panel on Major Grid Blackouts of 2003 in North America and Europe, IEEE PES General Meeting, Denver, CO, June 6-12, 2004

Kay, S. M. and S. L. Marple. 1981. "Spectrum analysis--a modern perspective." Proc. IEEE, pp. 13801419, November.

Kehler, J. H., D. Felzien, and J. Man. 1992. Alberta Interconnected System Mode Measurements of November 19/20, 1991. Report presented to the WSCC System Oscillations Ad Hoc Work Group, TransAlta, Alberta, Canada.

Kumaresan, R., L L. Scharf, and A. K. Shaw. 1986. "An algorithm for pole-zero modeling and spectral analysis." IEEE Trans. Acoustics, Speech, and Signal Processing, pp. 637-640, June. 
Kumaresan, R. and D. W. Tufts. 1982. "Estimating the parameters of exponentially damped sinusoids and pole-zero modeling in noise." IEEE Trans. Acoustics, Speech, and Signal Processing, pp. 833-840, December.

Kundur, P. 1994. Power System Stability and Control McGraw-Hill, New York.

Scharf, L. L. 1991. Statistical Signal Processing - Detection, Estimation, and Time Series Analysis. Addison-Wesley, New York.

Trudnowski, D. J., J. M. Johnson, and J. F. Hauer. "Making Prony Analysis More Accurate Using Multiple Signals," IEEE Trans. Power Systems, vol. 14, no. 1, pp. 226-231, February 1999. 


\section{APPENDIX A}

Characteristics of the Western North America Power System 


\section{APPENDIX A. Characteristics of the Western North America Power System}

Many of the results presented in this report to particular geographical locations in the western North America power system (see Figure A.1) or to particular aspects of that system. This Appendix provides some background information on these matters.

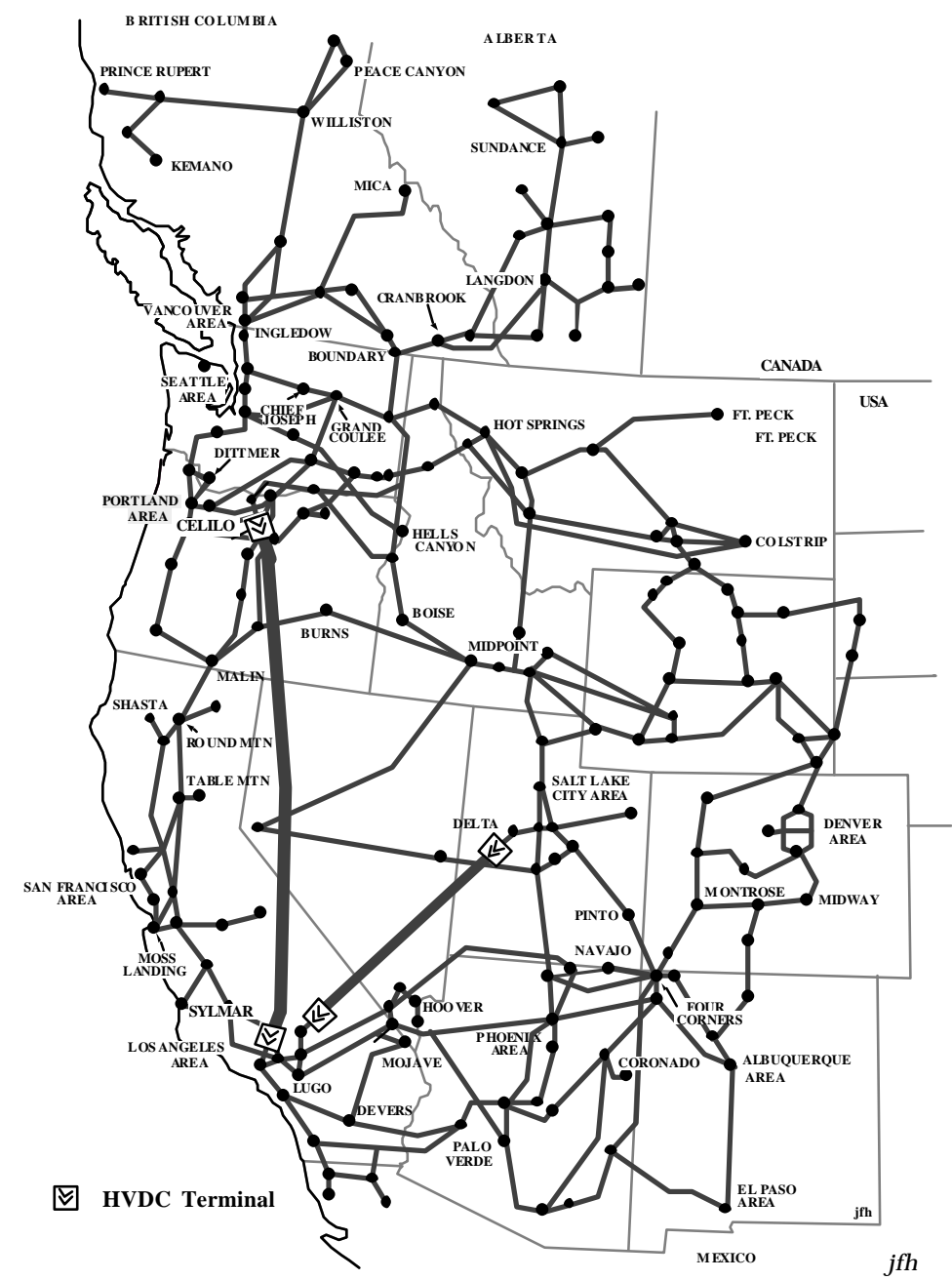

Figure A.1. General structure of the western North America power system.

The western North America power system has a peak capacity near 158,000 MW. It covers about 1.8 million square miles, and serves more than 65 million customers. This includes the Canadian provinces 
of Alberta and British Columbia, some or all of 14 states, and a portion of Baja California in Mexico. The most widely separated points in the system are about 1800 miles apart.

Geography, climate, and energy pricing have encouraged power transfers on long transmission paths. One result of this has been the construction of two powerful HVDC transmission lines. The larger of these lines is the Pacific HVDC Intertie (PDCI) from Celilo (on the lower Columbia River) to Sylmar (in the Los Angeles basin). The other is the Intermountain Power Project (IPP) HVDC Intertie, from Delta Utah to Adelanto (also in the Los Angeles basin and not far from Sylmar). These lines have continuous ratings of $3100 \mathrm{MW}$ and $1920 \mathrm{MW}$, respectively, and total lengths of 846 miles and 487 miles, respectively. Each of these two facilities has very strong "leverage" over western system dynamics.

HVDC systems of this scale require operational controls that are very accurate, very fast, and well instrumented. Bandwidths for the fundamental controls are usually on the order of $12 \mathrm{~Hz}$ or more. Overall, HVDC systems provide unusually good windows into power system behavior.

Figure A.2 shows response on the Malin-Round Mountain circuits of the Pacific AC Intertie to real and reactive power injections at the Celilo and the Sylmar terminals of the Pacific HVDC Intertie. These results were generated with a simulation model that had been calibrated against system disturbances of the early 1990s, and that is generally consistent with observations in the field.

The figure supports the following observations regarding power system response to controllable devices:

- At 0.33 Hz: (the Canada - California, or "AC Intertie" mode)

- response to Sylmar MW is $6 \mathrm{~dB}$ (i.e., twice) stronger than that for any other injection. Changes in this would substantially affect response to PDCI real power modulation.

- response to Sylmar MVar is strong, and can be expected to change substantially with Sylmar conditions.

- a reactive power device (such as an SVC) near Sylmar would have about the same "leverage" as a real power device (resistor brake or storage unit) near Celilo.

\section{- At 0.45 Hz: (the Alberta mode)}

- the response components are essentially the same for all injections

- single-component modulation of an SVC, resistor brake, or storage unit would all be equally effective for damping of the associated mode, if located near Celilo or Sylmar. 


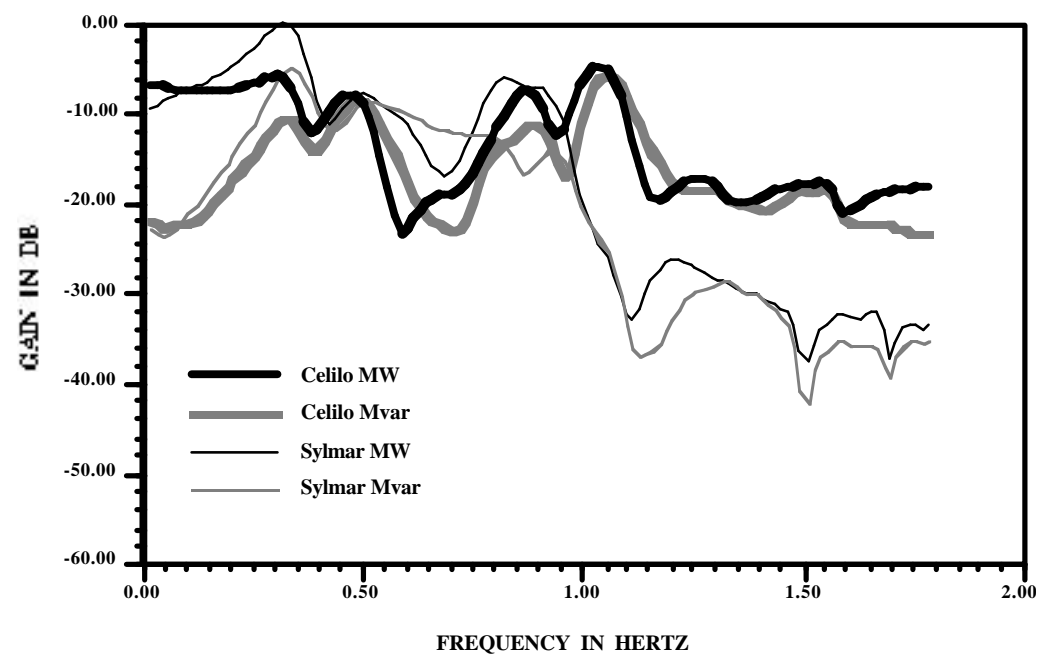

Figure A.2.Gain response of PACI line power to complex power injections at terminals of the PDCI

- Near 0.7 Hz: (the $0.7 \mathrm{~Hz}$ mode cluster)

_ there are indications of perhaps five modes between $0.75 \mathrm{~Hz}$ and $0.95 \mathrm{~Hz}$

- response to MW injections near Celilo approaches that for MVar injections near Sylmar, but may address different modes (and different generator groups).

- Near 1.03 Hz: (the Grand Coulee mode)

- response to MW or MVar injections near Celilo are essentially the same.

- there is no response to injections near Sylmar.

An SVC, or static Var controller, can be thought of as a shunt capacitor that is linked to the AC system through a highly controllable power electronic interface. Its series counterpart is the thyristor controlled series capacitor, or TCSC. At present there are several SVC and TCSC units operational in the western system.

Another consequence of the long transmission paths is a tendency toward system oscillations and other dynamic problems. In this respect the western system resembles other loosely connected power systems across the world, though its installed capacity and service area are greater than most. 


\section{APPENDIX B}

\section{Mathematical Modeling of Electric Power Systems}




\section{APPENDIX B. Mathematical Modeling of Electric Power Systems}

The different processes involved in power system behavior span an extraordinary range of time scales. The fastest of these, electromagnetic transients, consist of voltage and current waves that travel along conductors at nearly light speed (just less than 2 miles, or $3 \mathrm{~km}$, per microsecond). The slowest processes, like weather and human decisions, range from minutes to years. Between these limits we find

- mechanical dynamics (generator prime movers-hydraulic or steam turbines, wind, etc.)

- electromechanical dynamics (speed interactions among generators)

- continuous voltage controls (e.g., power electronic devices)

- switched controls (relays, breakers, some power electronic devices).

Time scales for the first three of these processes are usually described in terms of bandwidth, which indicates the highest rate of cyclic activity that the process can sustain. For these particular processes, the respective bandwidths are roughly $0.2,2.0$, and $20 \mathrm{~Hz}(1 \mathrm{~Hz}=$ one cycle per second $)$. Response time for switched controls is usually expressed in cycles, with a general range of 0.1 cycle to perhaps 10 cycles.

Large power systems discourage long distance propagation of the faster transients and interactions. The fastest of these, electromagnetic traveling waves, are largely confined to the lines (or cables) on which they originate, and to other devices nearby. At rather lower rates, voltage coupled interactions encounter a host of control systems and other devices that act to hold the voltage at fixed levels.

The most widespread interactive processes are those associated with electromechanical dynamics in the interarea range of frequencies, which is roughly $0.1 \mathrm{~Hz}$ to $1.0 \mathrm{~Hz}$. Electromechanical dynamics at higher frequencies are usually local to some particular generator or plant. Under normal circumstances, the associated local mode dynamic activity is not energetic enough to be conspicuous at long range. Under the right stimulus, however, local mode activity for a single generator may be clearly apparent and even disruptive 1,000 miles away.

Mechanical dynamics include many different processes, for which span of time scales is fairly broad. Electrical generators are basically just devices that convert mechanical power into usable electrical power. The mechanical power is provided by mechanical devices (prime movers) that, in their turn, draw upon fuel systems or other sources of raw energy. All of the involved mechanical devices have their own characteristics, and their own local controls. Overlaying this, there may be a wide area automatic generation control (AGC) system plus local and remote human operators.

Prime mover controls adjust mechanical power in an attempt to maintain correct generator speed as its electrical loading changes. AGC, in turn, signals a desired loading that prime mover controls and voltage controls at the generator work together to meet. Brief disturbances may affect just the voltage controls, which have comparatively fast actuation and are usually tuned for this purpose. Significant disturbances 
will involve the (slower) prime mover controls, and very serious disturbances will involve AGC and/or human operators (which are slower yet). Protracted disturbances may even involve the very slow local controls for steam boilers, fuel supply, or other raw energy sources.

Mathematical models at the device level tend to be very intricate and specific to particular equipment. Relations at the system level are much more generic. Electromagnetic transients are a good example of this. They propagate according to the wave equation, within a fairly narrow range of velocities. Specific media produce specific velocities and filtering effects, and media discontinuities produce reflected waves according to known laws.

Electromechanical dynamics are similarly well behaved. There are many ways to represent these in mathematical terms. The most natural formulation is a differentialalgebraic or DAE form (Praprost and Laparo 1996, Samuelsson 1997) such as

$$
\begin{aligned}
\dot{\mathrm{x}}_{\mathrm{d}} & =\mathrm{f}\left(\mathrm{x}_{\mathrm{d}}, \mathrm{x}_{\mathrm{a}}, \mathrm{u}\right) & & \text { (dynamic constraint } \mathrm{s}) \\
0 & =\mathrm{g}\left(\mathrm{x}_{\mathrm{d}}, \mathrm{x}_{\mathrm{a}}, \mathrm{u}\right) & & \text { (algebraic constraint } \mathrm{s}) \\
\mathrm{y} & =\mathrm{h}\left(\mathrm{x}_{\mathrm{d}}, \mathrm{x}_{\mathrm{a}}, \mathrm{u}\right) & & \text { (output relations) }
\end{aligned}
$$

All quantities are vectors and the superposed "dot" indicates differentiation with respect to time. Here u,y are, respectively, the input to the system and the resulting output. The total state vector has two components, a dynamic state $\mathrm{x}_{\mathrm{d}}$ and an algebraic state $\mathrm{x}_{\mathrm{a}}$.

These relations can be linearized as

$$
\begin{aligned}
{\left[\begin{array}{ll}
\mathrm{I} & 0 \\
0 & 0
\end{array}\right]\left[\begin{array}{l}
\dot{\mathrm{x}}_{\mathrm{d}} \\
\dot{\mathrm{x}}_{\mathrm{a}}
\end{array}\right] } & =\left[\begin{array}{ll}
\mathrm{A}_{11} & \mathrm{~A}_{12} \\
\mathrm{~A}_{21} & \mathrm{~A}_{22}
\end{array}\right]\left[\begin{array}{l}
\mathrm{x}_{\mathrm{d}} \\
\mathrm{x}_{\mathrm{a}}
\end{array}\right]+\left[\begin{array}{l}
\mathrm{B}_{1} \\
\mathrm{~B}_{2}
\end{array}\right] \mathrm{u} \\
\mathrm{y} & =\left[\begin{array}{ll}
\mathrm{C}_{1} & \mathrm{C}_{2}
\end{array}\right]\left[\begin{array}{l}
\mathrm{x}_{\mathrm{d}} \\
\mathrm{X}_{\mathrm{a}}
\end{array}\right]+\mathrm{D}_{1} \mathrm{u}
\end{aligned}
$$

Then, if the algebraic state $\mathrm{x}_{\mathrm{a}}$ is formally eliminated through the associated equality, the result can be written as

$$
\begin{aligned}
& \dot{x}=A x+B u \\
& y=C x+D u
\end{aligned}
$$

The system matrices $\{A, B, C, D\}$ in (B3) are derived from (B2) but are distinct from the indicated submatrices.

Each generator obeys the second order swing equation

$$
\mathrm{M} \ddot{\theta}+\mathrm{D} \dot{\theta}=\mathrm{P}_{\mathrm{m}}-\mathrm{P}_{\mathrm{e}}
$$


where $\theta$ describes the phasor angle for the generator, $\mathrm{M}$ and $\mathrm{D}$ are mass and damping coefficients, $\mathrm{P}_{\mathrm{m}}$ is the mechanical power applied to the prime mover, and $\mathrm{P}_{\mathrm{e}}$ is the generated electrical power.

The generated power is usually delivered to various loads through a network of transmission lines. When losses are neglected, the power flowing on each such line can be described by the power-angle equation

$$
P_{i j}=B_{i j} V_{i} V_{j} \sin \left(\theta_{i}-\theta_{j}\right)
$$

Here $\mathrm{V}_{\mathrm{i}} \angle \theta_{\mathrm{i}}$ is the phasor voltage at bus $\mathrm{I}$, and $\mathrm{B}_{\mathrm{ij}}$ is the admittance between bus $\mathrm{i}$ and bus $\mathrm{j}$.

Equation (B5) indicates that generator interactions through the electrical network can be very nonlinear for large disturbances. The situation is further complicated by load nonlinearities, and by control systems that may manipulate some or all of the parameters on the right hand sides of (B4) and (B5).

Another complicating factor is that generation and transmission involve three electrical phases. Ideally, the system is "balanced" so that all three phase voltages or phase currents have identical waveforms, shafted by 120 electrical degrees. This ideal is rarely achieved. So, for some purposes, many of the mathematical operations and variables in the above equations must be interpreted as representing threephase quantities. This would be especially important for equipment that presents a strongly unbalanced load to the power delivery system.

For the most part, the variables in these equations are also root-mean-square (rms) quantities. These are average measures that contain many imbedded assumptions concerning the waveforms to which they are applied. Usual assumptions are that the power system frequency is very close to the nominal $60 \mathrm{~Hz}$ (or 50 $\mathrm{Hz}$ ), that phase unbalance is small, and that electromechanical swing energy is concentrated near the nominal system frequency.

These can be very unrealistic, especially in a power system that is weakly connected. Some examples in point are the following:

- harmonics Every power system contains nonlinearities, and these produce at least some activity at integer harmonics of the actual system frequency. Some kinds of equipment may contribute to these harmonics, or even produce non-characteristic harmonics at other frequencies.

- vibration signatures Mechanical vibrations associated with rotating equipment can modulate one or more harmonics. Examples include turbine blade vibrations, shaft torsional oscillations, runout and chatter in bearings or couplings. 
- controller modulation When the primary output of a harmonic generating device is modulated, it is very likely that the harmonics will be modulated as well.

- parallel resonances It is not unusual for the three-phase transmission system to form a resonance with some nearby structure, or with the earth itself. This produces an additive component in power system activity, rather than modulating a component that is already present.

- large frequency transients Large disturbances in the western system can produce sustained frequency deviations as large as $2 \mathrm{~Hz}$. This may call for adjustments to some modeling parameters, and to rms instrument readings in the field.

- poor frequency control Ambient frequency deviations on the order of $0.25 \mathrm{~Hz}$ or more seem common in some smaller systems. The implication that such activity poses for modeling and instrumentation are not known.

Such factors indicate that rms measures are too gross for some kinds of power system analysis. When such measures are used, their implementation details and underlying assumptions should be taken into account very carefully. In many cases, it will be necessarily to simulate or measure the instantaneous "point on wave" (POW) signals in their entirety. 


\section{APPENDIX C}

\section{The Signal Environment for Power System Measurements}




\section{APPENDIX C. The Signal Environment for Power System Measurements}

Power system measurements are performed in a very complex signal environment. Field observations indicate that the raw "point on wave" signals there contain far more information than is usually examined. Those observations also indicate hidden problems in the conversion of these signals to root-mean-square (rms) values, and that some particular instruments for this (transducers) may not be reliable sources of detailed signature information.

Primary information in a three-phase power system is carried on three sinusoidal carriers that, nominally, have a frequency of $60 \mathrm{~Hz}$ (else $50 \mathrm{~Hz}$ ) are phased 120 degrees apart. This information is impressed through changes in magnitude, phase angle, and frequency. In addition to this primary information, there may be secondary information that modulates various harmonics of the primary carrier frequency or signals that simply add to the carriers without modulating them.

On April 24, 1996 a workteam of BPA and PNNL staff performed direct measurements on enhanced transducers at BPA's Slatt substation ${ }^{1}$. Figure C. 1 and Figure C. 2 show autospectra for A-phase current on the Slatt-Buckley 500-kV line, as determined with a Scientific Atlanta SD390 four channel dynamic signal analyzer (DSA). In Figure C.1, the peaks near $28 \mathrm{~Hz}$ and $92 \mathrm{~Hz}$ are probably associated with a modulating source at $32 \mathrm{~Hz}$ (very like ly a generator shaft). These spectra are in close agreement with Matlab analysis of signals extracted from a high-quality BEN 5000 digital fault recorder at Slatt, and the observed voltage spectra from that recorder was similarly complex.

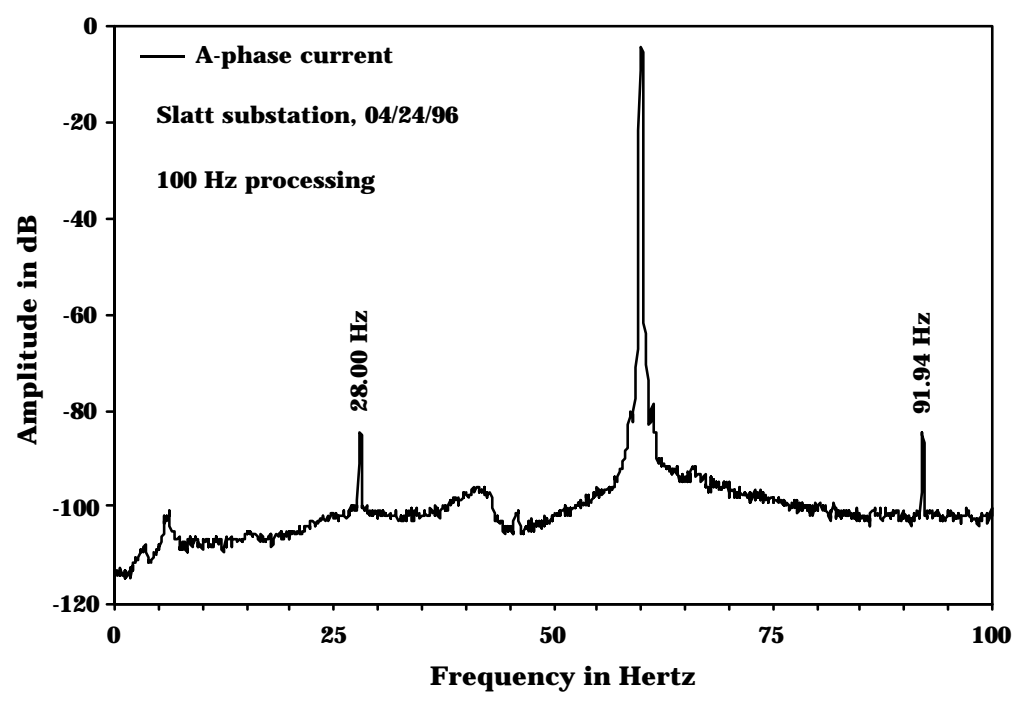

Figure C.1. Autospectrum for A-phase current (100 Hz processing)

\footnotetext{
${ }^{1}$ J.F. Hauer, A Preliminary Report on Transducer Measurements Performed at Slatt Substation on April 24, 1996. WAMS Working Note, June 5, 1996 (attachment to Hauer et al 1999a).
}

C.1 


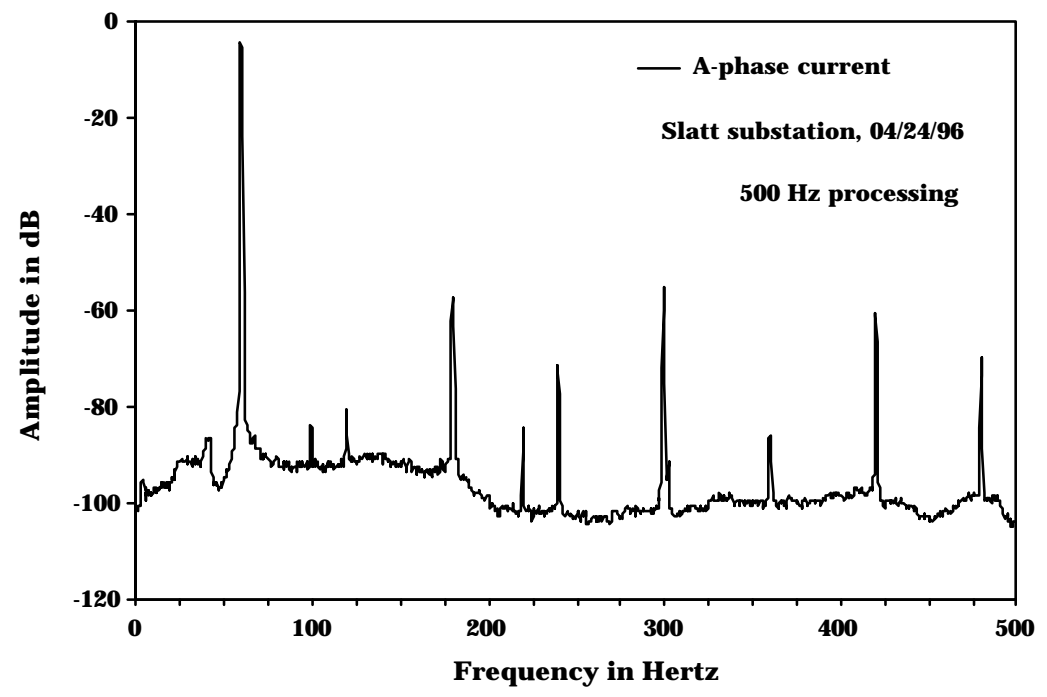

Figure C.2. Autospectrum for A-phase current $(500 \mathrm{~Hz}$ processing)

Outputs from various rms transducers on the Slatt-Buckley line were examined in a similar manner. The spectrum of Figure C.3 is typical. While some of the peaks there represent harmonics of $60 \mathrm{~Hz}$, others have no apparent relationship to the point-on-wave activity. These are likely to be processing artifacts of the transducer itself.

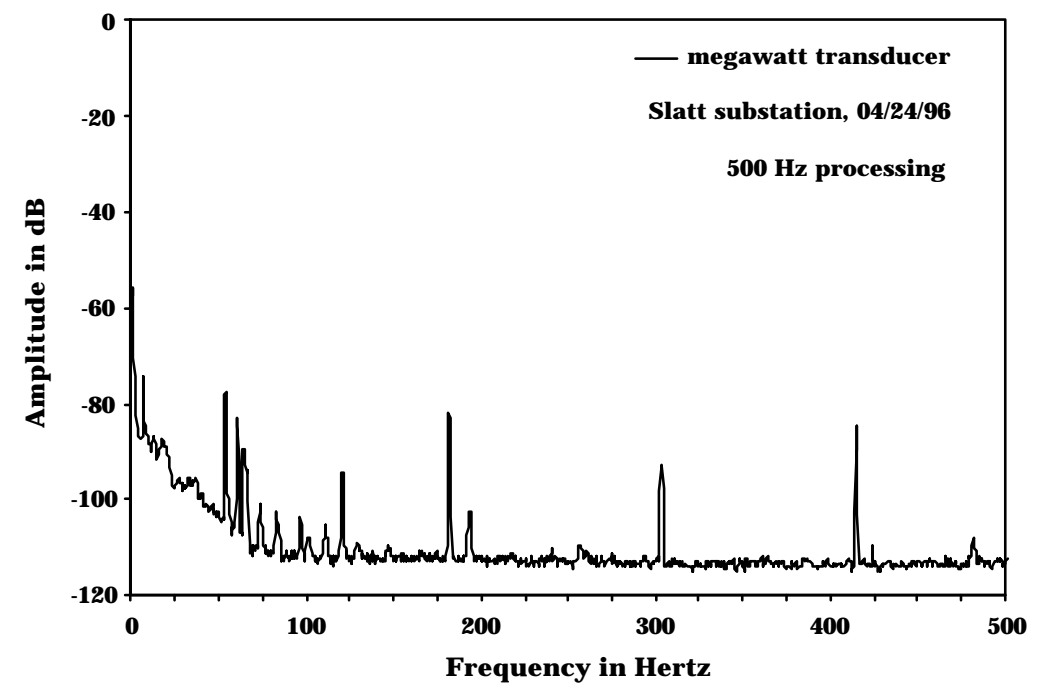

Figure C.3. Autospectrum for watt transducer $(500 \mathrm{~Hz}$ processing)

Power system measurements commonly rely upon the multitude of transducers that are already installed. To assure proper interpretation of the transducer output signals, it is prudent to validate them against POW signals and other measurement sources. These additional sources may include special high quality transducers with well known characteristics. 


\section{APPENDIX D}

Component Analysis of Highly Structured Point-on-Wave Signals 


\section{APPENDIX D. Component Analysis of Highly Structured Point-on- Wave Signals}

This appendix deals with the direct analysis of point-on-wave signals, without intervening rms calculations. Examples are based upon a synthetic set of test data that, under the DOE WAMS Project, was developed for use in assessing digital transducer logic. This particular set (HarmSigsN1) is part of a general family of test data that provides

- unbalanced phases

- significant excursions in system frequency

- one or more additive signals at frequencies characteristic of network resonances (e.g., 35 to 55 $\mathrm{Hz}$ ). These can include both voltage and current.

- modulation of the first harmonic $(60 \mathrm{~Hz})$ at frequencies that are characteristic of fast controllers (e.g., 20 to $25 \mathrm{~Hz}$ )

- modulation of the second harmonic $(120 \mathrm{~Hz})$ at frequencies that are characteristic of both mechanical vibrations (e.g., turbine blades), plus modulation for all harmonics at a controlled power electronics device (e.g., 20 to $25 \mathrm{~Hz}$ )

- numerous harmonics above the second. Their modulation is not required except in very special cases.

All processing is in Matlab ${ }^{\mathrm{TM}}$. The general characteristics of data set HarmSigsN1 are the following:

a) Harmonic number 1 (the fundamental) has a frequency of $60 \mathrm{~Hz}$, and a per-unit (pu) weight of 1.0 relative to all other harmonics.

b) Voltages and currents for the first harmonic are amplitude modulated at three frequencies: 1.05 $\mathrm{Hz}, 1.46 \mathrm{~Hz}$, and $18.2 \mathrm{~Hz}$.

c) Voltage and current both have a total of seven harmonics, with relative weights defined by the Matlab statements

$$
\text { HarmwtV=[100 2.0 5.8 1.0 2.1 0.8 3.2]/100; }
$$

HarmwtI=[100 4.0 6.1 1.2 2.5 1.8 5.8]/100;

d) There are up to three modulating terms for each of the first three harmonics. The relative weights for voltage and current modulation terms are:

$$
\mathrm{VMmag}=[2.21 .91 .2 ; 0.03 .90 .0 ; 1.850 .00 .0] / 100 ;
$$

$$
\text { IMmag }=[1.81 .81 .6 ; 0.02 .70 .0 ; 0.004 .80 .0] / 100 ;
$$

e) A 52-Hz sinusoidal signal is added to voltage and current.

f) A record length of maxBcyc $=560$ cycles ( 9.33 seconds), with refspc $=128$ samples per cycle.

Matlab statements (D1) and (D2) define arrays of 7 elements, each of which is divided by 100. Matlab statements (5) and (6) are a bit more complicated, in that each of the semi-colons defines the end of an 
array row. Full details of the data set are indicated in Figure D.1. The modulating frequencies are typical for large power systems and the generators in them. The 52-Hz additive signal typifies a network resonance near Los Angeles that has sometimes interacted with control equipment in the Pacific Northwest.

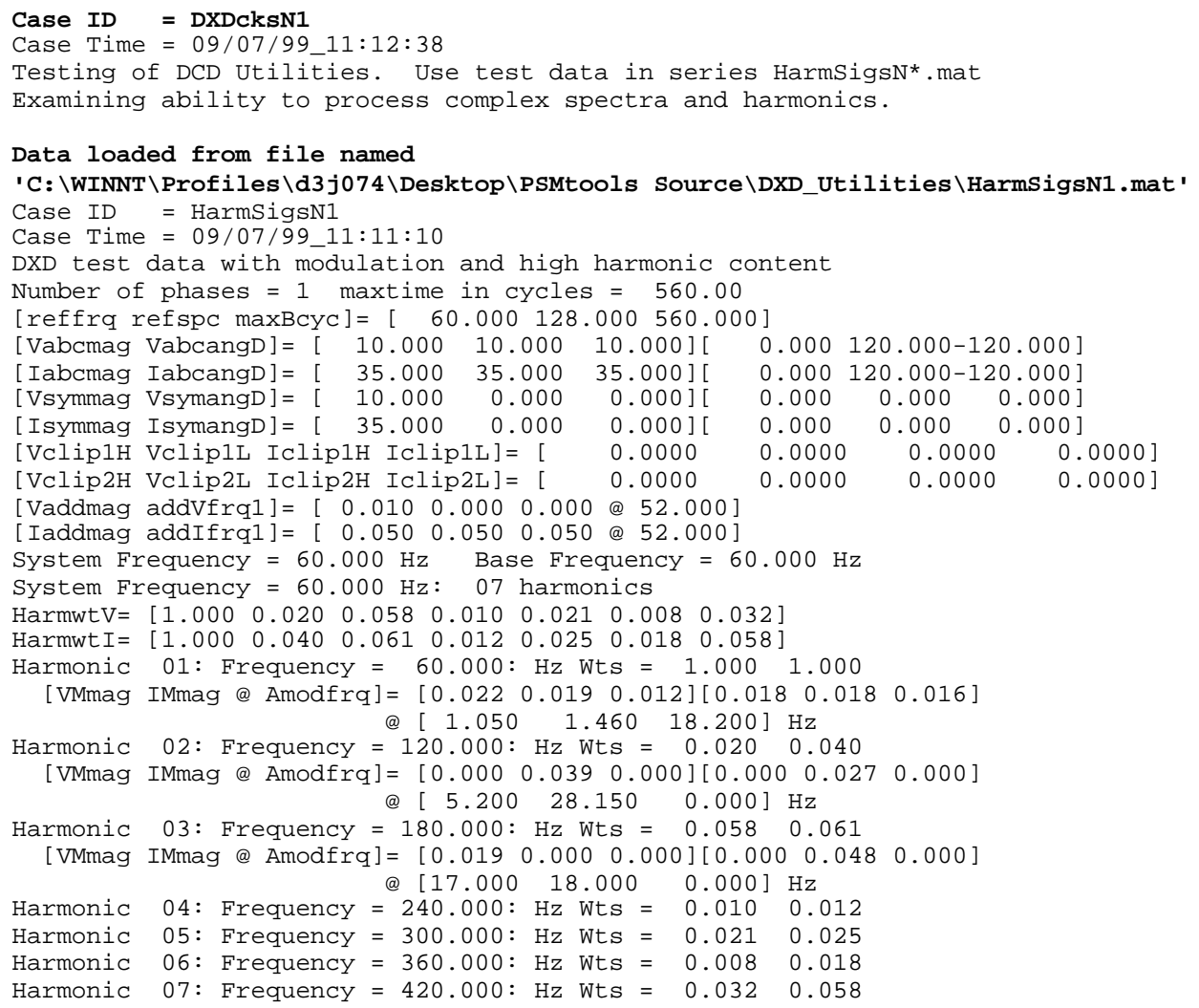

Figure D.1. Test data HarmSigsN1 for point-on-wave analysis.

Figure D. 2 shows A-phase voltage for HarmSigsN1, and Figure D. 2 through Figure D.5 show the associated voltage spectrum with increasing levels of detail. Each amplitude modulation term has produced two sidebands, according to the general relations

$$
\begin{aligned}
& \sin (x) \sin (y)=\frac{1}{2}[\cos (x-y)-\cos (x+y)] \\
& \sin (x) \cos (y)=\frac{1}{2}[\sin (x-y)+\sin (x+y)]
\end{aligned}
$$


P 9: Voltage VA

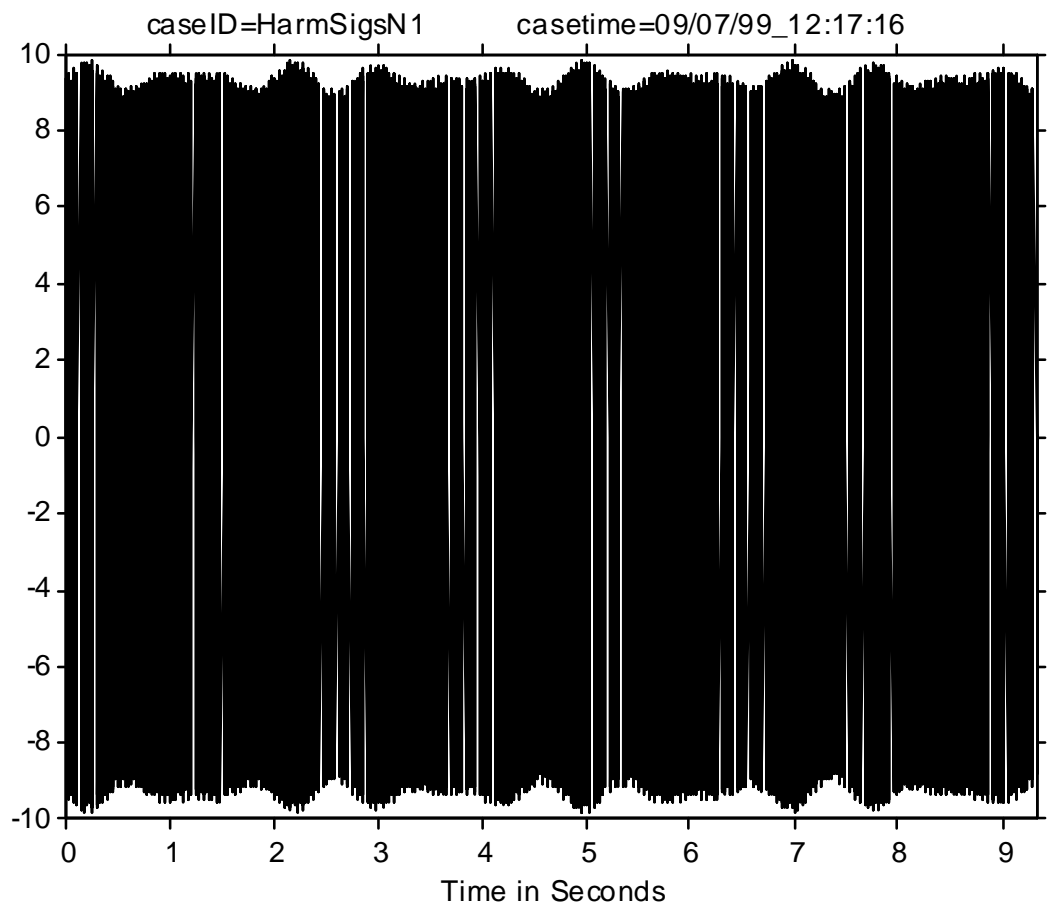

Figure D.2. Test signal HarmSigsN1

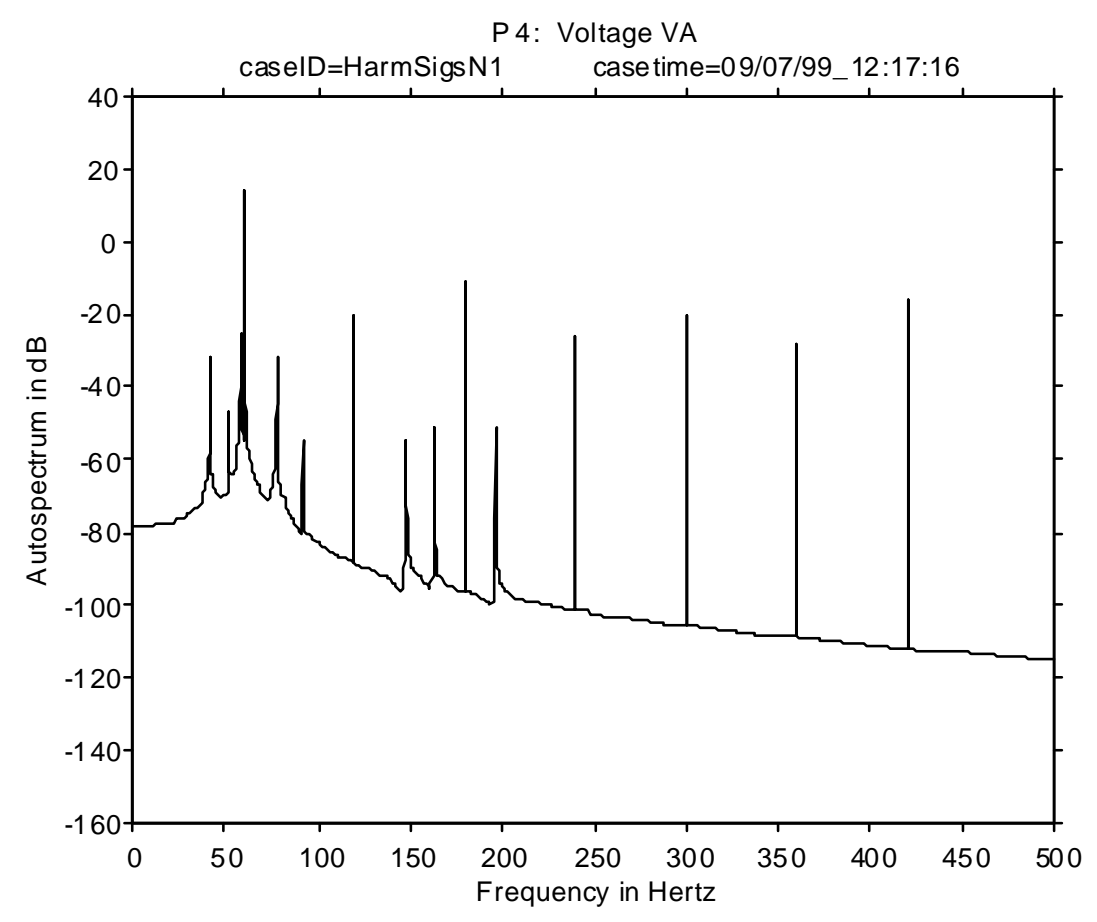

Figure D.3. Autospectrum for test signal HarmSigsN1

D. 3 


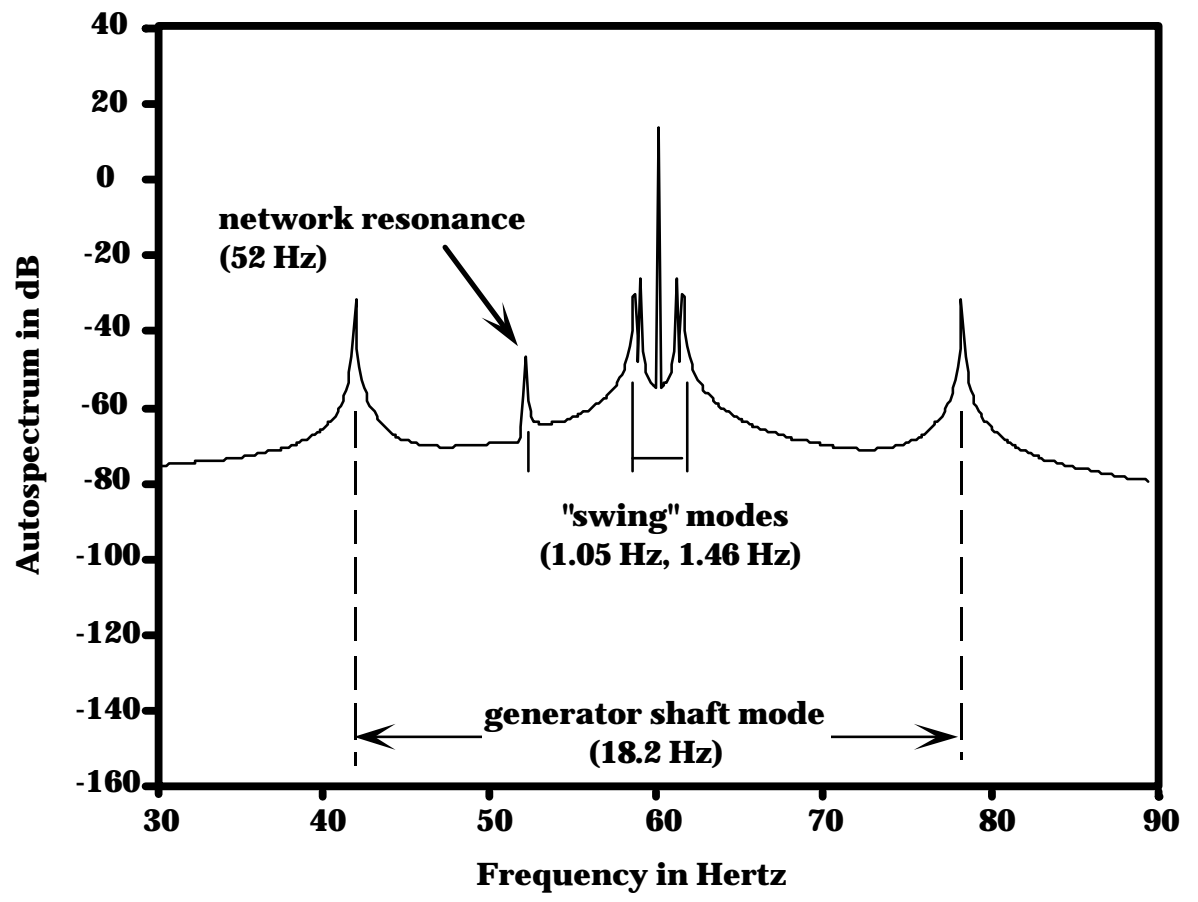

Figure D.4. Autospectrum for test signal HarmSigsN1 (detail 1)

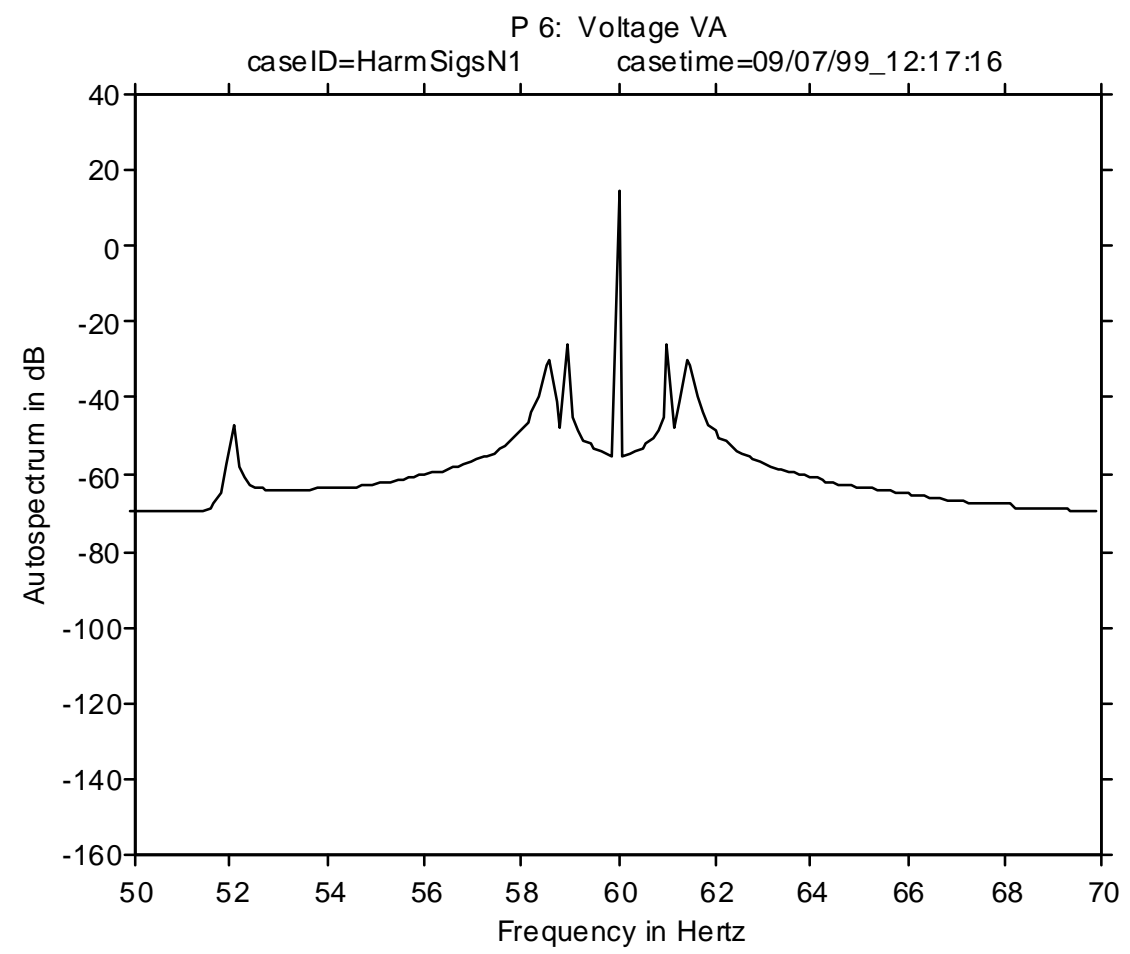

Figure D.5. Autospectrum for test signal HarmSigsN1 (detail 2)

D.4 
Thus $18.2-\mathrm{Hz}$ modulation of the $60-\mathrm{Hz}$ fundamental carrier produces peaks at $41.8 \mathrm{~Hz}$ and $78.2 \mathrm{~Hz}$. These are prominent in Figure D.4. The additive "resonance" component at $52 \mathrm{~Hz}$ produces only one peak, however.

Overall, test signal HarmSigsN1 contains 18 components. The results shown in Table D.1 demonstrate that Prony analysis can accurately extract all of these components from a 0.3 -second record. The identification process will become more difficult if noise is added, or if some of the components are made weaker. Numerical experiments can be performed to assess these problems and to develop countermeasures. Severe data environments will likely require that several identification methods be used in combination, and that candidate process models be fitted to redundant sets of (noisy) data.

Table D.1. Components Identified in Test Signal HarmSigsN1 by Prony Analysis

Modes identified from Voltage VA

DXDcksN1C

\begin{tabular}{|c|c|c|c|c|}
\hline Mode & Frequency (Hz) & $\begin{array}{c}\text { Damping Ratio } \\
\times 10^{-5}\end{array}$ & Amplitude & Phase in Degrees \\
\hline 1 & 59.999997 & 0.685057 & 10.003706 & -90.000783 \\
\hline 2 & 180.000000 & -0.000000 & 0.580000 & -89.999998 \\
\hline 3 & 420.000000 & -0.000000 & 0.320000 & -90.000000 \\
\hline 4 & 300.000000 & -0.000000 & 0.210000 & -89.999998 \\
\hline 5 & 120.000000 & -0.000001 & 0.200000 & -89.999984 \\
\hline 6 & 61.049705 & 1.827630 & 0.112550 & 178.509934 \\
\hline 7 & 58.952239 & 0.598758 & 0.112145 & 1.656001 \\
\hline 8 & 240.000000 & 0.000000 & 0.100000 & -90.000001 \\
\hline 9 & 58.540203 & 0.789686 & 0.095078 & -0.822855 \\
\hline 10 & 61.460463 & 1.048636 & 0.094528 & -179.330140 \\
\hline 11 & 360.000000 & -0.000002 & 0.080000 & -90.000002 \\
\hline 12 & 41.800000 & 0.000066 & 0.060000 & 0.000413 \\
\hline 13 & 78.200000 & -0.000011 & 0.060000 & 179.999888 \\
\hline 14 & 52.000000 & 0.002598 & 0.009998 & -89.997516 \\
\hline 15 & 197.000000 & -0.000000 & 0.005365 & -179.999977 \\
\hline 16 & 163.000000 & -0.000001 & 0.005365 & 0.000169 \\
\hline 17 & 91.850000 & 0.000002 & 0.003900 & 0.000209 \\
\hline 18 & 148.150000 & -0.000001 & 0.003900 & -179.999710 \\
\hline \multicolumn{5}{|c|}{ Signal $/$ Noise Ratio $=135.450704 \mathrm{~dB}$} \\
\hline
\end{tabular}




\section{APPENDIX E}

\section{Probing Signals for Direct Tests of Power System Dynamics}




\section{APPENDIX E. Probing Signals for Direct Tests of power System Dynamics}

The signals most often used to probe power system dynamics are the following:

- a rectangular pulse or step (high-level broad band tests)

- brief periodic waveforms (mid-level narrow band tests)

- sustained sinusoidal signal (low-level narrow band tests)

- sustained noise signal (low-level wide band tests).

Occasional use is made of swept sines, chirps, and waveforms that have been optimized to some special information target. In practice, the choice of signal is largely determined on the basis of available hardware and established test procedures.

Important factors in this choice are the level of the signal, its complexity and frequency content, and the length of time that it must be applied for useful results. Focusing actuator power into a narrow frequency range can produce quick results, but only for the frequencies examined. If the waveform is very regular, it may be perceived as a system oscillation, and trigger a false alarm among system operators. There is also an appreciable risk that the choice of frequency will actually stimulate some oscillatory mode, and perhaps do damage to equipment.

Such considerations tend to favor broadband signals, or narrow band signals that are applied briefly. The remainder of this appendix discusses some basic signals in these two catagories.

The rectangular pulse is a useful starting point for a discussion of this kind. Using the nomenclature of Figure E.1 together with some basic analysis, one determines that the Fourier transform of the pulse has the form

$$
\operatorname{sinc}(\mathrm{x})=\frac{\sin (\mathrm{x})}{\mathrm{x}}
$$

and that its spectrum is as shown in Figure E.2. The first null in the spectrum occurs at frequency $1 / T_{P}$ and additional nulls occur with this same spacing. The sidelobe amplitudes diminish as $1 / \mathrm{f}$. Thus a $0.5-$ second pulse will provide no stimulus at $2 \mathrm{~Hz}$ or $4 \mathrm{~Hz}$. In broadband tests, it would likely give good data at frequencies up to perhaps $1.5 \mathrm{~Hz}$, depending upon circumstances.

Similar patterns are seen in the spectra for the test signals shown in Figure E.3 and Figure E.4. Both of these signals are designed to probe a specific dynamic mode near $0.33 \mathrm{~Hz}$. The square wave is simpler to generate, and it was used very successfully in BPA's HVDC probing tests of April 27, 1999. Its spectrum has strong sidelobes near $1.0 \mathrm{~Hz}$ and $1.7 \mathrm{~Hz}$, however, and the greater selectivity offered by the sine wave might be advantageous for some purposes. 


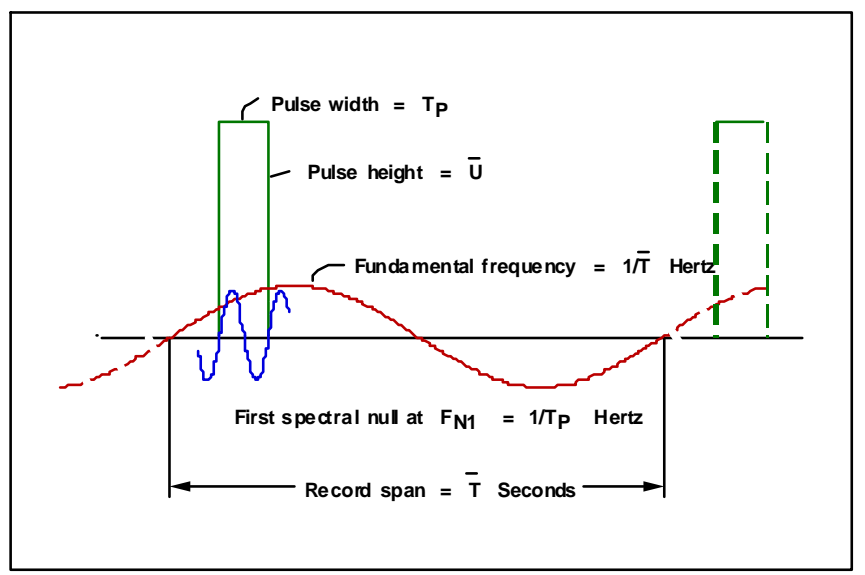

Figure E.1. Nomenclature for an ideal pulse

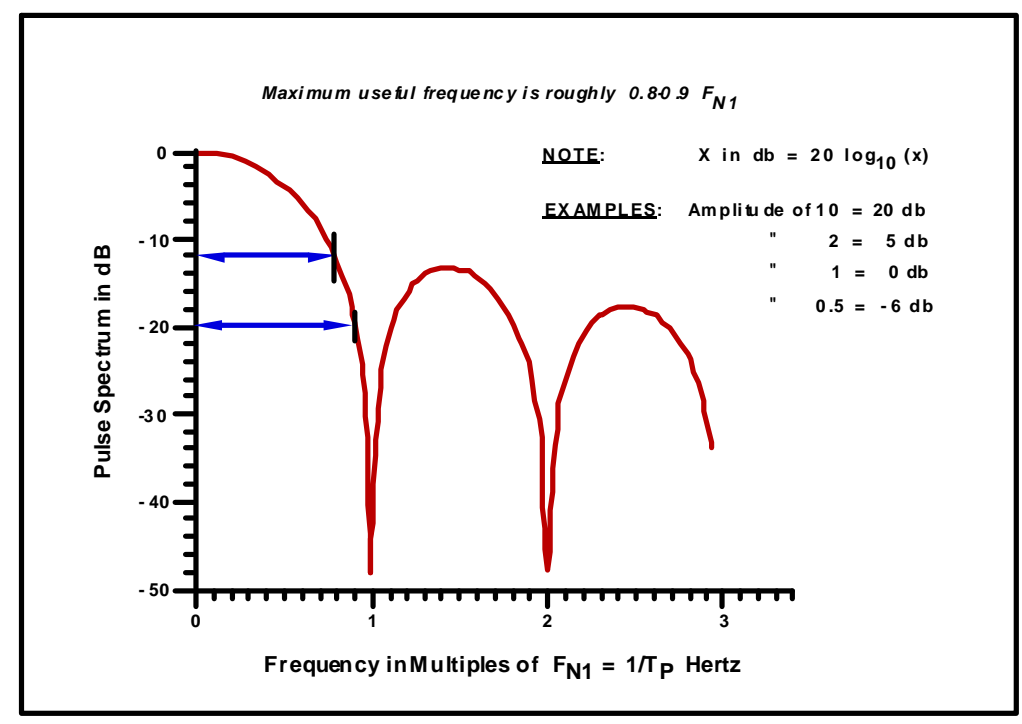

Figure E.2. Autospectrum for an ideal pulse 

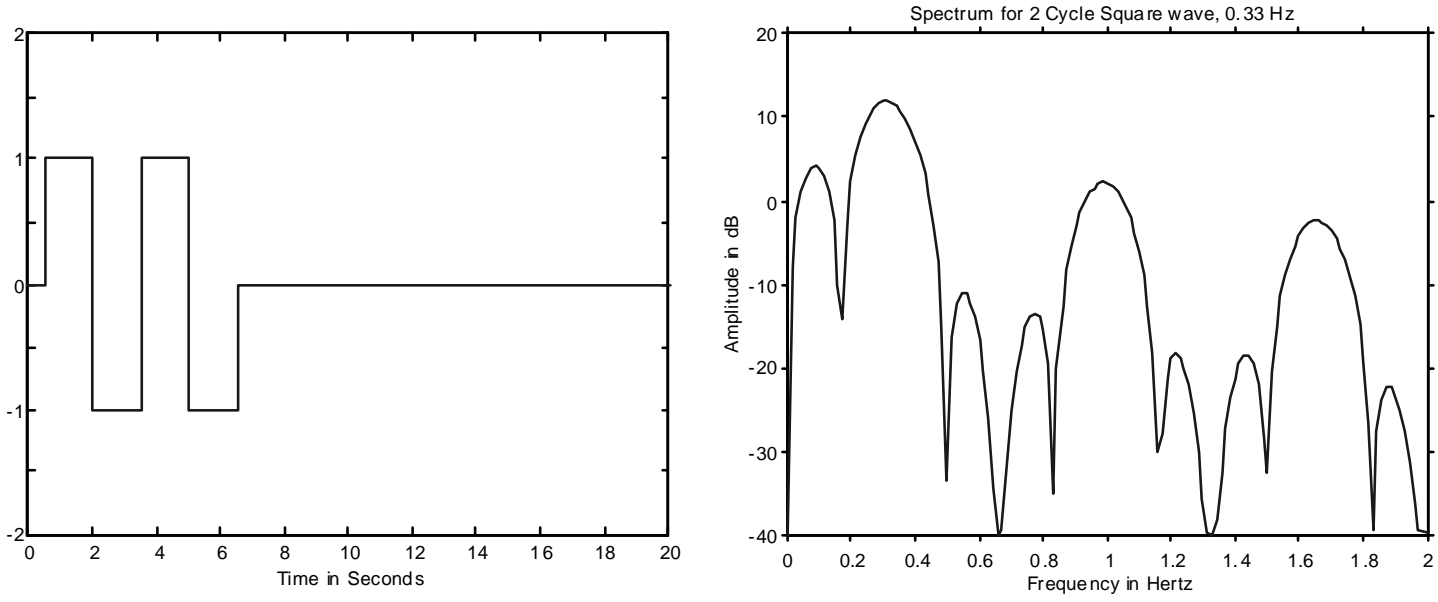

Figure E.3. Waveform and s pectrum for two-cycle square wave, $0.33 \mathrm{~Hz}$.
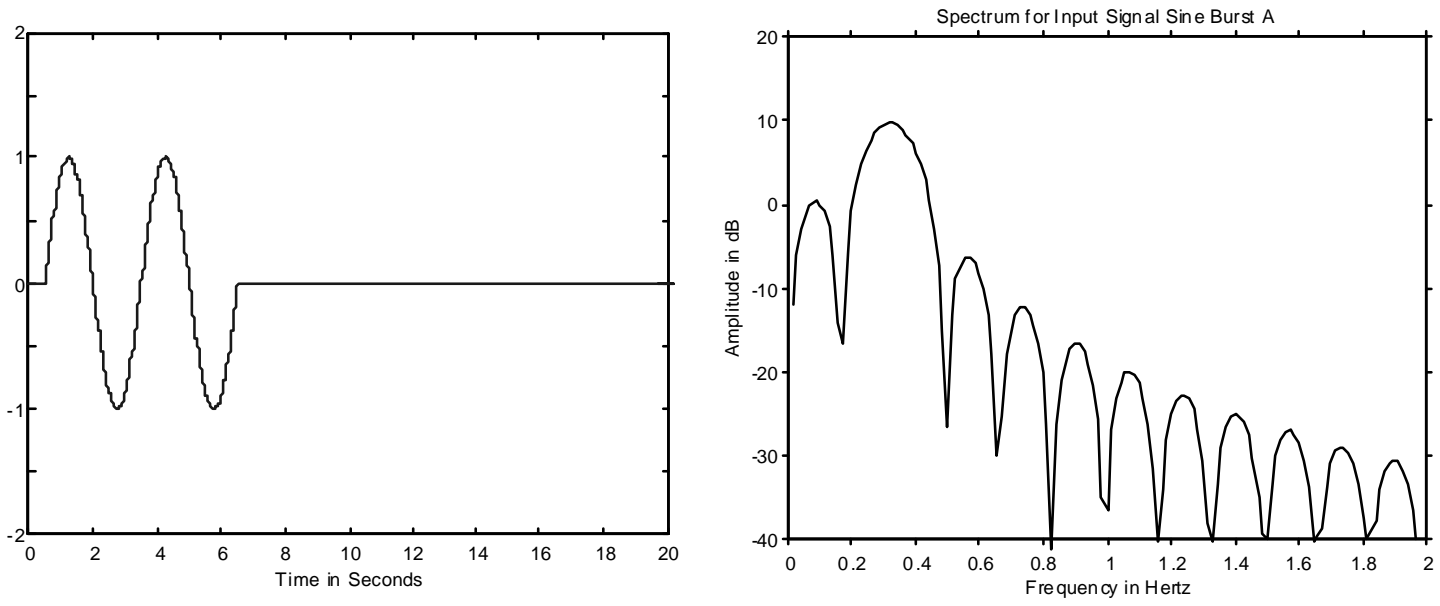

Figure E.4. Waveform and spectrum for two-cycle sine wave, $0.33 \mathrm{~Hz}$. 


\section{Distribution}

No. of

Copies

\section{OFFSITE}

20 U.S. Department of Energy Attn: Mr. Philip N. Overholt Program Manager

Transmission Reliability

EE-2D/Forrestal Bldg

000 Independence Ave., S.W.

Washington, D.C. 20585

AMEREN Services

Attn: Kirk Shah

PO Box 66149, MC-450

St. Louis, MO 63116-6149

American Electric Power Co.

NERC Interconnection Dynamics Work Group

Attn: Mr. Navin B. Bhatt, Chairman

825 Tech Center Drive

Gahanna, OH 43230-8250

2 Arizona Public Service Co.

Attn: Dr. Baj. L. Agrawal

Mr. Doug Selin

PO Box 53933

Phoenix, AZ 85072-3933

Arizona State University

Prof. Richard G. Farmer

E.E. Department

PO Box 875-706

Tempe, AZ 85287-5706

6 Bonneville Power Administration PO Box 61409

Vancouver, WA 98662-7905

Attn: John M. Haner

Gary M. Keenan

Carson W. Taylor

Dmitri N. Kosterev

Donald S. Watkins

Donald J. Bernhardsen

\section{No. of}

Copies

Bonneville Power Administration

Attn: Bill Mittelstadt

PO Box 491

Vancouver, WA 98666-0491

2 California ISO

Attn: Ms. Lisa Szot

Mr. John Doudna

A51 Blue Ravine Rd

Folsom, CA 95630

California ISO

(Southern Satellite Office)

Attn: Mr. Chuck Wu

1000 S. Fremont Ave.

Building A-13

Alhambra, CA 91803

Entergy Services, Inc.

Attn: Mr. Sharma Kolluri

639 Loyola Ave

Mail Stop ENTc61

New Orleans, LA 70113

ESBI Alberta Ltd.

Attn: Mr. John H. Kehler $900-736-8^{\text {th }}$ Ave., S.W.

Calgary, Alberta T2P-1H4

Canada

GE Power Systems

Attn: Mr. John J. Undrill

Power Systems Engineering Consulting

1 River Road, Bldg 2-600

Shenectady, NY 12345

Great River Energy

Mr. Karl N. Mortensen

Supervisor, System Engineering

17845 U.S. Highway 10

Ek River, MN 55330-0800 
No. of

\section{Copies}

2 ISO New England Inc.

Attn: Mr. Michael Henderson

Mr. Xiaochuan Luo

One Sullivan Road

Holyoke, MA 01040

2 Midwest ISO

Attn: Mr. Dale Osborn Mr. Terry Bilke

701 City Center Drive

Carmel, IN 46032

Minnesota Power Company

Attn: Mr. George Sweezy

300 W. Superior St

Duluth, MN 55802

Navigant Consulting

Attn: Mr. R. Peter Mackin

Chair, WECC Disturbance Monitoring Work Group

3100 Zinfandel Drive, Suite 600

Rancho Cordova, CA 95670

New York Independent System Operator

Attn: Mr. James W. Ingleson

Senior Operations Engineer

3890 Carman Road

Schenectady, NY 12303

2 Pacific Gas \& Electric

Attn: Ms. Gwynn Lockwood Mr. William Miller

PO Box 770000

San Francisco, CA 94177

Rensselaer Polytechnic Institute

Attn: Dr. Joe H. Chow

Dept of Electrica, Computer and Systems Eng.

Troy, NY 12180-3590

Southern California Edison

Attn: Mr. Bharat Bhargava, GO3

PO Box 800

2131 Walnut Grove Ave.

Rosemead, CA 91770
No. of

Copies

Tennessee Valley Authority

Attn: Michael R. Ingram

Ian S. Grant

400 Summit Hill Drive

Knoxville, TN 37902

The University of Illinois

Attn: Dr. Peter W. Sauer

Department of Electrical Engineering

Urbana, IL 61801

University of Wy oming

Attn: Dr. John W. Pierre

Dept of Electrical Engineering

Laramie, WY 82070

2 U.S. Bureau of Reclamation

Attn: J. Carl Agee

Shawn Patterson

Denver Federal Center

PO Box 25007

Denver, CO 80225-0007

VIASYN

Attn: Mr. Donald Sutphin

Executive VP for Operations \& Consulting

400 Spear St, Suite 117

San Francisco, CA 94105

Virginia Polytechnic Institute and State Univ.

Attn: Dr. Arun G. Phadke

The Bradley Department of Electrical Engineering

426 Whittemore Hall

Blacksburg, VA 24061-0111

WECC

Attn: Mr. Donald Davies

615 Arapeen Drive, Suite 210

Salt Lake City, UT 84108

2 Western Area Power Administration

Attn: Charles I. Clemans

Daniel M. Hamai

PO Box 281213

Lakewood, CO 80228-8213 
No. of

Copies

ONSITE

$\begin{array}{ll} & \text { D. P. Chassin, K5-16 } \\ & \text { J. E. Dagle, K5-02 } \\ 10 & \text { J. G. Desteese, K5-20 } \\ 20 & \text { M.K. Donnelly, K5-20 } \\ 10 & \text { R.T. Guttromson, K5-20 } \\ 10 & \text { J..F. Hauer, K5-20 } \\ & \text { Z. Huang, K5-20 } \\ & \text { C. H Imhoff, K5-02 } \\ & \text { L. D. Kannberg, K9-09 } \\ & \text { S. E. Widergren, K5-20 } \\ 2 & \text { Technical Information, P8-55 }\end{array}$

Distr-3 